\title{
THE RELATIONSHIP BETWEEN ENTERPRISE RESOURCE PLANNING (ERP) IMPLEMENTATION AND INTELLECTUAL CAPITAL UNDER THE MODERATING EFFECT OF ORGANIZATIONAL LEARNING CAPABILITY
}

\author{
by
}

Quang Vu Nguyen

\begin{abstract}
A thesis
submitted to the Victoria University of Wellington in fulfilment of the requirements for the degree of

Doctor of Philosophy in Information Systems
\end{abstract}

Victoria University of Wellington

2016 


\begin{abstract}
Although Enterprise Resource Planning (ERP) systems alone are not the source of competitive advantage, they may do this indirectly through enhancing or supplementing the organization's other strategic resources. Studies on ERP have not explicitly examined the interactions of ERP systems with other organizational capabilities to determine how investment in ERP systems can be leveraged into the creation of strategic resources of organizations.
\end{abstract}

Further, ERP systems are large and complex, and the degree to which they are implemented throughout an organization can vary - this is described as the ERP scope. The scope of ERP implementation is believed to influence the degree of its effects on an organization. Relying on the literature on ERP effects, business value of information technology (IT) and the notion that organizations are learning systems which utilize their knowledge to create value and to accumulate further knowledge, this study examines the influence of the scope of ERP implementation on a strategic resource of organizations, namely intellectual capital, under the moderating effect of organizational learning capability.

This study develops a research model to show the influence of the three dimensions of ERP implementation scope (breadth, depth, and magnitude) on intellectual capital and simultaneously the influence of organizational learning capability on these base relationships. The hypothesized relationships among variables are evaluated by a data set of 226 responses collected from manufacturing firms in Vietnam. With the support of SmartPLS version 2.0, the structural equation model is evaluated using the techniques of multiple regression analysis, and the moderation effects are analyzed using group comparison and product term approaches.

The findings provide support for the hypotheses. The three dimensions of ERP implementation show a positive impact on intellectual capital. Organizational learning capability more or less moderates the relationship between ERP implementation scope and intellectual capital. As a result of the group comparison approach for moderation analysis, firms with a low level of learning capability are 
likely to have no effect of ERP implementation on intellectual capital. However, in the group with a high level of learning capability the breadth and magnitude of ERP implementation have a positive effect on intellectual capital. By using the product term approach, only the magnitude of ERP implementation shows an interaction effect with organizational learning capability on intellectual capital. The breadth and depth of ERP implementation appear to have minimal interaction with organizational learning capability.

The results inform the literature on the business value of IT by demonstrating that an ERP system can become a strategic asset as its implementation has a positive effect on intellectual capital especially with the presence of a firm's learning capability. Additionally, the research reveals another ERP effect (e.g. the effect on the intellectual capital of organizations) that complements the understanding of ERP effects that have been identified in prior studies. The findings practically contribute to managerial knowledge by showing that ERP implementation should not be considered in isolation, but rather organizations should build a substantial level of learning capability to fully obtain the positive effect of ERP implementation on intellectual capital. 


\section{ACKNOLWEDGEMENTS}

Nothing in this world would exist without other things. Equally, my research work would not have been possible without support of other people.

I would like to express my most sincere gratitude to Dr. Philip Calvert, Dr. Mary Tate, and Prof. Benoit Aubert. I appreciate very much your valuable and patient guidance, enthusiastic encouragement, and useful critiques of this research work.

I would like to thank all academic, administrative, and technical staff of the School of Information Management for their help and support during my study. My thanks also to the Research Committee for the support in terms of conference attendance and field work.

My grateful thanks are extended to Mr. Tuan Manh Nguyen. You encouraged me, shared your thoughts with me as an academic colleague, a brother, and as a friend.

I would especially like to acknowledge Mr. Tuan Bao Huynh and Ms. Phuong Thi-Anh Nguyen at the School of Industrial Management, Ho Chi Minh City University of Technology; Mr. Thong Tri Nguyen at the Institute of Development of Economics Research, University of Economics Ho Chi Minh City. You kindly assisted me to contact with ERP consultants and supported me in data gathering work. I would also like to extend my thanks to all of my students who helped me in data collection.

I would like to acknowledge all companies who participated in the survey. Without them, I could not have completed this thesis.

My acknowledgement is to Ms. Jackie Bell who provided proof-reading service in accordance with the Editorial Advice Policy of Victoria University of Wellington.

Last but not least, I greatly express my deep gratitude to my parents. You give me an opportunity to live and learn in this world, and always love and believe in me. Thanks to my wife Thao Thi-Hong Nguyen and my daughter Minh Hong Nguyen, for your love and unconditional support during my study. 


\section{TABLE OF CONTENTS}

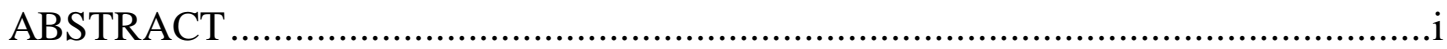

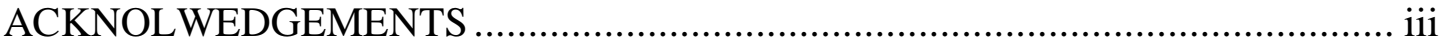

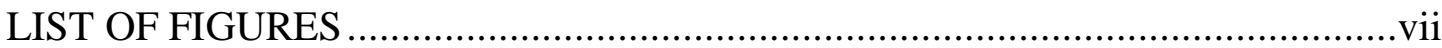

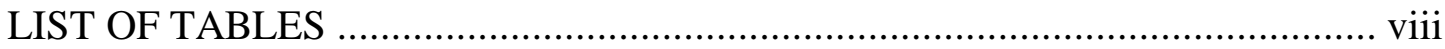

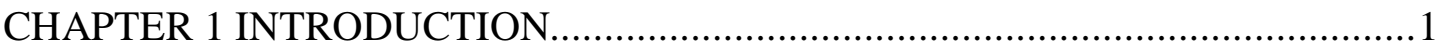

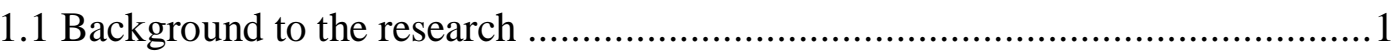

1.2 Research problem, research questions, and research objectives ......................4

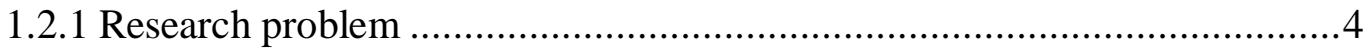

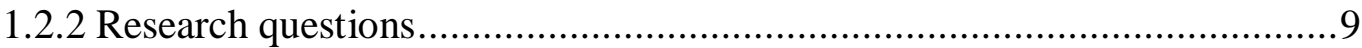

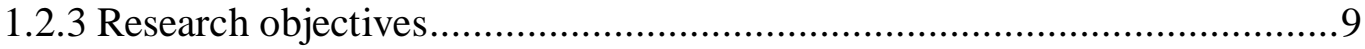

1.3 Scope and delimitation of the research....................................................... 10

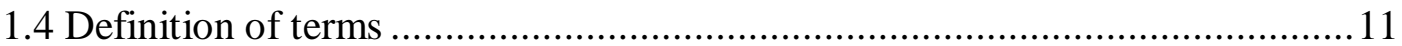

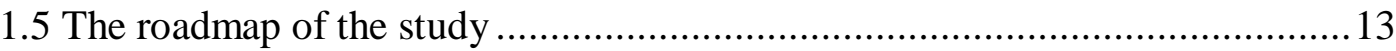

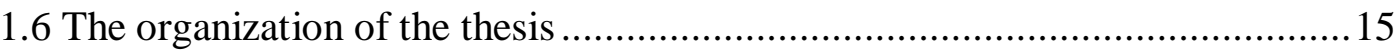

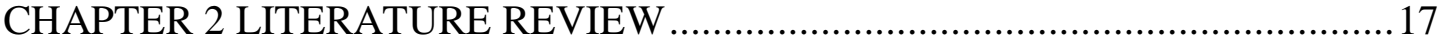

2.1 Enterprise resource planning (ERP) systems .............................................. 17

2.1.1 The history and concept of ERP systems .......................................... 17

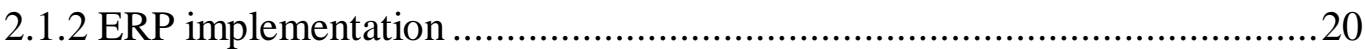

2.1.3 The extent or scope of ERP implementation........................................23

2.1.4 Measurement of the effects of ERP implementation .............................25

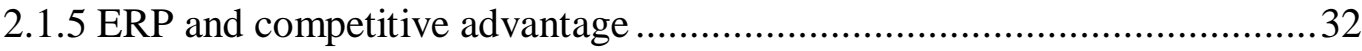

2.2 IT business value and the role of organizational resources ............................ 34

2.3 Two organizational resources: intellectual capital and organizational learning

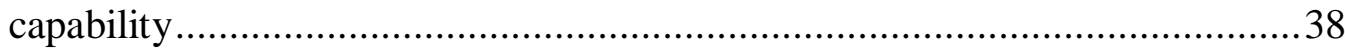

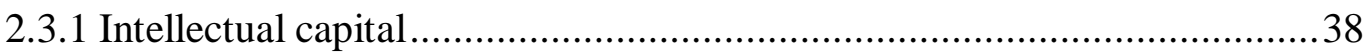

2.3.2 Organizational learning capability ...................................................... 41

2.3.3 Strategic characteristics of organizational learning capability and

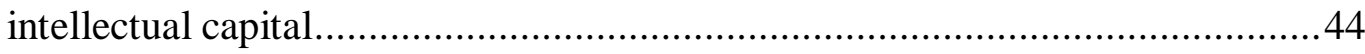

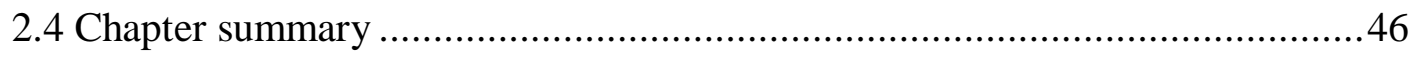


3.1 ERP implementation and intellectual capital.............................................48

3.2 Organizational learning capability and the relationship between ERP implementation and intellectual capital ....................................................52

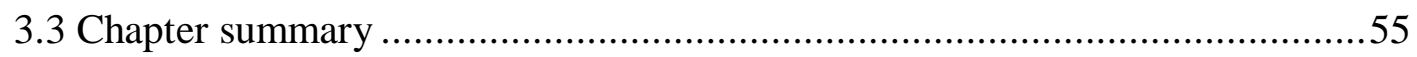

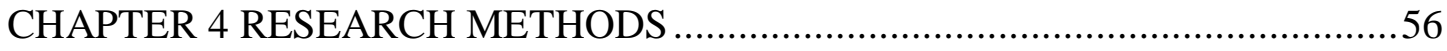

4.1 Justification of quantitative research design ..............................................56

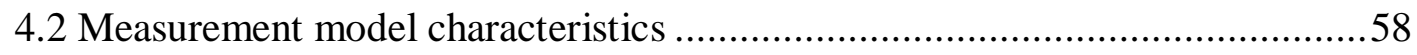

4.2.1 Reflective and formative constructs ...................................................5

4.2.2 Appropriateness of higher order constructs .......................................59

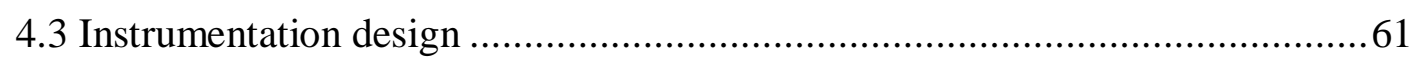

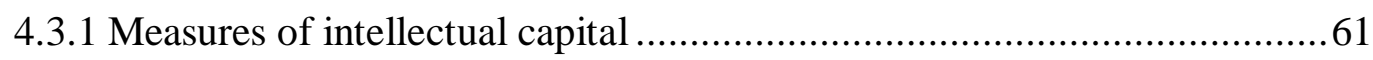

4.3.2 Measures of organizational learning capability .....................................63

4.3.3 Measures of ERP implementation scope .............................................65

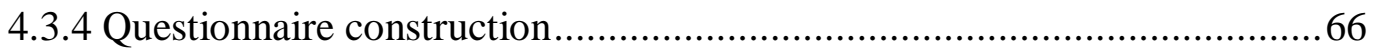

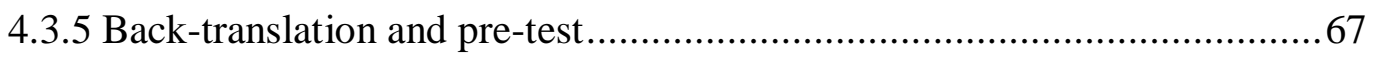

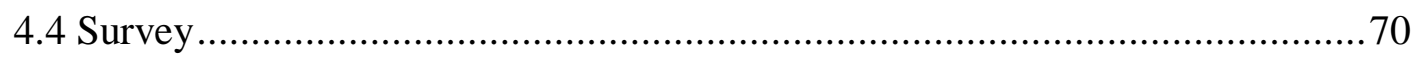

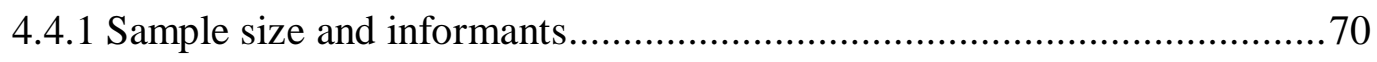

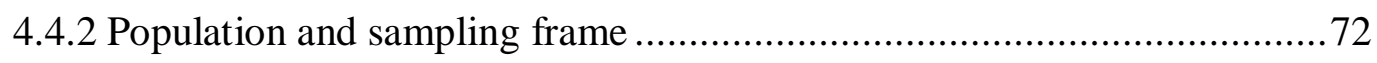

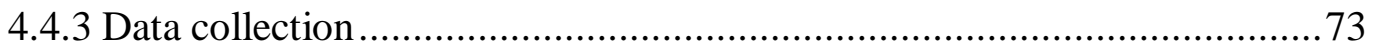

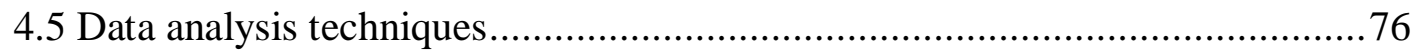

4.5.1 Covariance-based SEM and Partial Least Squares (PLS)........................77

4.5.2 Structural equation model assessment .............................................. 78

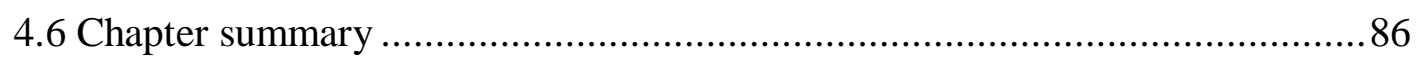

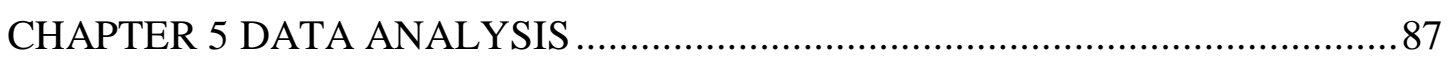

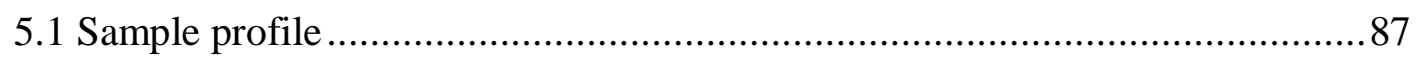

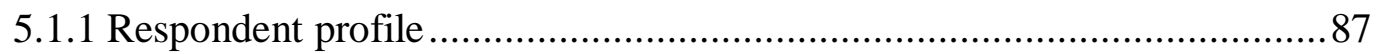

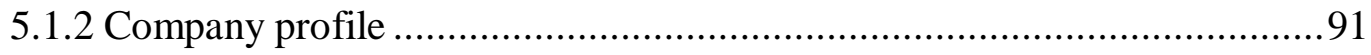

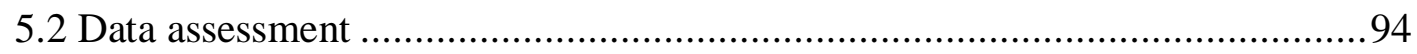

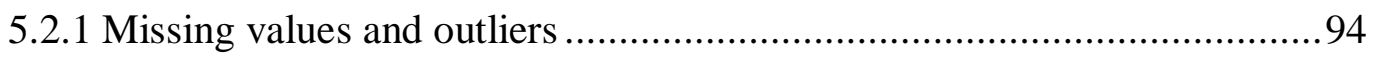

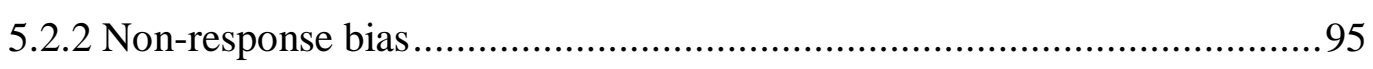

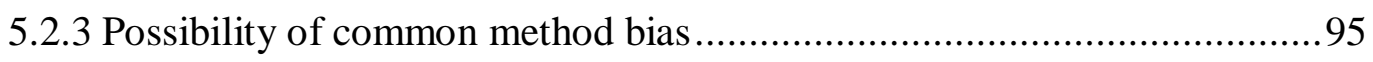


5.2.4 Normality assessment 96

5.3 Assessment of measurement models ........................................................ 97

5.3.1 Reflective measurement models ....................................................... 97

5.3.2 Formative measurement models ....................................................... 102

5.4 Assessment of the structural model....................................................... 104

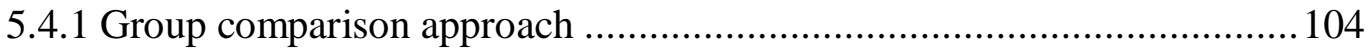

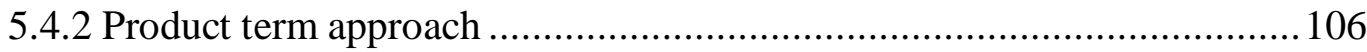

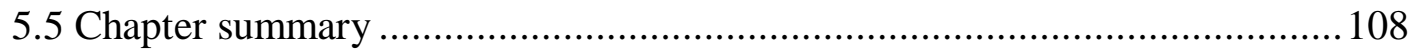

CHAPTER 6 DISCUSSION AND CONCLUSION .............................................. 109

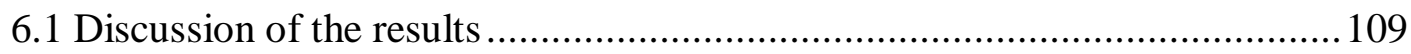

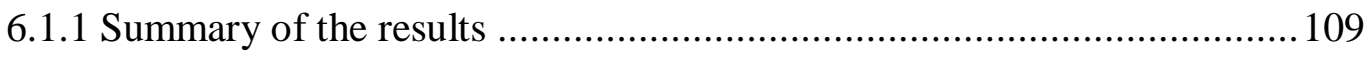

6.1.2 Discussion of the research questions ............................................... 109

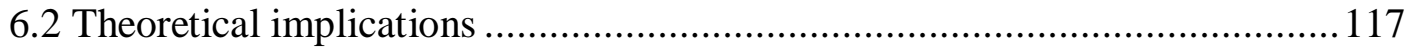

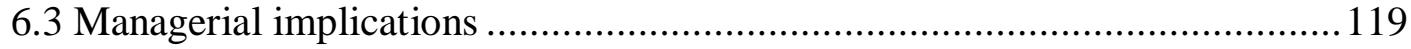

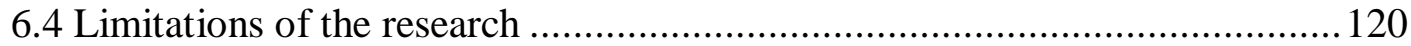

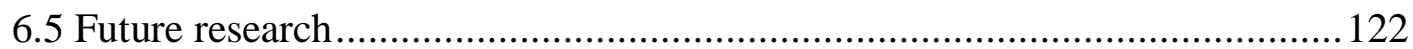

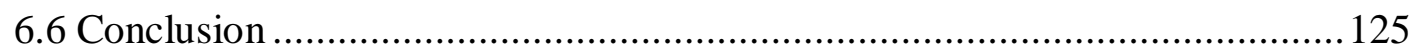

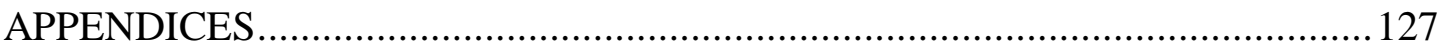

APPENDIX A. English Version of the questionnaire ...................................... 127

APPENDIX B. Vietnamese Version of the questionnaire ................................ 135

APPENDIX C. List of ERP software companies in Ho Chi Minh City ............... 143

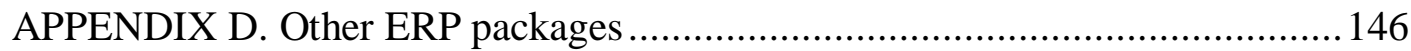

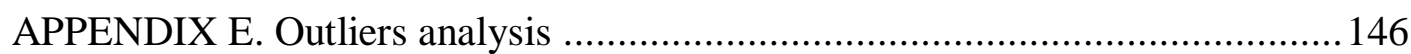

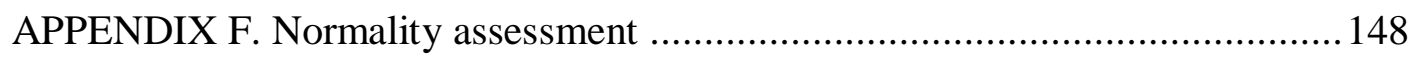

APPENDIX G. Factor loadings of reflective constructs .................................. 149

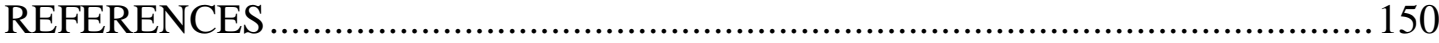




\section{LIST OF FIGURES}

Figure 1.1 The role of strategic value of ERP between ERP implementation and competitive advantage ................................................................. 10

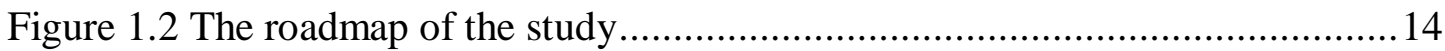

Figure 2.1 The enterprise system experience life cycle .........................................21

Figure 2.2 The IS-impact measurement model ...................................................26

Figure 2.3 The extended IS measurement model ................................................26

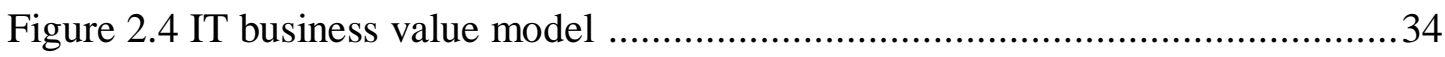

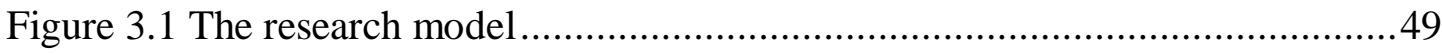

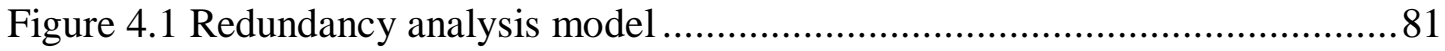

Figure 4.2 Moderating effect using group comparison approach ...........................8 84

Figure 4.3 Two-stage approach for moderating effects analysis with formative

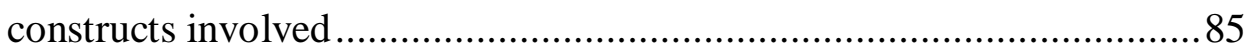

Figure 5.1 Structural model for moderating effect analysis using the group

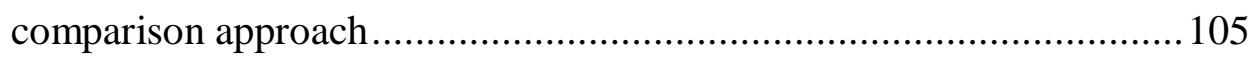

Figure 5.2 Structural models for moderating effect analysis using the product term

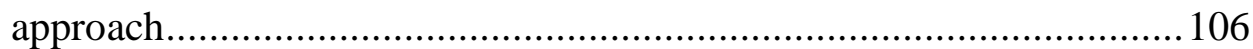

Figure 6.1 The virtuous circle of strategic ERP implementation ............................122 


\section{LIST OF TABLES}

Table 2.1 Second wave of ERP implementation ................................................22

Table 2.2 The effects of ERP implementation ....................................................29

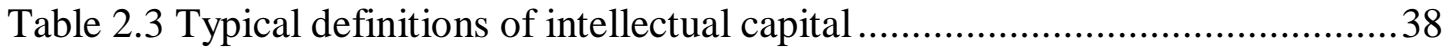

Table 2.4 Typical definitions of organizational learning ......................................41

Table 4.1 Criteria for distinguishing between formative and reflective models .........58

Table 4.2 Item measures of intellectual capital...................................................62

Table 4.3 Item measures of organizational learning capability ..............................64

Table 4.4 Item measures of ERP implementation scope ......................................65

Table 4.5 Modifications of ERP implementation scope measurement .....................69

Table 4.6 Key informants and multiple informants ........................................... 71

Table 4.7 Types of surveys and their features.................................................. 74

Table 4.8 Evaluation of reflective measurement models using PLS ........................78

Table 4.9 Evaluation of formative measurement models using PLS ......................8 80

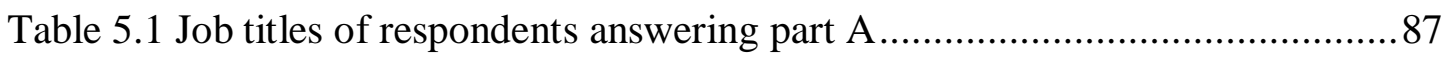

Table 5.2 Years in current organization of respondents answering part A..................8 88

Table 5.3 Self-rating of respondents answering part A …..................................... 88

Table 5.4 Job functions/work areas of respondents answering part B ......................8 89

Table 5.5 Job positions of respondents answering part B .................................... 89

Table 5.6 Years in current organization of respondents answering part B ................90

Table 5.7 Self-rating of respondents answering part B ......................................... 90

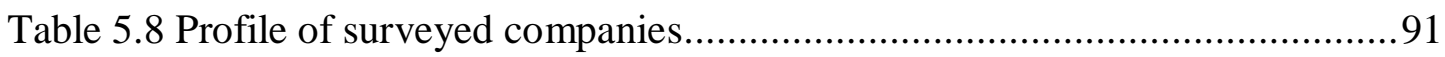

Table 5.9 ERP implementation characteristics ....................................................93

Table 5.10 Factor loadings of reflective constructs...............................................99

Table 5.11 AVE and reliability of constructs before and after items removal. ........100

Table 5.12 Correlation matrix, composite reliability, and AVE of constructs ......... 101

Table 5.13 Path coefficients and multicollinearity of formative dimensions ........... 103

Table 5.14 Moderating effect analysis using the group comparison approach......... 105

Table 5.15 Moderating effect analysis using the product term approach ................. 107 


\section{CHAPTER 1}

\section{INTRODUCTION}

\subsection{Background to the research}

Organizations implement enterprise resource planning (ERP) systems because they want to gain benefits from these technologies. ERP systems are complex software packages that are supposed to provide organizations with capabilities of coordinating information flows into business processes and integrating all business departmental functions into a united system (Markus \& Tanis, 2000). Due to the capabilities of ERP systems, organizations expect to obtain business benefits from the systems, such as more efficient business processes, inventory reduction, improved decision-making, customer services improvement, and business growth (Panorama, 2015; Shang \& Seddon, 2002). Organizations hope to achieve strategic advantage as a result of these benefits.

Nevertheless, the achievement of benefits from an ERP investment is equivocal. Some organizations have realized the benefits they anticipated, but other firms have not. A recent report on ERP benefits realization (Panorama, 2015) has shown that, on average, $53 \%$ of organizations achieved less than $50 \%$ of the benefits they expected. Not only is the achievement of benefits equivocal, there is also debate about how ERP implementation benefits should be measured.

There are many overlapping approaches for measuring the positive effects of ERP implementation, which are described variously by scholars as impacts, benefits, and performance. These are all measures of positive outcomes from different perspectives, which include: the balanced scorecard; the IS-Impact model; and benefit taxonomies of various sorts. However not all of these effectively measure strategic advantage. The balanced scorecard (BSC) has been used to identify the impact of ERP on organizations in terms of financial performance, internal processes, customer satisfaction, and growth and learning (Chang, Yen, Ng, Chang, \& Yu, 2011). This touches on competitive advantage in its measures of learning and growth, but strategic value of ERP is not the main focus. Other studies such as the IS-Impact 
model have attempted to measure the impact of ERP systems at individual, workgroup and organizational level (Gable, Sedera, \& Chan, 2008; Ifinedo, 2006). Once again, this does not have a strong strategic focus. Another research branch has attempted to assess the benefits of ERP in terms of five categories: operational, managerial, strategic, IT infrastructure, and organizational benefits (Shang \& Seddon, 2002). These studies have shown that the benefits of ERP can be measured across many aspects including the strategic benefits, which demonstrates the ability of ERP to produce and sustain superior performance or competitive advantage for organizations. This is the focus of this study.

Firms expect to achieve competitive advantage from ERP. According to the resourcebased view of the firm, organizations have sustainable competitive advantage when they own resources that are valuable, rare, inimitable, and cannot be substituted (Barney, 1991). Clearly, ERP systems by themselves can be valuable but it is difficult to argue they have other properties of a strategic resource. Since they are commercial IT products that can be bought and implemented when firms have sufficient financial power (Carr, 2005), they are not rare or inimitable.

The area of concern in this study is how ERP can become a strategic resource that is valuable for firms hoping to achieve competitive advantage. While ERP systems in particular have not been studied from this perspective, studies of other IT resources have shown that IT can produce superior performance for firms when they are supported by organizational capabilities (Ting-Peng, Jun-Jer, \& Chih-Chung, 2010), or when they interact with other organizational resources (Melville, Kraemer, \& Gurbaxani, 2004). IT resources become strategically valuable when firms merge and use them with other organizational resources over time (Piccoli \& Ives, 2005). From the perspective that IT resources need to combine with other organizational resources to deliver strategic value for firms, it is argued that ERP systems can produce strategic value when they reinforce other organizational strategic resources.

Strategic resources of organizations are intangible in nature and have received much attention from scholars (Michalisin, Smith, \& Kline, 1997). One important strategic resource is intellectual capital or the sum of knowledge of an organization (Subramaniam \& Youndt, 2005; Zack, 2002). This has arisen because in recent 
decades the world economy has experienced a movement from being production based to knowledge and information based. As such, in the present economy, firms create and maintain competitive advantage mainly on the basis of knowledge and other intangible resources (Dzinkowski, 2000; Stewart, 1997; Teece, 1998). In particular, organizations now use many electronic resources. In this movement, tangible resources in electronic formats have become easily approachable, capable of being copied and substituted.

Knowledge is seen by many scholars as the most important strategic resource of the firm (e.g. De Carolis, 2002). Knowledge resources enable a firm to gain sustainable competitive advantage because they have the characteristics of rareness, imperfect imitability, and non-substitutability (Barney, 1991). In the knowledge based economy, the creation of value is no longer based on material and physical things but on information, knowledge, and brainpower (Stewart, 1997, p. 43). A firm is considered as an entity creating and applying knowledge (Grant, 1996; Nonaka, Toyama, \& Nagata, 2000) and converting knowledge into competitive advantage (Kogut \& Zander, 1992).

Intellectual capital has been widely highlighted as an organizational resource and it is said to be essential for the attainment of high organizational performance (Bontis, 1999; Youndt, Subramaniam, \& Snell, 2004). Under the view that organizations are learning entities, while intellectual capital is the sum of knowledge owned by organizations, organizational learning capability plays an important role in the development of this resource (Vera \& Crossan, 2003). It is believed that for firms the only competitive advantage that they will have in the future will be the ability to learn faster than their competitors (De Geus, 1988). In the context of ERP implementation, it has been argued that organizational learning is absolutely essential for the success and the effectiveness of the system (Robey, Ross, \& Boudreau, 2002) because organizations need to overcome knowledge barriers to implement the complex software packages they purchase.

As illustrated above, in the literature on the effects of ERP that are measured at organizational level, many scholars have focussed directly on competitive advantage without consideration of other organizational resources and capabilities. Further, both 
ERP studies, and IT investment studies in general have established that implementing large IT systems is insufficient by itself to create strategic advantage. Strategic advantage may be produced by ERP deployment, however it is argued in this study that the strategic value of ERP systems can only be achieved when they interact with other organizational resources and capabilities (such as learning capability) to create strategic intangible knowledge-based assets (also described as intellectual capital). This study therefore aims to study how ERP implementation interacts with the learning capability of the organization to create intellectual capital as a strategic resource.

\subsection{Research problem, research questions, and research objectives}

Being guided by the need for an understanding of the relationship between ERP implementation and other organizational resources, the extant literature on the effects of ERP on organizations, IT business value creation, and the nature of organizational resources, especially intellectual capital, and learning capability has been reviewed. As a result of the review, the research problem, research questions, and research objectives are identified.

\subsubsection{Research problem}

Numerous studies on the positive effects of ERP implementation have mentioned the potential for creation of competitive advantage for firms when they implement ERP (Chang et al 2011; Ifinedo, 2006; Shang \& Seddon, 2002). In their study, Shang and Seddon (2002) have indicated that ERP implementation is expected to bring benefits to firms. These benefits are categorized into five groups: operational, managerial, strategic, IT infrastructure, and organizational. In terms of strategic benefit, ERP is expected to generate and sustain competitiveness for firms (Shang \& Seddon, 2002). Other studies have not directly measured the strategic advantage of ERP, but they have included competitive advantage in other measures of ERP impacts on organizations. For example, Chang et al. (2011) measured the impact of ERP on firms in terms of financial performance, internal processes, customer satisfaction, and growth and learning. The measures of growth and learning they proposed included 
the ability of ERP to increase competitive advantage for firms. Ifinedo (2006) has used the IS-impact model to measure the impact of ERP at organizational level, which included a measure of competitive advantage.

However, it is difficult for firms to create competitive advantage with ERP (Seddon, 2005). It is argued that one of the reasons for this is that ERP systems by themselves are not the source of competitive advantage. As Carr (2005) remarks, information technology assets are becoming a ubiquitous commodity and are easily imitable; this leads to the fact that buying an ERP system does not guarantee that a firm is enabled to create strategic value. Firms normally implement an ERP system that is provided by one of the limited number of vendors in the ERP market, thus firms' competitors with sufficient financial resources can also acquire an ERP system from the same vendor. Other studies argue that an ERP system can be customized to fit organizational requirements, thus making the system unique (Parthasarathy \& Anbazhagan, 2007), but the reality is that the degree of customization is limited because the system is normally designed and implemented in a way that embeds best practices that most adopting organizations are recommended to follow (Markus \& Tanis, 2000).

While it is questionable to assert that ERP systems by themselves can create competitive advantage, ERP systems can become a strategic resource when they are used to combine other organizational resources. Studies of IT resources hold the view that IT leads to business value and competitive advantage through the way IT complements or reinforces other organizational resources and capabilities (Bharadwaj, 2000; Clemons \& Row, 1991; Melville et al., 2004; Piccoli \& Ives, 2005; Young \& Tsai, 2012; Zhang \& Lado, 2001). From this perspective, ERP by itself is not the direct source of competitiveness, but successful ERP implementation supports and enables the enhancement of the firm's other resources and capabilities and that, in turn, leads to different levels of performance across firms. This is the basis of this study.

Previous studies have attempted to measure the positive effects of ERP implementation in terms of impacts, performance, and benefits (Chang et al. 2011; Gable et al. 2008; Ifinedo 2006; Shang \& Seddon, 2002). Although most of the 
studies have indicated that competitive advantage is one of the benefits that firms pursue when implementing ERP, they have typically examined competitive advantage as one of a range of measures of impact or benefit without considering the interaction with firms' other strategic resources and capabilities. Based on the literature on IT business value, this study argues that measures of the relationship between ERP and strategic advantage are over-simplified and this study posits that this explains the equivocal relationships found between ERP and strategic benefits. This study argues that the relationship and interactions between ERP implementation and other organizational strategic resources and capabilities needs to be investigated.

In addition, previous studies have not explicitly examined the relationship between the extent or scope of ERP implementation and ERP benefits. ERP systems typically contain many modules which in turn span a large number of business processes. Varying numbers of modules may be implemented, and varying numbers of business processes may be changed as a result. Similarly, ERP implementation may cross a varying number of geographic sites or divisions in an organization. These variations are captured in the concept of the scope of ERP implementation (Barki, Oktamis, \& Pinsonneault, 2005; Karimi, Somers, \& Bhattacherjee, 2007). The scope of ERP implementation defines its overall impacts on an organization as well as business performance (Markus, Tanis, \& Van Fenema, 2000; Ranganathan \& Brown, 2006). It is believed that the scope of ERP implementation has a relationship with the benefits achieved by the adopting firms (Barki et al., 2005). The scope of ERP implementation reflects the extent to which the ERP system is diffused within an organization and its business processes (Barki et al., 2005). ERP implementation involves changes in the organization (Yeh \& OuYang, 2010), therefore its scope may have an effect on firms' strategic resources. In sum, little attention has been paid to understanding how ERP can produce strategic advantage by examining the relationship between the scope of ERP implementation and firms' strategic resources.

Scholars have agreed that the strategic resources of a contemporary organization mainly derive from the collective knowledge resources available to the organization (Winter, 1998) which is usually described as intellectual capital. Intellectual capital is 
often defined as the sum of human capital (the knowledge and capabilities of its people), organizational capital (the institutionalized knowledge residing in databases, structures and processes), and social or relational capital (the knowledge and value of its relationships) (Youndt et al., 2004). The intellectual capital of each organization is inherently unique, because it represents the knowledge of the organization, and it is something absolutely peculiar to each and every company (Bontis, Dragonetti, Jacobsen, \& Roos, 1999).

The transformation in the economy from manufacturing-based to information-based has highlighted the importance of the intellectual capital of organizations. Intellectual capital and the support of information technology in creating intangible value are vitally important for firms if they are to be profitable in a fiercely competitive era (Brooking, 1996, p. 12; Stewart, 1997, p. 25; Youndt et al., 2004). Therefore it is widely agreed that intellectual capital is an important strategic resource. The trend in ERP adoption has taken place with, and is related to, the trend of increasingly emphasizing the role of intellectual capital in organizations. It is this relationship that is explored in this thesis.

While the relationship between ERP and intellectual capital has not been studied, explicitly (some previous studies have been conducted to evaluate the relationship between ERP and strategic advantage, without separating out intellectual capital in particular), previous literature has shown that IT investment in general can be associated with intangible capital in general and intellectual capital in particular. Brynjolfsson, Hitt, and Yang (2002) remarked that investment in computerization is associated with other intangible assets and collectively create a firm's market value. Youndt et al. (2004) found that organizations with higher levels of investment in IT display higher overall levels of intellectual capital.

Similarly, this study posits that the implementation of ERP systems may have a positive effect on intellectual capital. Furthermore, when firms implement an ERP system, they need to have, or acquire the knowledge to understand and use the system effectively (Robey et al., 2002). So some degree of learning capability is essential to successful ERP implementation. 
Equally, ERP systems are complex software packages, the implementation of an ERP system involves, and may change, many aspects of an organization such as human resources, training, business processes reengineering, project management, and ERP vendors relationship (Muscatello \& Chen, 2008). When this occurs in an organization with learning capability, intellectual capital - knowledge residing in employees, the organization as a whole, and in the relationships amongst employees and with an organization's partners (Youndt et al., 2004) - may receive a positive boost due to an ERP implementation. Thus the relationship between ERP implementation and intellectual capital may vary according to the firms' organizational learning capability.

Looking at the learning capability of an organization in more detail, learning capability defines the extent to which the organization accumulates knowledge (McElyea, 2002; Vera \& Crossan, 2003). Learning capability comprises the preconditions or facilitators for effective organizational learning, such as managerial commitment, systems perspective, openness and experimentation, and knowledge transfer and integration (Jerez-Gómez, Céspedes-Lorente, \& Valle-Cabrera, 2005). If a firm has strong learning facilitators, learning will occur easily and effectively (DiBella \& Nevis, 1998, p. 61). Because organizational learning involves the construction, organization, storage, distribution, and application of knowledge (Pentland, 1995), the learning capability of an organization, which is determined by learning facilitators, has an important role in the accumulation of knowledge within the organization.

Organizational learning capability may have an effect on the improvement of intellectual capital when firms implement ERP. While this effect has not been studied specifically in the ERP benefit literature, studies have shown that learning capability is related to the effectiveness of IT implementation in general (Attewell, 1992; Robey, Boudreau, \& Rose, 2000). A firm on the one hand needs a certain level of learning capability to acquire the new knowledge necessary to carry out the implementation (Robey et al., 2000); on the other hand the outcomes of the adoption of the new IT system and its integration into the firm's business processes (Robey et al., 2002) also enhance the firm's knowledge stock. Furthermore, organizations vary 
in their learning capability, which can explain the varying degrees of success of an IT implementation (Lee, Lee, \& Lin, 2007; Lin, 2008). The role of learning capability in IT implementation can lead to the argument that the relationship between the scope of ERP implementation and intellectual capital is influenced by the firm's organizational learning capability.

Using the idea that IT resources can produce strategic advantage for firms when they are supported by organizational capabilities or when they interact effectively with other organizational resources, this study proposes a research model that links the scope of ERP implementation with the enhancement of intellectual capital, and simultaneously evaluates the moderating influence of organizational learning capability. The model is developed in Chapter 3 and is empirically tested using a survey of 226 firms in Vietnam.

\subsubsection{Research questions}

Two research questions will be addressed:

(1) To what extent does the scope of ERP implementation lead to the enhancement of intellectual capital?

(2) What is the moderating effect of organizational learning capability on the relationship between the scope of ERP implementation and the enhancement of intellectual capital?

\subsubsection{Research objectives}

This thesis aims to fill the identified gaps emerging from a review of prior studies in the areas of ERP organizational effects including competitive advantage, IT business value creation, and two organizational resources including organizational learning capability and intellectual capital. Accordingly the study objectives are:

- To examine the impact of ERP implementation scope on the enhancement of intellectual capital. 
- To examine how organizational learning capability affects the impact of ERP implementation on the enhancement of intellectual capital.

\subsection{Scope and delimitation of the research}

The scope and delimitation of this study are as follows.

The purpose of this study is to examine the relationship between ERP implementation scope and other organizational resources and capabilities: in particular, organizational learning capability and intellectual capital. The study does not cover all factors and processes explaining the impact of ERP on firms' performance. Therefore, although the study mentions the relationship between ERP and the competitive advantage of firms overall, this is not an integral part of the study's findings. The review of this relationship aims to show that it is complicated and not straightforward. This study goes back a step; it concentrates solely on the relationship between the scope of ERP implementation and two types of strategic resources that have an important impact on the firm's performance and competitive advantage, as shown in Figure 1.1.

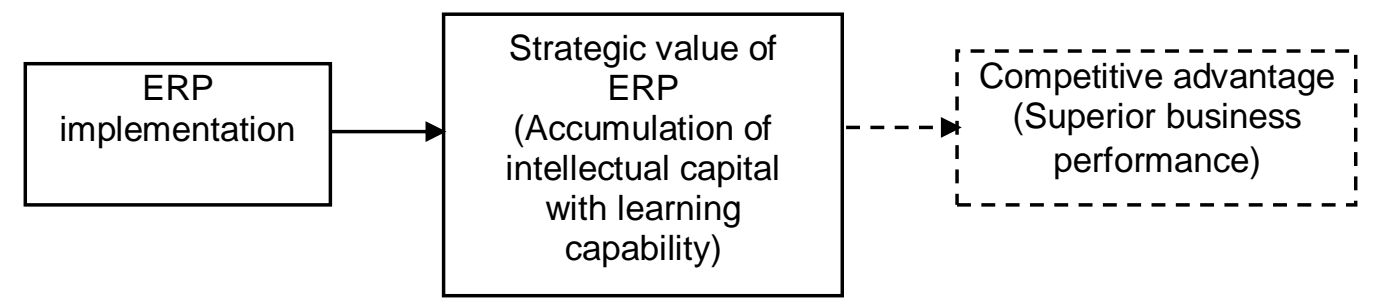

Figure 1.1 The role of strategic value of ERP between ERP implementation and competitive advantage

The sample of the study was limited to businesses listed in the Business Directory issued in 2013 by the Vietnamese Chamber of Commerce and Industry (VCCI). Additionally, the sample was also limited to manufacturing businesses in Ho Chi Minh City and Dong Nai province for two reasons. First, these areas are the major adjacent economic centres of Vietnam where business activities are concentrated, and they are two of four areas with the highest rate of firms adopting ERP. Also, the majority of ERP providers are located in these locations. Second, confounding effects may exist due to industry variations and ERP packages may have various 
characteristics for specific industries; therefore the study concentrates on manufacturing businesses. The use of such a sample cannot avoid weaknesses such as not including all businesses in all areas and all industry sectors and therefore may have limited the generalizability of the findings. However, with the stated constraints and explanations this context is judged to be suitable for the conduct of the study. Although the study was conducted in Vietnam, organizational learning capability and intellectual capital, according to their definitions, are expected to be generalizable concepts. It is not expected that the context of the study will have significant unique features that will affect the usefulness of the study in informing ERP implementation projects in other country contexts.

\subsection{Definition of terms}

Based on a review of existing literature, this study uses the following definitions of important terms:

Enterprise Resource Planning System (ERP): ERP is a packaged business software system that lets an organisation automate and integrate the majority of its business processes, share common data and practices across the enterprise and produce and access information in a real-time environment.

ERP implementation scope: the extent to which the ERP system is diffused within an organization and its business processes.

ERP implementation breadth: the extent to which implementation of the system (including hardware, and software) and business process reengineering (BPR) is diffused horizontally across an organization.

ERP implementation depth: the extent to which implementation of the system and BPR is diffused vertically in an organization.

ERP implementation magnitude: the extent to which (a) BPR changes the work of people involved in ERP implementation, (b) business processes become more automated via ERP implementation, and (c) ERP software needs or does not need to be modified in order to conform to an organization's business processes. 
Intellectual capital (IC): the sum of all knowledge an organization is able to leverage in the process of conducting business to gain competitive advantage.

Human capital (HC): individual employee‘s knowledge, skills, and abilities.

Organizational capital (OC): institutionalized knowledge residing in databases, manuals, structures and processes.

Social capital (SC): knowledge embedded in the social relationships and networks among employees and in the linkage with customers, suppliers, alliance partners, and the like.

Organizational learning capability (OLC): the conditions for or facilitators of effective organizational learning.

Managerial commitment: the willingness and involvement of people in the firm's management group to create a culture of learning.

Systems perspective: the extent to which the firm is considered a system where all parts have a clear view of the firm's objectives and are coordinated towards these objectives.

Openness and experimentation: the tendency of an organization to welcome new ideas and implement innovative suggestions.

Knowledge transfer and integration: the ability of an organization to spread and integrate knowledge among its members.

First-order factor model: Covariances between measured variables explained with a single latent factor layer.

Second-order factor model: measurement theory involving two "layers" of latent constructs (Hair, Black, Babin, \& Anderson, 2010, p. 735).

Formative measurement theory: theory based on the assumptions that (1) the measured variables cause the construct and (2) the error in measurement is an inability to fully explain the construct (Hair et al., 2010, p. 733). 
Reflective measurement theory: theory based on the assumptions that (1) latent constructs cause the measured variables and (2) the measurement error results in an inability to fully explain these measures (Hair et al., 2010, p. 734).

Reflective first-order and formative second-order construct model: the model represents a second-order construct that has first-order formative dimensions which are themselves measured by several reflective manifest items (Diamantopoulos, Riefler, \& Roth, 2008).

Moderating effect: effect of a third variable or construct changing the relationship between two related variables/constructs; that is, the relationship between two variables changes based on the level/amount of a moderator.

\subsection{The roadmap of the study}

Figure 1.2 presents the roadmap of the study. The roadmap is a flowchart illustrating the actions that constitute each step in the study. The process includes the key elements that lead to research questions, the research methods, analysis and findings, and conclusions and implications of the study. The solid line represents the flow of the process. The dotted line represents the feedback from the findings that answers the research questions and provide the theoretical implications. 


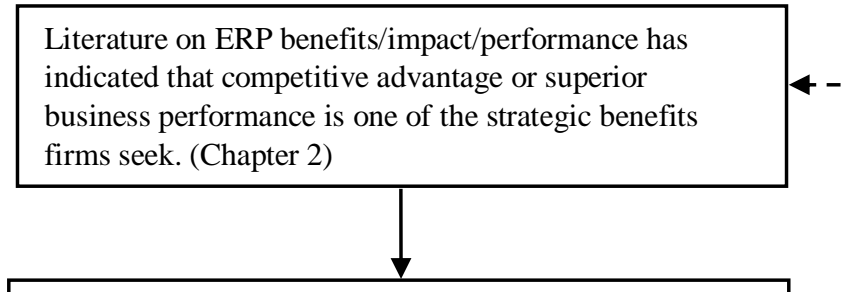

According to the Resource Based View, organizational resources are key factors for competitive advantage when they have specific attributes of rareness, value, imperfect imitability, and non-substitutability. ERP software is a commodity, therefore, the ability of ERP to produce competitive advantage or superior business performance is not justifiable. (Chapter 2)

Literature on IT business value has shown that IT resources become strategically valuable when they have relationships with other organizational resources. (Chapter 2)

The need to look at the ability of ERP to enhance or create other organizational resources; which make ERP become strategicallv valuable. (Chapter 3 )

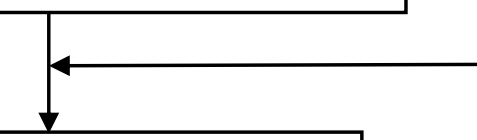

From the viewpoint that organizations are learning entities, intellectual capital and learning capability are two important organizational The examination of the relationship between ERP implementation and intellectual capital and the role of organizational learning capability in that relationship (Chapters 3) resources and they have relationships with the implementation of an advanced IT such as ERP. (Chapter 2)

Research questions:

(1) To what extent does the scope of ERP implementation lead to the enhancement of intellectual capital?

(2) What is the moderating effect of organizational learning capability on the relationship between the scope of ERP implementation and the enhancement of intellectual capital?

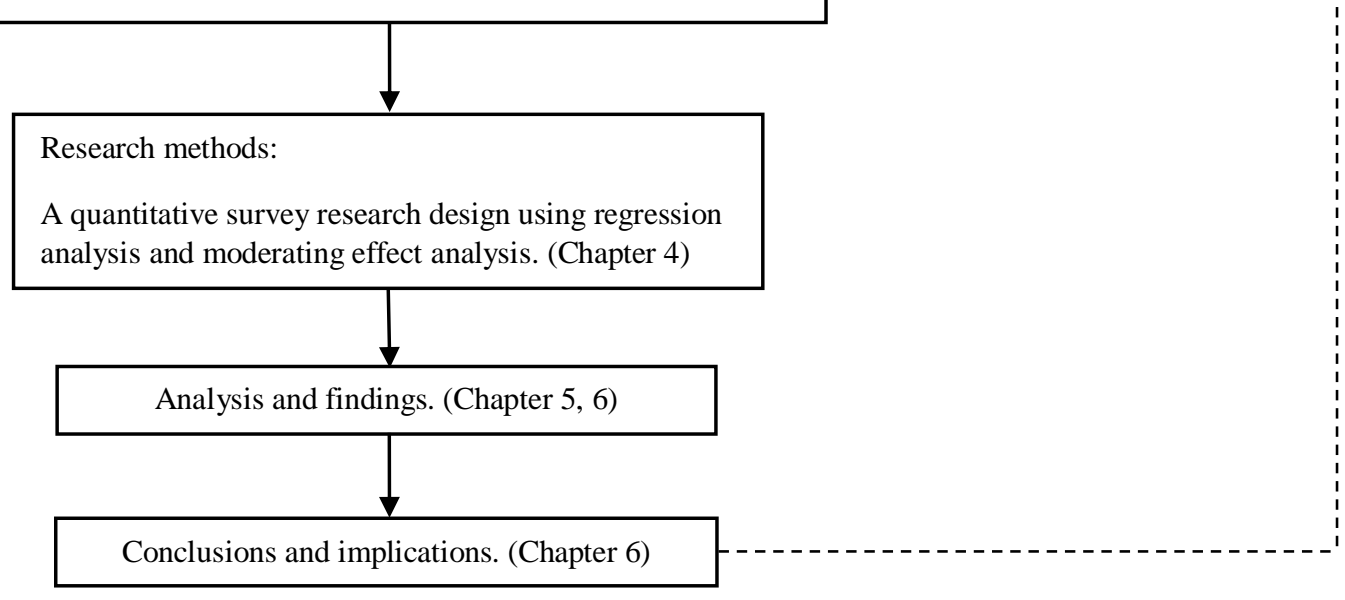

Figure 1.2 The roadmap of the study 


\subsection{The organization of the thesis}

The study proposes and empirically tests an equation model that is used to theorize the link between the scope of ERP implementation and a strategic resource; intellectual capital. The effect of organizational learning capability as a moderating factor between ERP implementation and intellectual capital is modelled and tested. The thesis includes six chapters.

Chapter 1 provides an introduction to the research problem. It describes the purpose of the study, then states the research questions and research objectives. In addition, this chapter also explains the research scope and presents definitions of important terms used in the study. Lastly the thesis structure is presented.

Chapter 2 provides a thorough review of the research literature that relates to ERP systems, ERP benefits and impacts, IT business value creation, and organizational resources including intellectual capital and organizational learning capability. Because the study is based upon the resource based view of the firm, this chapter also reviews the strategic characteristics of intellectual capital and organizational learning capability.

Chapter 3 aims to develop a research model that links the scope of ERP implementation with intellectual capital as mediated by organizational learning capability. The research hypotheses are then established to deal with the research questions proposed in Chapter 1.

Chapter 4 presents the justification of the research methodology and the research design process used to test the research model. In particular, the chapter considers questionnaire development, the identification of the population and sample type. It then describes the data collection processes including the administration of questionnaire distribution and collection. The chapter includes a detailed explanation of the data analysis techniques used in the study.

Chapter 5 reports the results and findings of the statistical analysis. In particular, the description of the respondent and firm profile is presented, and the construct validity 
and measurement model are assessed. The hypotheses that were proposed in Chapter 3 are tested and proven. The structural model is then examined to test the significance of theoretical relationships. Finally, the strength of the moderating effect of organizational learning capability on the relationship between the scope of ERP implementation and intellectual capital is assessed using both the product term method and the group comparison method.

Chapter 6 discusses the theoretical and practical implications of the study's major finding, that successful ERP implementation can, through the moderation of organizational learning capability, have an impact on the firm's strategic resource of intellectual capital. The chapter provides answers to the research questions posed in Chapter 1 and makes suggestions for how the results can be interpreted. The limitations of the study are described. Finally, suggestions for future research have been made. 


\section{CHAPTER 2}

\section{LITERATURE REVIEW}

The aim of this chapter is to review the topics that constitute the theoretical background for this study. This section firstly introduces the terminology of ERP systems and the definition of ERP used in this study. Then it discusses what ERP implementation is, including the extent of scope of ERP implementation. Next, the literature regarding the impact, performance, and benefits of ERP implementation for organizations is reviewed to indicate that when examining the possibility of producing competitive advantage through ERP, it is necessary to examine the relationship between ERP implementation and other organizational strategic resources. The chapter continues with a discussion of the IT/IS business value process and the role of organizational resources in this process. Finally, the two organizational resources - intellectual capital and organizational learning capability are discussed.

\subsection{Enterprise resource planning (ERP) systems}

This section firstly reviews the history of ERP systems and clarifies the concept of ERP used in this study. Then it presents the process of ERP implementation, which has a multi-phase nature and involves other organizational factors. The section continues with the characteristics of an ERP implementation that reflect the extent or scope of ERP implementation. Lastly, this section provides a review of the impact and benefits of ERP and the possibility that ERP can create competitive advantage for organizations.

\subsubsection{The history and concept of ERP systems}

The term ERP was first used in the early 1990s by the Gartner Group to describe criteria used to evaluate the degree that software in organizations encompassed integrated functions (Wylie, 1990). ERP systems have been widely adopted by companies because of their integration capability, standard software packages and client/server architecture (Chung \& Snyder, 2000). ERP systems integrate most 
business processes. During the 1990s, in addition to the core modules of ERP, the vendors extended ERP by adding more modules such as advanced planning and scheduling (APS), customer relationship management (CRM), and supply chain management (SCM) (Hossain, Patrick, \& Rashid, 2002, p. 4).

With the explosive development of the internet, the diffusion of e-commerce, and the globalization of business, ERP vendors have made changes in their product strategies to offer ERP software packages that are compatible with internet-based architecture, and include even more modules (Ronald \& Angappa, 2007). Presently, the major vendors in the ERP software market are SAP, Oracle, Microsoft, Epicor, and Infor (Panorama, 2015).

Although widely mentioned in the trade press, the concept of ERP had not been discussed in IS conferences until 1997 and information systems (IS) journals until 2000 (Klaus, Rosemann, \& Gable, 2000). From the literature review, it can be seen that there is no universal definition of ERP. The concept of ERP can be examined from several perspectives. ERP can be seen as a set of integrated software applications used to manage all functions within the organization (Yen, Chou, \& Chang, 2002) and integrate data through embedded business processes (Esteves \& Pastor, 2001). Klaus et al. (2000) define ERP as a comprehensive package of software solutions that strives to integrate the full range of business processes and functions in order to present a holistic view of the business in a unified information and IT architecture. As standardized packaged software, the aim of an ERP system is to integrate the entire value chain in an organization (Lengnick-Hall, Lengnick-Hall, \& Abdinnour-Helm, 2004). Paying attention to the strategic perspective, Chakraborty and Sharma (2007) consider ERP not only a software application but also a business strategy, i.e. ERP implementation is a strategic step that helps companies gain competitive advantage by streamlining business processes and optimizing the available resources. ERP is also considered the enabling technology for business process reengineering (BPR) and business transformation (Møller, 2005).

The components that are included in an ERP system vary, and based on the components there are alternative terms for ERP. For example, depending on the type of adopting organization and the industry, ERP may or may not include a material 
requirements planning module (MRP). Additionally, ERP may be extended to include front-office and back-office applications such as CRM and SCM. In order to avoid the common misunderstanding that ERP must evolve from and always includes MRP, which derives from their historical order of appearance, researchers have suggested other terms to replace ERP such as enterprise resource management (ERM) systems (Chuang \& Shaw, 2008), enterprise systems (ES), and business systems (Davenport, 2000), to emphasize the coverage and integration of all organizational functions of ERP.

Recently, the concept of ERP II has been proposed. ERP II systems are seen as an expansion of ERP systems to include components for e-business and collaboration supporting the supply chain (Møller, 2005). ERP II systems include electronic business applications that comprise other non-ERP vendors' technological innovations such as application frameworks (for example.NET), a database, decision support systems (DSS), and the use of internet standards. The ERP II system of the future is described as a combination of distributed web services. ERP II is web-based, open and componentized (Møller, 2005). It is also predicted that with the growing trend toward cloud computing, software as a service (SaaS), platform as a service (PaaS), and infrastructure as a service (IaaS), ERP systems will evolve into a new generation (Lenart, 2011; Raihana, 2012).

In conclusion, there are various terminologies and descriptions that are used to define ERP systems. It can be seen that the boundary and the definition of ERP systems has changed over time with the rapid growth of information technology. The present study adopts the term of enterprise resource planning that is defined by Marnewick and Labuschagne (2005, p. 145) as "A packaged business software system that lets an organisation automate and integrate the majority of its business processes, share common data and practices across the enterprise and produce and access information in a real-time environment".

An ERP system comprises all applications that integrate the business processes of organizational divisions. Due to its wide scope and complex nature, the implementation of an ERP system is time- and resource-consuming, and is likely to 
lead to considerable impacts on the organization. The process of ERP implementation and the impacts of ERP on organizations are presented next.

\subsubsection{ERP implementation}

Using the process for the implementation of an information technology enabled system suggested by Kwon and Zmud (1987), the implementation of an ERP system can be characterized as having six stages. They are initiation, adoption, adaptation, acceptance, routinization, and infusion.

The initiation stage refers to the introduction of ERP implementation into organizational thinking. The organization chooses to implement ERP for many reasons, such as to deal with current inefficient business processes, to respond to the force of competition, a need to change strategy, and the interest of top management. These reasons evolve from organizational need or technological innovation, or both (Cooper \& Zmud, 1990). The decision to implement an ERP system is made in the adoption stage. In order to come to the decision, the organization has to determine the rationale for implementation, including ERP strategic alignment, cost benefit analysis in the short and long term, financial resources, and the readiness of other organizational factors. After the decision is made and an appropriate ERP vendor is selected, the adaptation stage occurs in which current IT infrastructure and business processes are investigated, ERP modules are configured and installed, and employees are trained, etc. At the end of the adaptation stage, the ERP system is available for use in the organization. Next, the process moves to the stage of employing ERP in organizational work. In this acceptance stage, employees are induced to commit to ERP use. After that, in the routinization stage, ERP is assimilated and becomes a normal activity in the organization. In this stage, there are no major difficulties during ERP use and the organization starts to achieve benefits. Finally, at the infusion stage, comprehensive and integrated ERP use leads to increased organizational effectiveness and supports higher levels of organizational work (Cooper \& Zmud, 1990).

Using the perspective of process theory for IS success, Markus and Tanis (2000) modelled the ERP implementation process in four phases (see Figure 2.1): project chartering (phase I), project (phase II), shakedown (phase III), and onward and 
upward (phase IV). During phase I, an organization makes a series of decisions that lead to funding for an ERP implementation. In the project phase, the organization conducts the activities of setting up, installing and starting to run the ERP system. These activities include software configuration, system integration, testing, data conversion, training, and rollout. During the shakedown phase, the organization has to overcome a number of difficulties in order to become familiar with ERP use and to get the system aligned with normal activities. The onward and upward phase is the situation when the organization obtains stable operation of the system and starts to achieve benefits. This phase ends when the system is upgraded or replaced by another information system.

It can be seen that the six stages in Kwon and Zmud's model are equivalent to the four phases in Markus and Tanis' model in terms of life cycle pattern. The pattern starts with a need to have a system and ends with the operation of the system and the firm achieving benefits.

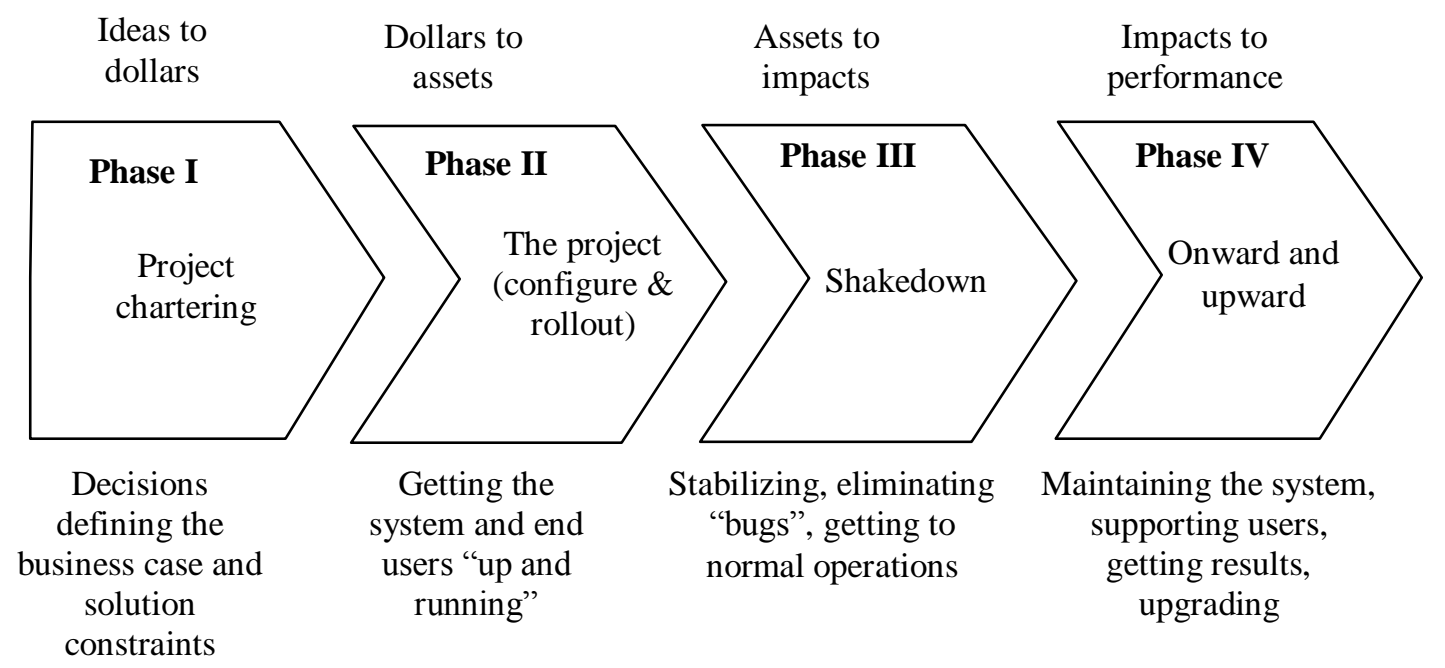

Figure 2.1 The enterprise system experience life cycle (Markus \& Tanis, 2000)

In addition to the studies that describe the whole process of ERP implementation, other studies have only emphasized the phase when ERP systems are completely installed, namely post go-live or post implementation. After successfully implementing ERP, adopting organizations experience the "second wave" of implementation (Deloitte, 1999; Esteves, 2009; Hawking, Stein, \& Foster, 2004), which comprises several stages with different durations (see Table 2.1). The 
stabilised stage is when organizations have to deal with many issues to familiarize themselves with the system and all associated business process changes. At the synthesise stage the system is in normal operation, and organizations look for ways to improve their business processes by adding new functionality modules and motivating end-users to support the changes. Finally, the synergise stage is when organizations achieve the optimization of business processes that is expected to lead to enterprise transformation (Esteves, 2009).

Table 2.1 Second wave of ERP implementation (Deloitte, 1999)

\begin{tabular}{llll} 
& Stabilise & Synthesise & Synergise \\
\hline Go live & $3-9$ months & $6-18$ months & $12-24$ months \\
\hline
\end{tabular}

The above discussion shows that the ERP implementation is complex, and an organization can only experience the impacts of ERP systems after a period of time, normally at least nine months after going live when the organization starts to stabilize the system. ERP implementation is time consuming and occurs through a number of stages.

It is during the ERP implementation and post implementation phases that it becomes clear that there are many organizational factors that influence the impact the system has on the organization. Organizations are required to have many conditions and capabilities in place to implement the system successfully and achieve effectiveness. For example, the success and effectiveness of the implementation of an enterprise system are affected by top management support, user training, enterprise-wide communication (Dezdar \& Ainin, 2011); project management, business-process reengineering (Dezdar \& Sulaiman, 2009; Ram, Corkindale, \& Wu, 2013); knowledge transfer between the organization and its consultants (Ko, Kirsch, \& King, 2005; Maditinos, Chatzoudes, \& Tsairidis, 2011; Wang, Lin, Jiang, \& Klein, 2007); and organizational culture (Ke \& Wei, 2008) and learning capability (Nwankpa \& Roumani, 2014).

The aforementioned points are significant for studies on ERP systems because (1) they indicate that after an ERP implementation, organizations need time to experience 
the system's impacts, and (2) they reveal that other organizational resources and capabilities play important roles in order for organizations to achieve effective ERP implementation. For this study, the first point will be considered in the procedure of selecting survey organizations, while the second point will be mentioned in a later section that discusses the role of organizational resources in the mechanism by which information technology brings business value to organizations.

While the ERP implementation process shows that organizations need to invest time and effort in order to experience the impacts of an ERP system, it is argued that the extent or scope of an ERP implementation also influences the strength of impact (Markus et al., 2000; Ranganathan \& Brown, 2006). Scholars have attempted to conceptualize and measure the scope of ERP implementation. This point is discussed next.

\subsubsection{The extent or scope of ERP implementation}

An ERP implementation is a time consuming and complex project, and the extent to which an organization implements the system defines its subsequent impacts (Markus $\&$ Tanis, 2000). The scope of ERP implementation is important for firm performance (Markus et al., 2000; Ranganathan \& Brown, 2006).

To measure the scope of ERP projects, Parr and Shanks (2000) categorized a typical ERP implementation into three broad categories, namely "comprehensive", "middle road" and "vanilla". A comprehensive ERP implementation is characterized by multiple sites, full functionality of ERP, and a high scope and level of business process reengineering. In a vanilla ERP project, the system is implemented at only one site, with only core ERP functionality, and with a minimal level of business process reengineering. Finally, a middle road ERP project is mid-way between the comprehensive and vanilla categories. In this category, the system is implemented at multiple sites, with only core ERP modules, and with a relatively significant level of business process reengineering. The authors proposed a number of characteristics that can be used to identify the three categories. These characteristics are physical scope, business process reengineering scope, technical scope, the strategy of module implementation, and resource scope in terms of time and budget. The set of 
characteristics Parr and Shanks (2000) used to identify the scope of ERP projects has some limitations. First, the resource scope in terms of time and budget is a result of, and should be separated from, the scope of ERP implementation that an organization decides (Barki et al., 2005). Second, the strategy of module implementation reflects the way the modules of an ERP are integrated, not the scope of an ERP implementation (Barki et al., 2005).

According to Barki et al. (2005), the scope of ERP implementation reflects the extent to which ERP systems are diffused within an organization and its business processes and has three dimensions: breadth, depth, and magnitude. The breadth of implementation indicates the extent to which the implementation of the system (including hardware and software) and business process reengineering is diffused horizontally across an organization. The number of functional units, the number of sites that are integrated by the system and BPR activities, among others, are examples of this dimension. The depth of implementation refers to the extent to which the implementation of the system and business process reengineering is diffused vertically in an organization. The depth of ERP implementation is measured by the number of users of the system and the number of employees whose activities are changed due to business process reengineering (Barki et al., 2005). Finally the magnitude of ERP implementation represents the magnitude of business process reengineering, business processes automation, and ERP customization. This dimension reflects how much the system changes employees' work and business processes.

Other scholars have proposed a number of measures for the extent of ERP implementation. For example, Karimi et al. (2007) believed that the extent of ERP implementation is determined by three factors: functional scope, which refers to the range of business functions such as accounting, manufacturing, and sales; organizational scope, which involves the organizational locations covered by the ERP implementation; and geographical scope, which indicates the regional, national, and global reach of the ERP implementation. Ranganathan and Brown (2006) argued that the scope of ERP implementation is characterized by the functional scope and physical scope. The functional scope refers to the number of ERP modules that 
facilitate the value-chain activities and enterprise-support activities of an organization. The physical scope indicates the number of sites the ERP implementation covers, as well as business divisions and geographies. Tsai et al. (2015) measured the extent of ERP implementation using the number of ERP modules and number of other information technology systems that are integrated by the ERP implementation. Nicolaou (2004) and Brazel and Dang (2008) only used the number of ERP modules to measure the extent of ERP implementation.

As shown, the extent or scope of ERP implementation is clearly defined by Barki et al. (2005) and its dimensions include most of the characteristics of the ERP implementation scope proposed by other scholars. For that reason, the current study follows Barki et al. (2005) and defines the scope of ERP implementation as the extent to which an ERP system is diffused within an organization and its business processes.

An ERP system is large and has a great impact on the implementing organization. The next section will present the literature on the measurement of effects of ERP implementation in terms of its impact, performance, and benefits.

\subsubsection{Measurement of the effects of ERP implementation}

The effects of ERP on organizations are acknowledged in the literature and are described as impacts, performance, and benefits. These measures are categorized in different perspectives: the IS-impact model (Gable, Sedera, \& Chan, 2003; Gable et al., 2008; Ifinedo, 2006) , the balanced scorecard (Chang et al., 2011; Mei-Yeh \& Lin, 2006; Sedera, Gable, \& Rosemann, 2001), and the ERP benefits assessment model (Shang \& Seddon, 2002).

From their study in 2003 (Gable et al., 2003), that was based on the widely cited model of IS success measurement of DeLone and McLean (1992), Gable and his colleagues produced a model to measure the impact of ERP in the public sector (Gable et al., 2008). According to the authors, there are two types of ERP impacts: individual and organizational. Individual impact refers to the influences individuals receive when interacting with the system, such as learning, decision effectiveness, and individual productivity. Organizational impact represents the consequences 
created by the system at an organizational level, such as overall productivity, increased capacity etc. The IS-impact model includes the quality of the system and the quality of information produced from the system. However the authors claim that although these factors can define the success of an ERP system they do not represent the present impact; instead they are the factors determining the future impact of the system (see Figure 2.2).

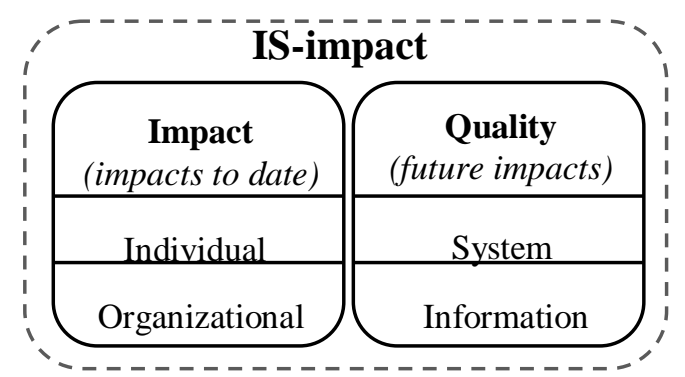

Figure 2.2 The IS-impact measurement model (Gable et al., 2003, 2008)

Inspired by the IS-impact model of (Gable et al., 2003), in an attempt to determine the factors influencing the success of ERP systems in the private sector, Ifinedo (2006) supplemented the model by adding two other factors: vendor/consultant quality and workgroup impact. According to the author, the success of an ERP system is defined by three quality factors (vendor/consultant, system, and information) and three impact factors (individual, workgroup, and organizational). The impact of ERP at the individual and organizational level is defined the same way as in Gable et al. (2003). The impact at workgroup level reflects the influence of ERP on work teams/groups performance, such as participation improvement, wide communication, and inter-departmental coordination (see Figure 2.3).

\begin{tabular}{|c|c|}
\hline Vendor/Consultant quality & \\
\hline System quality & \\
\hline Information quality & ERP systems \\
\hline Individual impact & \\
\hline Workgroup impact & \\
\hline Organizational impact & \\
\hline
\end{tabular}

Figure 2.3 The extended IS measurement model (Ifinedo, 2006) 
While the aforementioned authors mainly evaluate the effects of ERP on organizations in terms of the impacts directly arising from the interaction between the system and the individual, group, and organizational levels, other scholars have different views and solely measure the effects of ERP implementation at the organizational level. These measures have used the balanced scorecard, and benefits taxonomies.

As regards ERP implementations' effects on the performance of organizations, scholars have attempted to measure the performance of ERP through using the framework of the balanced scorecard (Change et al., 2011; Mei-Yeh \& Lin, 2006; Sedera et al., 2001). The balanced scorecard was proposed by Kaplan and Norton (1992); the central philosophy of the framework is that the measurement of business performance requires a balanced presentation of both financial and non-financial elements. According to the balanced scorecard, the performance of ERP can be evaluated using four categories: financial performance, internal processes, customer satisfaction, and innovation and learning. Financial performance measures reflect the contribution of an ERP implementation to improvement in financial status of an organization. The financial performance of the organization derives from the effectiveness of the three other activities: internal processes, customer satisfaction, and innovation and learning. It is important for an organization to understand and satisfy its customers, therefore the performance of the ERP implementation should be linked to specific measures indicating customers' concerns such as service time, service quality, service performance, and cost. To do this, the organization has to pay attention to internal business processes in order to support these customer-based measures. The internal business processes can be improved via ERP implementation, which facilitates operational efficiency, reduction in repetitive operations, reduction in work complexity, etc. (Chang et al., 2011; Tsai et al., 2012). Finally, in order to cope with a changing environment, organizations need to evaluate their capability in learning and innovation or growth (Kaplan \& Norton, 1996). Under this perspective, the performance of an ERP implementation is measured through the ability of the organization to learn and grow. This perspective is measured in terms of computer use and training (Fang \& Lin, 2006), the understanding of business process, and job achievement of employees (Tsai et al., 2012). This perspective is also evaluated by 
the ability of the system to offer more accurate and immediate information for decision making, to facilitate connections among departments through information sharing, to enhance employees' sense of achievement, and to increase competitive advantage (Chang et al., 2011). Furthermore, the change in management processes also illustrated the learning and innovation of an organization that commonly follows an ERP implementation (Chand, Hachey, Hunton, Owhoso, \& Vasudevan, 2005).

Beside using the balanced scorecard for ERP performance measurement, the effects of ERP system implementations on organizations can be identified under five categories of benefits according to Shang and Seddon (2002): operational, managerial, strategic, IT infrastructure, and organizational benefits. Operational benefits refer to the advantages that the operational processes of an organization may receive, such as improvements in procurement, inventory management, customer service, etc. Managerial benefits represent the efficiency and effectiveness that the ERP system introduces into managerial decision processes. Strategic benefits denote the competitive advantages supported by the ERP system in terms of business growth, alliances, innovation, cost leadership, etc. IT infrastructure benefits reflect an increased capability to handle IT-related applications and jobs resulting from the ERP implementation. Finally, organizational benefits represent the improvement of the organization in several aspects, such as learning, changing work patterns, concentrating on core work, increasing employees' morale, building a common vision, etc.

As has been shown, studies have attempted to identify the effects of ERP implementation in terms of impacts, performance, and benefits. They have concentrated on building a list of factors representing these effects. In sum, as shown in Table 2.2, the impacts of ERP implementations can be measured at individual, group, and organizational level, which are derived from the DeLone and McLean IS success model (e.g. Gable et al., 2003, 2008; Ifinedo, 2006). The performance of ERP systems can be measured by using four aspects of the balanced scorecard (Chang et al., 2011). Finally, the benefits of ERP can be measured by using the five-category framework of Shang and Seddon (2002). 
Chapter 2: Literature Review

Table 2.2 The effects of ERP implementation

\begin{tabular}{|c|c|c|c|c|}
\hline & \multicolumn{2}{|c|}{$\begin{array}{l}\text { The ERP impacts derived from the IS } \\
\text { success model of DeLone \& McLean }\end{array}$} & $\begin{array}{l}\text { The performance } \\
\text { of ERP using the } \\
\text { balanced } \\
\text { scorecard }\end{array}$ & $\begin{array}{l}\text { The five-category } \\
\text { framework of } \\
\text { ERP benefits }\end{array}$ \\
\hline Authors & $\begin{array}{l}\text { Gable et al. } \\
(2003,2008)\end{array}$ & $\begin{array}{l}\text { Ifinedo (2006); } \\
\text { Ifinedo et al. } \\
(2010)\end{array}$ & $\begin{array}{l}\text { Chang et al. } \\
(2011)\end{array}$ & $\begin{array}{l}\text { Shang and } \\
\text { Seddon (2002) }\end{array}$ \\
\hline Categories & $\begin{array}{l}\text { Organizational } \\
\text { impact } \\
\text { - Organizational } \\
\text { costs } \\
\text { - Reduced staff } \\
\text { costs } \\
\text { - Cost reduction } \\
\text { - Overall } \\
\text { productivity } \\
\text { - Improved } \\
\text { outcomes } \\
\text { - Increased } \\
\text { capacity } \\
\text { - E-government } \\
\text { - Business } \\
\text { process change } \\
\text { Individual impact } \\
\text { - Learning } \\
\text { - Awareness/ } \\
\text { recall } \\
\text { - Decision } \\
\text { effectiveness } \\
\text { - Individual } \\
\text { productivity }\end{array}$ & $\begin{array}{l}\text { Organizational } \\
\text { impact } \\
\text { - Organizational } \\
\text { costs } \\
\text { - Overall } \\
\text { productivity } \\
\text { - E-business/ } \\
\text { e-commerce } \\
\text { - Competitive } \\
\text { advantage } \\
\text { - Customer } \\
\text { service/ } \\
\text { satisfaction } \\
\text { - Business } \\
\text { process } \\
\text { change } \\
\text { - Decision } \\
\text { making } \\
\text { support } \\
\text { - Better use of } \\
\text { organizational } \\
\text { data resource } \\
\text { Individual } \\
\text { impact } \\
\text { - Individual } \\
\text { creativity } \\
\text { - Organizational } \\
\text { learning and } \\
\text { recall for } \\
\text { individual } \\
\text { workers } \\
\text { - Individual } \\
\text { productivity }\end{array}$ & $\begin{array}{l}\text { Financial } \\
\text { performance } \\
\text { - Reduce costs } \\
\text { - Increase } \\
\text { business } \\
\text { volume and } \\
\text { profits } \\
\text { - Increase the } \\
\text { inventory } \\
\text { turnover rate } \\
\text { - Reduce the } \\
\text { financial pay- } \\
\text { up cycle } \\
\text { - Reduce the } \\
\text { costs of } \\
\text { information } \\
\text { techniques } \\
\text { - Reduce the } \\
\text { total cycle time } \\
\text { Internal process } \\
\text { - Improve the } \\
\text { performance in } \\
\text { operational } \\
\text { procedures } \\
\text { - Better } \\
\text { operational } \\
\text { efficiency } \\
\text { - Improve the } \\
\text { performance of } \\
\text { the supply } \\
\text { chain } \\
\text { - Reduce the } \\
\text { time to enter }\end{array}$ & $\begin{array}{l}\text { Operational } \\
\text { benefits } \\
\text { - Cost reduction } \\
\text { - Cycle time } \\
\text { reduction } \\
\text { - Productivity } \\
\text { improvement } \\
\text { - Data quality } \\
\text { improvement } \\
\text { - Customer } \\
\text { services } \\
\text { improvement } \\
\text { Managerial } \\
\text { benefits } \\
\text { - Better resource } \\
\text { management } \\
\text { - Better decision } \\
\text { making and } \\
\text { planning } \\
\text { - Better } \\
\text { performance } \\
\text { control } \\
\text { Strategic benefits } \\
\text { - Support } \\
\text { business growth } \\
\text { - Support } \\
\text { business } \\
\text { alliances } \\
\text { - Support } \\
\text { business } \\
\text { innovation } \\
\text { imationg }\end{array}$ \\
\hline
\end{tabular}


Chapter 2: Literature Review

\begin{tabular}{|c|c|c|c|c|}
\hline & \multicolumn{2}{|c|}{$\begin{array}{l}\text { The ERP impacts derived from the IS } \\
\text { success model of DeLone \& McLean }\end{array}$} & $\begin{array}{l}\text { The performance } \\
\text { of ERP using the } \\
\text { balanced } \\
\text { scorecard }\end{array}$ & $\begin{array}{l}\text { The five-category } \\
\text { framework of } \\
\text { ERP benefits }\end{array}$ \\
\hline Authors & $\begin{array}{l}\text { Gable et al. } \\
(2003,2008)\end{array}$ & $\begin{array}{l}\text { Ifinedo (2006); } \\
\text { Ifinedo et al. } \\
(2010)\end{array}$ & $\begin{array}{l}\text { Chang et al. } \\
\text { (2011) }\end{array}$ & $\begin{array}{l}\text { Shang and } \\
\text { Seddon (2002) }\end{array}$ \\
\hline & & $\begin{array}{l}\text { - Beneficial for } \\
\text { individual's } \\
\text { tasks } \\
\text { - Higher-quality } \\
\text { decision } \\
\text { making } \\
\text { - Saving time } \\
\text { for individual } \\
\text { tasks/duties } \\
\text { Workgroup } \\
\text { impact } \\
\text { - Workers' } \\
\text { participation } \\
\text { in the } \\
\text { organization } \\
\text { - Organizational } \\
\text {-wide } \\
\text { communi- } \\
\text { cation } \\
\text { - Inter- } \\
\text { departmental } \\
\text { coordination } \\
\text { - Sense of } \\
\text { responsibility } \\
\text { - Efficiency of } \\
\text { sub-units in } \\
\text { the } \\
\text { organization } \\
\text { - Work-groups } \\
\text { productivity } \\
\text { - Solution } \\
\text { effectiveness }\end{array}$ & $\begin{array}{l}\text { the market } \\
\text { - Reduce } \\
\text { repetitive } \\
\text { operations } \\
\text { - Reduce work } \\
\text { complexity } \\
\text { Customer } \\
\text { - Reduce the } \\
\text { time to react } \\
\text { - Enhance the } \\
\text { level of } \\
\text { customer } \\
\text { satisfaction } \\
\text { and loyalty } \\
\text { - More } \\
\text { immediate } \\
\text { delivery } \\
\text { - Improve } \\
\text { product quality } \\
\text { Learning and } \\
\text { growth } \\
\text { (innovation) } \\
\text { - Offer more } \\
\text { accurate and } \\
\text { immediate } \\
\text { information for } \\
\text { decision } \\
\text { making } \\
\text { - Enhance the } \\
\text { connection } \\
\text { among } \\
\text { departments } \\
\text { through }\end{array}$ & $\begin{array}{l}\text { - Support cost } \\
\text { leadership } \\
\text { - Support product } \\
\text { differentiation } \\
\text { - Enable } \\
\text { worldwide } \\
\text { expansion } \\
\text { - Enable } \\
\text { e-commerce } \\
\text { - Generate and } \\
\text { sustain com- } \\
\text { petitiveness } \\
\text { IT infrastructure } \\
\text { benefits } \\
\text { - Increased } \\
\text { business } \\
\text { flexibility } \\
\text { - IT cost } \\
\text { reduction } \\
\text { - Increased IT } \\
\text { infrastructure } \\
\text { capability } \\
\text { Organizational } \\
\text { benefits } \\
\text { - Support } \\
\text { business } \\
\text { organisational } \\
\text { changes } \\
\text { - Facilitate } \\
\text { business } \\
\text { learning and } \\
\text { broaden } \\
\text { employee skills }\end{array}$ \\
\hline
\end{tabular}


Chapter 2: Literature Review

\begin{tabular}{|c|c|c|c|c|}
\hline \multirow[b]{2}{*}{ Authors } & \multicolumn{2}{|c|}{$\begin{array}{l}\text { The ERP impacts derived from the IS } \\
\text { success model of DeLone \& McLean }\end{array}$} & \multirow{2}{*}{$\begin{array}{l}\text { The performance } \\
\text { of ERP using the } \\
\text { balanced } \\
\text { scorecard } \\
\begin{array}{l}\text { Chang et al. } \\
(2011)\end{array}\end{array}$} & \multirow{2}{*}{$\begin{array}{l}\text { The five-category } \\
\text { framework of } \\
\text { ERP benefits } \\
\text { Shang and } \\
\text { Seddon (2002) }\end{array}$} \\
\hline & $\begin{array}{l}\text { Gable et al. } \\
(2003,2008)\end{array}$ & $\begin{array}{l}\text { Ifinedo (2006); } \\
\text { Ifinedo et al. } \\
(2010)\end{array}$ & & \\
\hline & & & $\begin{array}{l}\text { information } \\
\text { sharing } \\
\text { - Increase } \\
\text { organizational } \\
\text { productivity } \\
\text { - Increase } \\
\text { enterprise } \\
\text { competitive } \\
\text { advantages } \\
\text { - Reduction of } \\
\text { personnel } \\
\text { - Improve the } \\
\text { information } \\
\text { system } \\
\text { framework } \\
\text { - Enhance } \\
\text { employees' } \\
\text { sense of } \\
\text { achievement } \\
\text { - Help monitor } \\
\text { the global } \\
\text { operation } \\
\text { environment } \\
\text { - Enhance } \\
\text { information } \\
\text { system } \\
\text { functions }\end{array}$ & $\begin{array}{l}\text { - Empowerment } \\
\text { - Build common } \\
\text { vision } \\
\text { - Shift work } \\
\text { focus } \\
\text { - Increase } \\
\text { employee } \\
\text { morale and } \\
\text { satisfaction }\end{array}$ \\
\hline Field & $\begin{array}{l}\text { Public sector } \\
\text { Government } \\
\text { Agencies }\end{array}$ & $\begin{array}{l}\text { Private sector } \\
\text { Multiple } \\
\text { industries }\end{array}$ & $\begin{array}{l}\text { Private sector } \\
\text { Multiple } \\
\text { industries }\end{array}$ & $\begin{array}{l}\text { Private sector } \\
\text { Multiple } \\
\text { industries }\end{array}$ \\
\hline $\begin{array}{l}\text { Evaluation } \\
\text { viewpoint }\end{array}$ & Users at all levels & $\begin{array}{l}\text { Top and middle } \\
\text { management of } \\
\text { both business } \\
\text { and IT sides }\end{array}$ & $\begin{array}{l}\text { ERP supervisors; } \\
\text { top and middle } \\
\text { management }\end{array}$ & $\begin{array}{l}\text { Managerial } \\
\text { perspective }\end{array}$ \\
\hline
\end{tabular}


The examination of the previous approaches that are used to evaluate the effects of ERP on organizations exhibits three noticeable points. First, the measure of competitive advantage is included in most of these approaches. Except for the model of Gable and his co-workers that paid attention to measuring the impacts of ERP on organizations in the public sector, other studies expressed concern about competitive advantage when measuring the effects of ERP on firms in the private sector. The ability to produce competitive advantage of ERP is measured along with other measures as organizational impact in the IS-impact model (Ifinedo, 2006); in the learning and growth aspect of the balanced scorecard framework (Chang et al., 2011); and in the strategic benefit of the five-category framework (Shang \& Seddon, 2002). However, as discussed in the next section it is difficult for firms to produce competitive advantage with ERP; therefore the inclusion of competitive advantage in a range of measures of ERP effects is over-simplified.

Second, these approaches have not mentioned the strategic benefit of ERP in terms of its effect on the other strategic resources of organizations, which are important to explain the ability of ERP to produce competitive advantage. Finally, they have not considered the scope of ERP implementation and have not explicitly examined the relationship between the scope of ERP implementation and its effect on organizations.

\subsubsection{ERP and competitive advantage}

Firms expect ERP systems to provide competitive advantage, but it is difficult for firms to produce competitive advantage only with ERP (Seddon, 2005). ERP systems use IT, and Carr (2005) argued that IT has become a commodity, therefore an investment in IT is highly unlikely to create strategic value for organizations. A commodity does not have the characteristics of a strategic resource of an organization. According to the resource-based view (RBV), a firm outperforms its competitors because it possesses strategic resources, which explain different levels of organizational performance (Barney, 1991). Barney (1991) identified the attributes of firms' resources that are able to produce competitive advantage: rareness, value, imperfect imitability, and non-substitutability. A resource is valuable when it can 
enable a firm to conceive or implement strategies that improve its efficiency or effectiveness. A resource is rare when it is not possessed by a large number of competing firms. The imperfect imitability indicates that the valuable resource cannot be easily imitated. Finally, a resource that is non-substitutable cannot be easily replaced by other substitutes.

ERP software packages fail to meet Barney's criteria for a competitive resource. Although ERP software packages are valuable, they are not rare, inimitable, or nonsubstitutable (Lengnick-Hall et al., 2004; Stratman, 2007). ERP software packages are valuable due to their capability for facilitating operational processes, improving customer service, and providing accurate and reliable information to facilitate managerial decision making (Markus \& Tanis, 2000). ERP packages are neither rare, inimitable, nor non-substitutable because they are commercial products with built-in common business processes (or best practice solutions) that are widely available for client firms to implement (Holland, Light, \& Kawalek, 1999). Beard and Sumner (2004) suggested that ERP implementations may remove the competitive advantage that firms previously possessed because firms normally adopt the same information systems and business processes embedded in ERP packages. Although the customization of ERP may make the system unique and rare, it is also very risky, time-consuming, and costly (Parthasarathy \& Anbazhagan, 2007). Seddon (2005) believed that although the implementation of an ERP system can provide benefits including better information sharing, cost reduction, improved business processes, etc., ERP software is an unlikely source of competitive advantage because this type of software has been available for many years and many firms have realized its benefits.

Although the possibility of achieving competitive advantage from ERP implementations is not justifiable from the standpoint of ERP software as a commodity, it can be further examined for the business value created by using IT/IS resources in which the relationship between these resources and other organizational resources is emphasized. This point is presented in the next section. 


\subsection{IT business value and the role of organizational resources}

ERP systems use IT, therefore it is useful to examine the business value of ERP by using the mechanism through which IT resources brings business value to organizations even though the mechanism does not directly involve ERP systems.

Organizations apply IT to improve their business activities and performance; however, the value organizations realize does not always match what they expect (Brynjolfsson \& Hitt, 1998). The difficulty for organizations to realize value can be attributed to the fact that IT contributes value to organizations in multiple ways (Davern \& Wilkin, 2010). The business value of IT depends on many organizational factors, which are referred to as value-conversion contingencies (Davern \& Kauffman, 2000). This notion is illustrated in the model of IT business value process by Melville et al. (2004) (see Figure 2.4).

According to Melville et al. (2004, p. 287), IT business value is defined as "the organizational performance impacts of information technology at both the intermediate process level and the organizational level, and comprising both efficiency impacts and competitive impacts". In this model, the business value that IT resources create for a firm is determined by many external and internal factors.

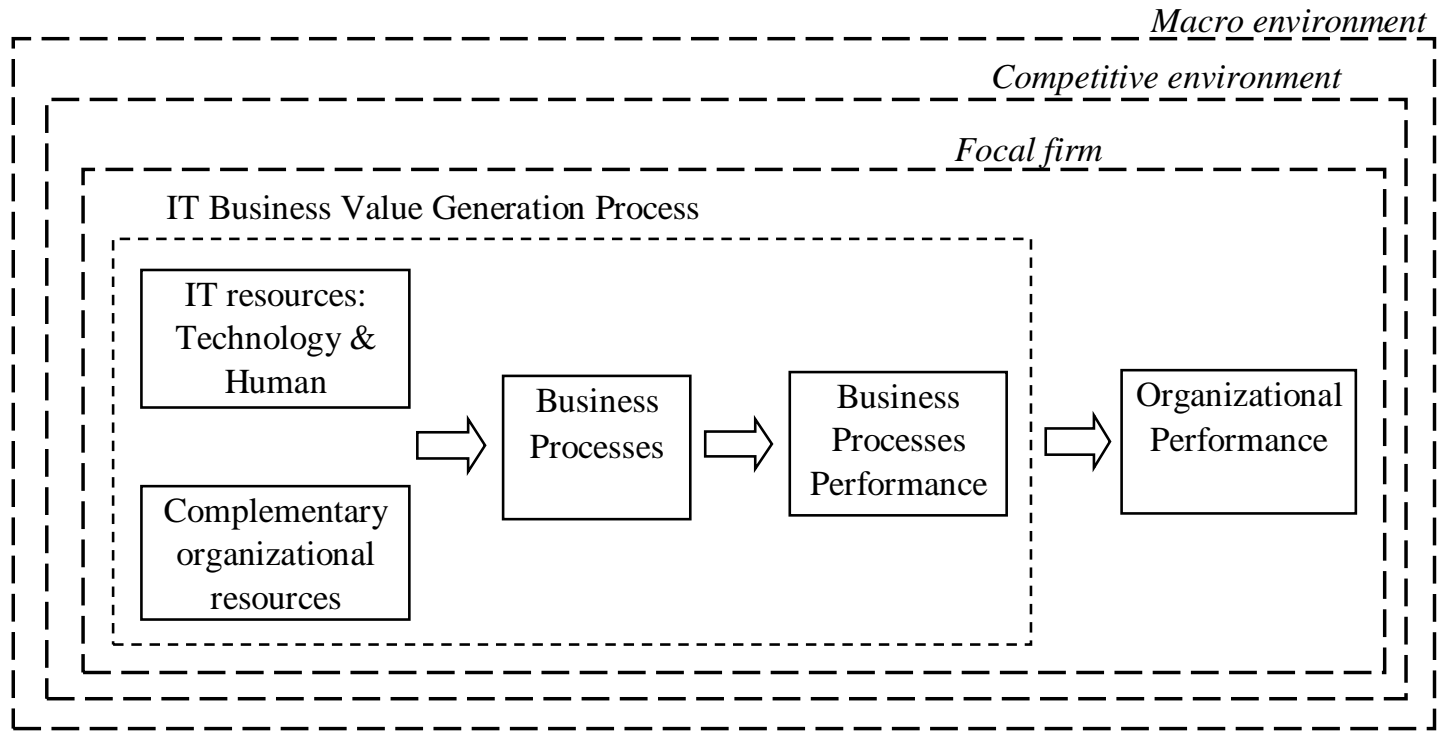

Figure 2.4 IT business value model (Melville et al., 2004) 
External factors beyond the boundary of the firm have influences on the firm's performance. These factors lie in the competitive environment and macro environment, such as a firm's IT application-based business relationship with its trading partners, the extent of competition in the industry, and the characteristics of IT infrastructure in the country (Melville et al., 2004).

As regards internal factors, the model shows that IT resources contribute value to organizational performance indirectly. IT resources are able to build business value when they are combined with other organizational resources to support business processes; this leads to an improvement in process performance, and finally in organizational performance. In this mechanism, IT resources may have a direct impact on operational processes, or may have relationships with other organizational resources and together create value for firms (Melville et al., 2004). Melville et al. (2004) proposed that certain organizational resources are complementary to IT resources in producing business value for the firm, and the strength of this complementarity is influenced by organizational and technological contexts. This point was agreed by Wade and Hulland (2004) who point out that the relationship between IT resources and organizational resources in business value creation can be in the form of complementarity and moderation. Resources are complementary when their combination leads to a higher impact than using them separately (Teece, 1986). Moderation occurs when some organizational factors influence the relationship between IT resources and organizational business value (Wade \& Hulland, 2004). The model of Melville et al. (2004) indicates the important role of other organizational resources necessary for IT resources to create impacts on the firm's performance, which include competitive impacts.

The relationship between IT and other organizational resources in producing competitive advantage is in harmony with what Zhang and Lado (2001) theorized. According to the authors, the potential for information systems to produce sustainable competitive advantage should be examined using their indirect effect on fostering organizational competencies including input-based, transformation-based, and outputbased competencies. Input-based competencies involve the physical resources, 
organizational capital resources, and human resources that are necessary for firms to create and deliver valuable products and services to customers. Transformation-based competencies indicate organizational capabilities in the process of converting inputs into outputs. Output-based competencies include all knowledge-based and invisible resources. All of these organizational competencies provide the economic values that can help firms produce competitive advantage (Zhang \& Lado, 2001).

The role of organizational resources in IT business value creation is also emphasized by Piccoli and Ives (2005), who proposed that the sustained competitive advantage of a firm depends on the complementarity of IT and other organizational resources, especially with the response-lag effect. When a firm deploys an IT innovation, it needs other non-IT resources to support it. IT and non-IT resources are merged over time under the process of organizational learning, and as a result a firm builds up unique complementary resources. This explains why it is not sufficient for competitors to merely replicate an IT system a firm has implemented to lessen the ITdependent competitive position of that firm (Piccoli \& Ives, 2005).

The role of organizational resources and capabilities to leverage the firm's IT/IS assets to create value has been emphasized in recent work. For example, Schryen (2013) proposes research that would examine the mutual effect between IS assets, IS capabilities and organizational capabilities in creating internal value and competitive value for firms. Masli, Richardson, Sanchez, and Smith (2011) highlight one of the focuses in IT business value evaluation, that is, the complementarities between IT and business.

Looking back at studies on the measurement of ERP effects, they have measured competitive advantage as one of a range of measures of all effects at the organizational level. As presented in the literature on IT business value, measuring competitive advantage in a general list of ERP effects without considering other organizational resources and capabilities is not adequate. 
Prior studies have provided some examples illustrating that ERP can be combined with other organizational resources and capabilities to indirectly build competitive advantage (e.g. Holland et al., 1999; Hsu, 2013; Laframboise \& Reyes, 2005). Hsu (2013) found that ERP indirectly provides firms with competitive advantage when it is combined with e-business technology and organizational resources such as managerial skills and organization change management to build business integration capability. Holland et al. (1999) hold that in order for ERP systems to be a source of competitive advantage, firms need to develop bespoke solutions in critical business areas beyond the common system and common business processes embedded in the systems. Firms have to supplement their common systems to add innovative ways of providing differentiation and for leveraging distinctive capabilities (Holland et al., 1999) Laframboise and Reyes (2005) showed that ERP and total quality management are complementary resources that lead to competitive advantage and improved organizational performance.

In summary, studies of the competitive advantage of ERP require consideration of other organizational strategic resources and capabilities. Informed by the literature on IT business value the current study explicitly proposes to investigate the relationship between ERP and organizational resources and capabilities. This will provide a missing link in understanding the value chain linking ERP implementation and competitive advantage.

As Piccoli and Ives (2005) point out, the implementation and use of an IT innovation are associated with the process of organizational learning, through which a firm accumulates its asset stock of resources. Other scholars have acknowledged that firms are learning systems (Nevis, DiBella, \& Gould, 1995), which utilize their knowledge to create value and to accumulate further knowledge (Grant, 1996; Nonaka et al., 2000; Vera \& Crossan, 2003). From this perspective, a firm's learning capability and sum of knowledge (or intellectual capital) are important organizational factors especially in combination with an IT implementation in general and an ERP implementation in particular. These two resources are reviewed next. 


\subsection{Two organizational resources: intellectual capital and organizational learning capability}

\subsubsection{Intellectual capital}

The term intellectual capital (IC) is a broad concept that has a relation with intangible firm assets (Marr \& Adams, 2004). The concept may be used with different meanings depending on the field or background that researchers are interested in (Marr \& Chatzkel, 2004). For example (see Table 2.3), Edvinsson and Sullivan (1996, p. 358) define intellectual capital as "knowledge that can be converted into value". This definition broadly includes inventions, ideas, designs, data processes, computer applications, and publications. According to Stewart (1997, p. xi), intellectual capital denotes "the intellectual materials - knowledge, information, intellectual property, experience - that can be put to use to create wealth". Roos et al. (1997, p. 27) define intellectual capital as the sum of knowledge of a company's members and the practical translation of this knowledge into trademarks, patents, and brands. Dzinkowski (2000) gives the definition that intellectual capital is the total stock of capital or knowledge-based equity that the company possesses. Closer to the knowledge management field, Bontis (1999) defines intellectual capital as the stock of knowledge in a firm. Similarly, by the definition of Youndt et al. (2004, p. 337), intellectual capital is "the sum of all knowledge an organization is able to leverage in the process of conducting business to gain competitive advantage".

Table 2.3 Typical definitions of intellectual capital

\begin{tabular}{|l|l|}
\hline Authors & Intellectual capital definitions \\
\hline $\begin{array}{l}\text { Edvinsson and Sullivan } \\
(1996, \text { p. 358) }\end{array}$ & Knowledge that can be converted into value \\
\hline Stewart (1997, p. xi) & $\begin{array}{l}\text { Knowledge, information, intellectual property, } \\
\text { experience - that can be put to use to create wealth - } \\
\text { collective brainpower }\end{array}$ \\
\hline Bontis (1999, p. 444) & The stock of knowledge in the firm \\
\hline
\end{tabular}


Chapter 2: Literature Review

\begin{tabular}{|l|l|}
\hline Authors & Intellectual capital definitions \\
\hline Dzinkowski (2000, p. 33) & $\begin{array}{l}\text { Total stock of capital or knowledge-based equity that } \\
\text { the company possesses }\end{array}$ \\
\hline $\begin{array}{l}\text { Chang, Chen, and Lai (2008, } \\
\text { p.300) }\end{array}$ & $\begin{array}{l}\text { Knowledge-related intangible assets embedded in an } \\
\text { organization }\end{array}$ \\
\hline Youndt et al. (2004, p. 337) & $\begin{array}{l}\text { The sum of all knowledge an organization is able to } \\
\text { leverage in the process of conducting business to gain } \\
\text { competitive advantage }\end{array}$ \\
\hline $\begin{array}{l}\text { Nahapiet and Ghoshal (1998, } \\
\text { p. 245) }\end{array}$ & $\begin{array}{l}\text { Knowledge and knowing capability of a social } \\
\text { collectivity, such as an organization, intellectual } \\
\text { community, or professional practice. }\end{array}$ \\
\hline
\end{tabular}

Although intellectual capital has numerous definitions, researchers in the intellectual capital field have agreed that intellectual capital is a multidimensional construct that has three dimensions: human capital, organizational capital (or structural capital), and social capital (or relational capital) (Martín-de-Castro, Delgado-Verde, López-Sáez, \& Navas-López, 2011; Youndt et al., 2004).

Human capital refers to the knowledge, attitudes, skills, competences, commitment, and experience of organizational members (Bontis, 1998). Human capital is viewed as a core asset of an organization (Becker, 1962). (Roos et al., 1997, p. 34) maintain that the human asset is the soul of an organization and the most essential component of intellectual capital. Human capital is one of the most important factors for organizational competitive advantage (Hatch \& Dyer, 2004). Human capital contributes to the innovation and renewal of the company (Roos et al., 1997, p. 40). For Stewart (1997, p. 82), the human asset denotes the capabilities of employees to provide solutions to customers and is a source of learning, knowledge transfer, and innovation.

Although employees and their collective intellect are important assets of an organization, they are not owned by the organization. An organization must have the 
structure and processes through which the knowledge of employees is synergistically utilized for optimum organizational performance (Bontis, 1999). Organizational capital is represented by institutionalized knowledge residing in databases, manuals, structures and processes (Youndt et al., 2004). The structure and processes of an organization are the assets that are defined as what is left behind at the organization when people go home (Edvinsson, 1997; Roos et al., 1997, p. 42). Organizational capital includes elements of the processes, activities, routines, and practices of organizations (Bontis, 1998).

While human capital and organizational capital refer to the intangible resources being vested in people and in the organization as a whole, social capital does not. Social capital represents the value embedded in the social relationships and networks among individuals, communities, or society (Tsai \& Ghoshal, 1998; Youndt et al., 2004). Social capital represents the potential value an organization may produce from its relationships with its partners (Bontis, 1999). It comprises the valuable relationships of an organization with its suppliers, clients, and entities outside the organization (Curado, Henriques, \& Bontis, 2011; Hsu \& Fang, 2009). With these relationships, the organization can absorb, exploit, and explore knowledge from its environment to obtain and sustain its competitive advantage (Martín-de-Castro et al., 2011). The social relationships of individuals can provide a mechanism for exchanging information and knowledge that is more efficient and less costly than more formal mechanisms (Nahapiet \& Ghoshal, 1998).

As shown above, intellectual capital is a broad concept. It may be used to include many intangible factors of an organization. It is recommended that researchers clarify the concept of intellectual capital in their studies (Marr \& Chatzkel, 2004). This study views organizations as learning entities (Nevis et al., 1995). In the context of ERP implementation, organizations potentially accumulate an amount of knowledge through the implementation of a complex information system such as ERP. To avoid including all intangible assets of organizations, this study uses the definition of Youndt et al. (2004), which is "the sum of all knowledge an organization is able to leverage in the process of conducting business to gain competitive advantage". 


\subsubsection{Organizational learning capability}

\section{Organizational learning}

Organizations are viewed as complex arrangements of people in which learning takes place (Nevis et al., 1995). Organizational learning is a phenomenon that has gained a lot of attention in the management literature (Bontis, Crossan, \& Hulland, 2002). An early view was that organizational learning manifest changes in the organization's routines that will affect future behaviour (Cyert \& March, 1963). The complexity of the phenomenon leads to the variety of its definitions (see Table 2.4). For example, according to Robey et al. (2000), organizational learning is an organizational process enabling the acquisition of, access to, and revision of organizational memory, thereby providing direction to organizational action. By the definition of Fiol and Lyles (1985), organizational learning is seen as the process of improving actions through better knowledge and understanding. Huber (1991) gives the definition that an entity learns if, through its processing of information, the range of its potential behaviours is changed. DiBella, Nevis, and Gould (1996) look at organizations as environments in which learning takes place and define organizational learning as the capacity or processes within an organization to maintain or improve performance based on experience.

Table 2.4 Typical definitions of organizational learning

\begin{tabular}{|l|l|}
\hline Authors & Organizational learning definitions \\
\hline $\begin{array}{l}\text { DiBella et al. (1996, p. } \\
\text { 363) }\end{array}$ & $\begin{array}{l}\text { Organizational learning is the capacity (or processes) } \\
\text { within an organization to maintain or improve } \\
\text { performance based on experience }\end{array}$ \\
\hline $\begin{array}{l}\text { Duncan and Weiss (1979) } \\
\text { - cited by Daft and Weick } \\
(1984, \text { p. 286) }\end{array}$ & $\begin{array}{l}\text { Organizational learning is a process by which } \\
\text { knowledge about action-outcome relationships between } \\
\text { the organization and the environment is developed }\end{array}$ \\
\hline $\begin{array}{l}\text { Fiol and Lyles (1985, p. } \\
803)\end{array}$ & $\begin{array}{l}\text { Organizational learning means the process of improving } \\
\text { actions through better knowledge and understanding }\end{array}$ \\
\hline
\end{tabular}




\begin{tabular}{|l|l|}
\hline Authors & Organizational learning definitions \\
\hline Huber (1991, p. 89) & $\begin{array}{l}\text { An entity learns if, through its processing of } \\
\text { information, the range of its potential behaviours is } \\
\text { changed }\end{array}$ \\
\hline $\begin{array}{l}\text { Levitt and March (1988, p. } \\
\text { 320) }\end{array}$ & $\begin{array}{l}\text { Organizations are seen as learning by encoding } \\
\text { inferences from history into routines that guide } \\
\text { behaviour }\end{array}$ \\
\hline Panayides (2007, p. 69) & $\begin{array}{l}\text { Organizational learning refers to the organization-wide } \\
\text { activity of creating and using knowledge to enhance } \\
\text { competitive advantage }\end{array}$ \\
\hline Probst and Buchel (1997, & $\begin{array}{l}\text { Organizational learning is a process by which the } \\
\text { organizations' knowledge and value base changes, } \\
\text { leading to its improved problem solving ability and } \\
\text { capacity for action }\end{array}$ \\
\hline Robey et al. (2000, p. 130) & $\begin{array}{l}\text { Organizational learning refers to the capacity or } \\
\text { processes within a firm enabling the acquisition of, } \\
\text { access to and revision of organizational memory, } \\
\text { thereby providing directions for organizational action }\end{array}$ \\
\hline
\end{tabular}

Regardless of the variety of definitions or organizational learning, it can be seen that all scholars describe organizational learning as a process or organization-wide activity that results in changes in organizational knowledge and subsequent actions of an organization (Argote, 2011).

\section{Organizational learning capability}

Learning capability is different to organizational learning. Organizational learning has been studied both from descriptive and prescriptive perspectives (Tsang, 1997). The descriptive research stream is concerned with how an organization does learn, whereas prescriptive or normative studies address how an organization should learn. DiBella and Nevis (1998, p. 24) reflect these streams when they propose that organizational learning can be understood through the examination of two parts. One 
part is about the learning orientations within an organization. They refer to how and what an organization learns. The other part consists of facilitating factors that promote organizational learning. Although the combination of these two parts might assist our understanding of organizational learning as a whole, learning orientations do not provide criteria for evaluating an organization's learning capability; they only help us understand and describe the learning processes that currently take place in an organization (DiBella \& Nevis, 1998, p. 56). By contrast, facilitating factors help to explain the learning from a normative perspective. Put differently, if these factors are strong and widespread in an organization, learning will occur easily and there will be more of it (DiBella \& Nevis, 1998, p. 61).

According to Jerez-Gómez et al. (2005), organizational learning capability comprises the conditions or facilitators for effective organizational learning. Organizational learning capability has been conceptualized as a multidimensional construct that comprises managerial commitment, systems perspective, openness and experimentation, and knowledge transfer and integration (Jerez-Gómez et al., 2005). Managerial commitment refers to the role of the management team in creating a culture of learning. Managers should hold a view that learning is of fundamental value. They should participate and also encourage employees to participate in learning. A systems perspective denotes the ability to think broadly about the interdependency of organizational factors (Nevis et al., 1995). It is associated with system thinking and the ability to create a shared vision in an organization (Senge, 2006, pp. 8-9). For proactive learning, openness and experimentation are necessary for the organization to welcome new ideas. Openness and experimentation are also associated with the notion of "unlearning" which is vital for organizational change (Sinkula, Baker, \& Noordewier, 1997). Finally, knowledge transfer and integration represents the extent to which the organization has the ability to spread and integrate knowledge among its members (Jerez-Gómez et al., 2005).

ERP implementation is an opportunity for organizational learning (Besson \& Rowe, 2001; Soh, Kien, \& Tay-Yap, 2000), therefore learning capability is important in order to achieve the positive effects of the implementation. This study follows the 
prescriptive stream of organizational learning research and posits that the ability of an organization to leverage the potential of an ERP implementation is determined by facilitating factors that promote learning. When an organization implements a new information system (such as ERP), learning occurs throughout the organization (Attewell, 1992). It needs to acquire knowledge to understand and use the system effectively (Pentland, 1995; Purvis, Sambamurthy, \& Zmud, 2001). The adoption of a complex technology requires the organization to modify and adjust its business processes and the technical aspects of the technology (Attewell, 1992). From this view, the organizational factors that promote and facilitate learning will influence ERP implementation results.

\subsubsection{Strategic characteristics of organizational learning capability and intellectual capital}

The Resource-Based View of the firm (RBV) suggests that firms with strategic resources have the potential to achieve superior performance (Barney, 1991). Strategic resources have the characteristics of rareness, value, imperfect imitability, and non-substitutability that allow firms to be able to achieve strategic goals (Barney, 1991). Strategic resources are intangible in nature (Michalisin et al., 1997). Organizations obtain high performance and create value when they implement appropriate strategies to take advantage of market opportunities through managing and exploiting their resources and capabilities (Penrose, 1959). Resources of an organization refer to all assets, capabilities, organizational processes, organizational attributes, information, and knowledge that are used for the improvement of organizational efficiency and effectiveness (Barney, 1991).

Organizational learning capability and intellectual capital are firm-specific. Intellectual capital is a key determinant of organizational performance and value creation (Nahapiet \& Ghoshal, 1998; Teece, 1998). Intellectual capital is the sum of all knowledge in an organization that can be used in the process of conducting business to gain competitive advantage (Youndt et al., 2004). Knowledge with appropriate exploitation can be a source of long-term competitive advantage for the organization (Drucker, 1993, p. 176). According to Grant (1996), knowledge is a 
critical input in production and is the primary source of value. Knowledge is seen as the most important strategic resource of the firm (De Carolis, 2002). A firm performs differently to its competitors because it has the ability of creating, applying, and putting knowledge into competitive advantage (Kogut \& Zander, 1992; Nonaka et al., 2000). The strategic attribute of intellectual capital has been increasingly acknowledged in the knowledge-based economy, in which the creation of value is no longer based on material and physical things but on information, knowledge, and brainpower (Stewart, 1997, p. 15).

While intellectual capital is the sum of knowledge of an organization, organizational learning capability is important because it defines the extent to which a firm is able to accumulate knowledge (McElyea, 2002; Vera \& Crossan, 2003). A firm itself is considered a learning entity, which creates and applies knowledge (Grant, 1996; Nevis et al., 1995; Nonaka et al., 2000) and converts knowledge into competitive advantage (Kogut \& Zander, 1992). Learning capability is seen as a source of heterogeneity between organizations and formulates competitive advantage through the accumulation of knowledge (March, 1991). Learning capability facilitates learning process (DiBella \& Nevis, 1998) that involves the process of knowledge transfer (Argote, 2011), which is in itself a basis for competitive advantage (Argote $\&$ Ingram, 2000). Organizational learning capability is a strategic resource because the competitive advantage of a firm in the future is determined by its ability to learn faster than its competitors (De Geus, 1988). Learning capability is firm-specific because it is related to the history of firms (Pan, Newell, Huang, \& Galliers, 2007) in that the firms adapt their behaviour based on interpretations of past events.

In the context of ERP implementation, organizations are considered learning entities (Grant, 1996; Nevis et al., 1995; Nonaka et al., 2000), ERP implementation is considered to provide an opportunity for organizational learning through which organizations may accumulate their sum of knowledge or intellectual capital. These relationships will be developed in the next chapter. 


\subsection{Chapter summary}

This chapter presented a review of the literature on the effects of ERP on organizations with regard to the possibility of ERP helping firms to achieve competitive advantage. Based on the literature on IT business value, the chapter revealed a need to examine the relationship between ERP implementation and other organizational resources prior to any attempt at identifying the benefits of ERP in terms of competitive advantage. The chapter also presented the importance of the link between the scope of ERP implementation and ERP benefits. Finally, taking the view that organizations are learning entities, the chapter emphasized two strategic resources of an organization in the context of ERP implementation: intellectual capital and organizational learning capability.

The next chapter continues to elaborate these issues and proposes a research model to examine the relationship between the scope of ERP implementation and the two strategic resources of intellectual capital and organizational learning capability. 


\section{CHAPTER 3}

\section{RESEARCH MODEL AND HYPOTHESES DEVELOPMENT}

As was explained in Chapter 2, ERP systems by themselves do not have strategic benefits, however these systems can become strategically valuable when they combine with other organizational resources. This can be explained by the literature on IT business value, which indicates that IT resources become strategically valuable resources that help firms achieve superior performance or competitive advantage only when they complement, interact with, or enhance other organizational resources and capabilities (Melville et al., 2004; Piccoli \& Ives, 2005; Wade \& Hulland, 2004; Zhang \& Lado, 2001).

Based on this view, it is over-simplified that prior studies on ERP effects have tended to measure competitive advantage without considering the relationship of ERP with the firms' other strategic resources and capabilities. This study argues that instead of focusing on the direct relationship between ERP and competitive advantage, it is the relationship between ERP and other organizational resources that may be used to explain how ERP implementation leads to competitive advantage.

Firms are considered learning systems (Nevis et al., 1995) and the entities that create and apply knowledge (Grant, 1996; Nonaka et al., 2000). When firms implement an IT system such as ERP, they have to learn to overcome knowledge barriers and experience changes. In such a context, organizational learning capability and intellectual capital are two important resources that need to be considered. The current study will address these two questions:

Research question 1: To what extent does the scope of ERP implementation lead to the enhancement of intellectual capital?

Research question 2: What is the moderating effect of organizational learning capability on the relationship between the scope of ERP implementation and the enhancement of intellectual capital? 
This chapter will represent the research questions in a conceptual model followed by its hypotheses. The model visualizes the relationships between the scope of ERP implementation, intellectual capital, and organizational learning capability.

\subsection{ERP implementation and intellectual capital}

In a broader view, the IT literature has shown that investment in IT may lead, or have a relation to, the enhancement of a firm's intangible capital. Firms, when investing in IT, also need to improve their human resources (i.e. human capital) in order to achieve high value (Kaplan \& Norton, 2004). Similarly, Brynjolfsson et al. (2002) point out that in order to realize benefits from IT investment, firms need to invest in intangible assets such as organizational processes and structures, worker knowledge, and redesigned systems of monitoring, reporting, and incentivisation. Their survey data from public capital markets show that firms have a higher measured output than others when they invest in IT and at the same time invest in other organizational practices.

In terms of intellectual capital, Youndt et al. (2004) conducted a study to explore the pattern of intellectual capital profiles in association with the extent of investment in three areas - human resources, IT, and research and development (R\&D) - among organizations. The findings show that firms with a high level of IT investment display higher overall intellectual capital. In their study, IT investment seems to help build social capital but not organizational capital. Their study focuses on IT investment in general, not on ERP implementation.

As regards ERP implementation, the implementation of ERP systems may have a positive effect on intellectual capital. ERP systems are large complex software packages, therefore the implementation of these systems is supposed to lead to changes in the organization (Markus, 2004) and involves not only the technological aspect but also organizational and social aspects (Yeh \& OuYang, 2010). An ERP implementation involves many aspects of an organization such as human resources, training, business processes reengineering, project management, and ERP vendor's 
relationship (Muscatello \& Chen, 2008). Because of these, all aspects of intellectual capital of an organization - knowledge residing in employees and the organization as a whole, and relationships among employees and with an organization's partners (Youndt et al., 2004) - may be influenced by the extent or scope of ERP implementation.

The scope of ERP implementation is the extent to which the ERP system is diffused within an organization and its business processes (Barki et al., 2005). The scope of ERP implementation includes breadth, depth, and magnitude dimensions (Barki et al., 2005). The breadth and depth of implementation refers to the horizontal and vertical diffusion, respectively. The magnitude of implementation reflects the change in employees' work and business processes due to ERP implementation. The scope of ERP implementation determines its overall impacts on organization (Markus, Tanis, \& Van Fenema, 2000; Ranganathan \& Brown, 2006), hence it may have a positive effect on intellectual capital. The hypothesized relationships between ERP implementation scope and intellectual capital are visualized in Figure 3.1, and are presented next.

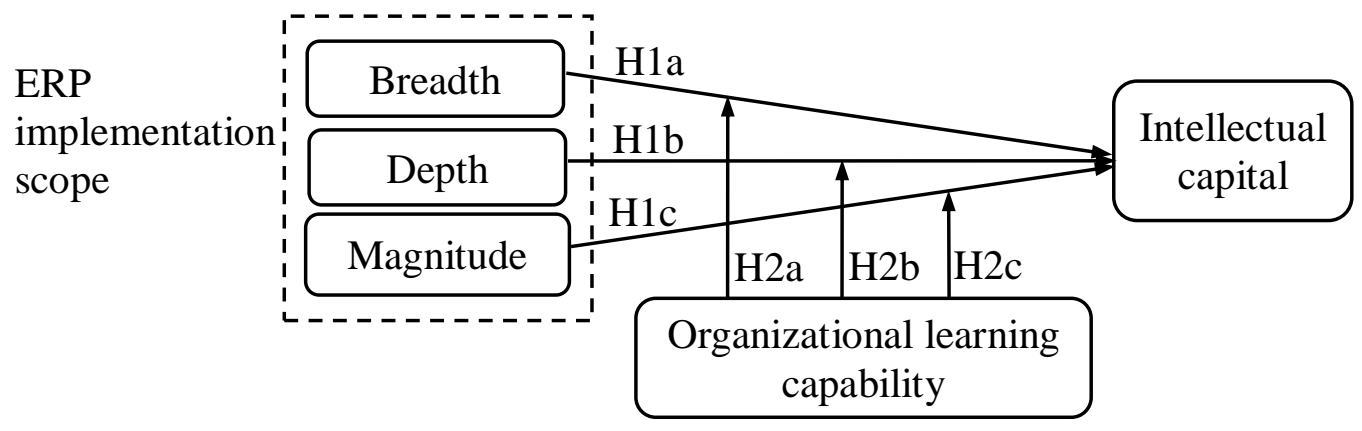

Figure 3.1 The research model

The characteristics of ERP implementation may be significantly related to all aspects of intellectual capital. As regards human capital, organizations have to carry out training programs for their employees at all levels in the organization during ERP implementation. Employees must learn skills and knowledge so they can use the features of ERP systems (Davenport, 2000). It is necessary for employees to understand the objectives of ERP implementation, to become committed to, and to maintain supportive and positive attitudes during ERP implementation. The changes 
in understanding and work-related skills are required not only at the operational level, but also at the managerial level. Managers need to acquire knowledge about business processes and the ERP system to support and have commitment to the process of implementation and use of the system (Muscatello \& Chen, 2008). The literature on the effects of ERP has shown that people are affected by the system through several aspects such as learning through the presence of the system, enhancing the awareness and recall of job related information, and increasing job effectiveness and employee productivity (Gable et al., 2008). Employees who join the training programs deployed by the organization will gain experience from interaction with the ERP system, and they gain knowledge and understanding about the ERP software and business process (Jones, Zmud, \& Clark, 2008).

Intellectual capital may be influenced by an ERP implementation in terms of organizational capital. The main purposes of ERP implementation are: (1) to automate and integrate business processes, (2) to share common data and practices across the entire enterprise, and (3) to produce and access information in a real-time environment (Deloitte, 1999). Thus, an ERP implementation leads to the improvement of automated and integrated business processes and common databases, which facilitates accessing information, creating reports and making decisions. This improvement is equivalent to the enhancement of organizational capital. As a result of an ERP implementation, firms can create documents regarding business processes and practices, standardize the processes according to those embedded in software applications, convert data into databases, and make all of these become daily activities and routines (Davenport, Harris, \& Cantrell, 2004). A firm may have the benefits of cycle time reduction, data quality improvement, better performance control, etc. (Shang \& Seddon, 2002). An ERP implementation can improve a firm's internal processes through better operational efficiency and work complexity reduction (Chang et al., 2011). In sum, all of these changes manifest the improvement in the organizational capital of a firm, which comprises institutionalized knowledge and codified experience residing in databases, manuals, systems, structures, and processes (Bontis, 1999; Youndt et al., 2004). 
In addition to human capital and organizational capital, social capital may also be affected by ERP implementations. The ERP system is complex so its acquisition requires organizations to seek support from external partners such as ERP vendors and consultants. Mutual understanding between ERP vendors and consultants and adopting organizations is crucial in ERP projects (Ifinedo, 2011; Markus \& Tanis, 2000). When a firm implements an ERP system, it enters a long-term relationship with the ERP vendors. The components of an ERP system need maintenance, updating, and upgrading (Davenport, 1998; Markus \& Tanis, 2000). The vendors support the firm with technical assistance, service, and user training (Ramayah, Roy, Arokiasamy, Zbib, \& Ahmed, 2007). Moreover, the relationship with the consultants is important because they provide the expertise to firms in performing requirements analysis, selecting suitable solutions, and managing overall implementation (Thong, Yap, \& Raman, 1994). They also support adopting organizations by offering related and required knowledge, solving problems, assisting in configuration, mobilizing various skills, and deriving value from the ERP package (Ifinedo, 2011). In addition to the relationship with ERP vendors and consultants, firms also hope to strengthen the relationships with their suppliers and customers through investment in ERP (Sánchez-Rodríguez \& Martínez-Lorente, 2011). ERP implementation is expected to support business alliances, and improve customer service, and supplier relationships (Shang \& Seddon, 2002).

Internal relationships, such as the networks of relationships and interactions among employees, may go through a significant change due to an ERP implementation. Enterprise integration through an ERP implementation is associated with mutual coordination and cooperation among individuals and workgroups (Elbanna, 2007; Ifinedo, 2006). ERP systems improve communication and business integration. As a result, the systems will support users in different business functions who work together, exchange information, and have better interaction (Yeh \& OuYang, 2010). Additionally, an ERP implementation is expected to provide the opportunity for a change of culture, with a common vision leading to the evolution of individual relationships (Shang \& Seddon, 2002). 
The above discussion on the relationship between ERP implementation and intellectual capital proposes that a broader scope of implementation (involving more modules, business processes, and business units) will create more opportunities for the firm to create intellectual capital. Accordingly, it is hypothesized that:

H1a: The breadth of ERP implementation scope has a positive effect on intellectual capital.

H1b: The depth of ERP implementation scope has a positive effect on intellectual capital.

H1c: The magnitude of ERP implementation scope has a positive effect on intellectual capital.

\subsection{Organizational learning capability and the relationship between ERP implementation and intellectual capital}

According to Robey et al. (2000), the relationship between organizational learning and information technology can be examined in two main streams: studies that examine the implementation and use of IT itself as a learning experience, and studies concerned with the design and use of IT applications to achieve organizational learning. Relying on this, therefore, organizational learning and ERP implementation can be investigated in two tracks: organizational learning occurs during ERP implementation and use, and organizational learning is supported by ERP implementation. This study views the implementation of ERP systems as an opportunity for organizational learning (Besson \& Rowe, 2001; Soh et al., 2000), thus is mainly positioned in the first track.

The implementation of a new complex technology requires firms to learn. During implementation a firm not only receives knowledge that is embodied in the technology from the supply side but also learns new skills and knowledge within itself (Attewell, 1992). The implementation of a new technology is a learning process that requires both individual and organizational learning. Individual learning occurs when the individual's experiences regarding the technology are transformed into 
personal understanding. Organizational learning involves the process by which individual insights and skills are embodied in organizational routines, practices, and beliefs that last longer than the presence of the originating individual in the organization (Levitt \& March, 1988).

Equally, organizations are considered to be knowledge systems that comprise five knowledge processes: the construction, organization, storage, distribution, and application of knowledge (Pentland, 1995). When an organization implements a new information system, these knowledge processes operate, and as a whole, represent learning that occurs in the organization. Pentland (1995) provided an example when an engineering consultancy implemented a new system that automatically helped to conduct the audit of energy systems. The implementation and use of the system lead to a change in the proportion of knowledgeable stakeholders including programmers in the development phase, and technicians and administrative staff in the use phase. This change is likely to lead to a change in knowledge construction and other knowledge processes (Pentland, 1995). Additionally, the knowledge domain also changes during system implementation. Before the implementation, organizational people were mainly interested in the knowledge of energy systems so they could understand how to audit these systems. During implementation, they acquired knowledge regarding the design and development of the software. Finally, after implementation they now focus on knowledge or understanding of how to use the system.

Pentland (1995)'s example is applicable to ERP implementation. An ERP implementation is more than the spread and adoption of a particular technological artefact; it relates to the processes of knowledge sharing and integration involved in the implementation and appropriation of the system (Pan et al., 2007). Appropriation occurs when the ERP system that has been implemented has become routine in the organization (Light \& Papazafeiropoulou, 2008). When an ERP system is implemented, the organization must acquire complex new knowledge (Robey et al., 2002). It must learn to overcome knowledge barriers related to ERP and the organizational changes associated with the implementation. To overcome the 
knowledge barriers regarding ERP, the organization needs to provide formal training on change management and process orientation as well as the software procedures. It learns to assimilate the new business processes embodied in the ERP package. It also learns to manage the consultant-client relationship in order to make use of the external knowledge of consultants in the process of assimilation of the new system (Wang et al., 2007; Xu \& Ma, 2008).

From the above discussion, it can be seen that organizational learning capability has an effect on the relationship between the scope of ERP implementation and intellectual capital. When an organization implements an ERP system, the organization is involved in learning, which comprises various knowledge processes such as acquisition, distribution, application, and storage (Pan et al., 2007; Pentland, 1995). Furthermore, learning facilitators, which determine learning capability, foster organizational learning (DiBella \& Nevis, 1998, p. 61), therefore they have an effect on outcomes of the ERP implementation. In this way, intellectual capital, which is the sum of knowledge of organization (Youndt et al., 2004) is probably enhanced by the scope of ERP implementation (as discussed previously), and this relationship may also be influenced by organizational learning capability.

The above argument can be supported by some illustrations of the effect of learning facilitators on the effectiveness of IS implementation. For example, a case study conducted by Ke and Wei (2006) found that top management's involvement and advocacy are crucial for the motivation of learning and have a positive influence on the outcomes of the enterprise system implementation. Additionally, Lin (2008) found that managerial commitment, systems perspective, knowledge dissemination, and knowledge acquisition are among the factors that affect the success of electronic business implementation.

Based upon the notion that organizations are learning systems, and that the organizational learning capability fosters organizational learning, this study argues that the sum of knowledge a firm acquires through the process by which an organization learns to implement and use an ERP system is likely to have a 
significant impact if organizations have an adequate level of organizational learning capability. Therefore it is hypothesized that:

H2a: The relationship between the breadth of ERP implementation and intellectual capital is moderated by organizational learning capability.

$\mathrm{H} 2 \mathrm{~b}$ : The relationship between the depth of ERP implementation and intellectual capital is moderated by organizational learning capability.

H2c: The relationship between the magnitude of ERP implementation and intellectual capital is moderated by organizational learning capability.

\subsection{Chapter summary}

This chapter has reviewed the relationship between the scope of ERP implementation and intellectual capital and the potential influence of organizational learning capability on that relationship. Six hypotheses were developed along with a research model. The next chapter will discuss the research methods employed to validate and examine this research model. 


\section{CHAPTER 4}

\section{RESEARCH METHODS}

This chapter aims to justify the research design applied for evaluating the structural model. It starts with the reason for choosing a quantitative methodology, then presents the components of the survey method including questionnaire design, sampling, and mode of data collection. The chapter also provides a discussion about reflective and formative measurement, and the concept of second-order constructs. Finally, data analysis techniques are explained.

\subsection{Justification of quantitative research design}

Researchers need to design plans and procedures for conducting their research. According to Creswell $(2009$, p. 4), the three types of research designs are qualitative, quantitative, and mixed methods. Each of the three types of design has three main components that differ in accordance with the nature of the research problem. The three components involved in research design are the philosophical worldview, strategies of inquiry, and research methods.

The selection of a research design is firstly determined by the philosophical worldviews that a researcher holds. A worldview or a paradigm is a framework or set of basic beliefs about the nature of reality (Guba \& Lincoln, 1994, p. 107). The four widely employed worldviews are post-positivism, constructivism, advocacy and participatory, and pragmatism (Creswell, 2009). Researchers who follow post positivism typically hold a deterministic philosophy in which causes probably determine effects or outcomes and hence typically employ quantitative research approaches. According to Creswell (2009, p. 7), post-positivist research possesses the following characteristics:

- There is a need to identify and assess the causes that influence outcomes.

- There is a reduction of the ideas into a small, discrete set of ideas to test, such as the variables that comprise hypotheses and research questions. 
- The development of knowledge is based on careful observation and measurement of the objective reality that exists "out there" in the world.

- There are laws or theories that govern the world and they need to be tested or verified and refined to understand the world.

The current research has typical characteristics of the post-positivist worldview. First, the study is to investigate the causes that influence outcomes. Specifically, it assesses the influence of ERP implementation on intellectual capital and simultaneously evaluates how this relationship is moderated by organizational learning capability. Second, the study utilizes a model that reduces the research ideas into variables to test the hypotheses in order to answer the research questions. Third, the study assumes that the variables can be objectively measured and are independent of the researcher. Lastly, the findings of the study are expected to reflect the laws that govern organizational activities that need to be tested or verified and refined to gain more understanding.

Holding the post-positivist worldview, the current study adopted a quantitative approach (Creswell, 2009, p.17). Because it was designed with the purpose of explaining the relationships among variables, this study used observational data to test hypotheses of a specific model. For these reasons, the appropriate strategy of inquiry was in the form of surveys rather than experiments (Pinsonneault \& Kraemer, 1993). In survey research, researchers "carefully record answers from many people who have been asked the same questions" (Neuman, 2011, p. 49). Survey research is probably considered the best method for a study in which the researcher wants to collect original data for understanding a population that is too large to observe directly (Babbie, 2010, p. 254).

Although experimental studies can be used in the quantitative approach, this strategy of enquiry is not appropriate for the current study. In experimental studies, researchers have the intention of taking action and observing the outcomes of that action (Babbie, 2010, p.231). Creswell (2009, p. 146) also notes that researchers conduct experimental studies when they want to examine the impact of a treatment on 
an outcome while controlling all other factors that might have an influence on that outcome. In the current study, there are no controlled variables.

\subsection{Measurement model characteristics}

\subsubsection{Reflective and formative constructs}

In social science, concepts or latent constructs are phenomena of theoretical interest that researchers cannot observe directly and have to assess through manifest measures/indicators which are observable (Edwards \& Bagozzi, 2000). A measurement model features the relationships between latent constructs and their measures. The direction of relationship between a latent construct and its measures can either be from construct to the measures (reflective construct) or from the measures to the construct (formative construct). Reflective and formative measurements are known as the principal factor model and the composite latent variable model, respectively (Jarvis, MacKenzie, \& Podsakoff, 2003). In reflective specifications, constructs are supposed to cause their measures rather than being caused by them. As a result, measures of reflective constructs are strongly correlated and interchangeable (Jarvis et al., 2003). In contrast, the formative measurement model views a construct as being caused by its measures. Each measure represents a specific aspect of the construct's domain; therefore the measures are not interchangeable and are not required to have specific patterns of inter-correlations (Diamantopoulos et al., 2008; Jarvis et al., 2003). Jarvis et al. (2003) propose criteria to guide researchers to determine whether a measurement model is formative or reflective (see Table 4.1).

Table 4.1 Criteria for distinguishing between formative and reflective models

\begin{tabular}{|l|l|l|}
\hline $\begin{array}{l}\text { 1. Direction of causality from } \\
\text { construct to measure implied by } \\
\text { the conceptual definition }\end{array}$ & $\begin{array}{l}\text { Formative model } \\
\text { firection of causality is } \\
\text { from items to construct }\end{array}$ & $\begin{array}{l}\text { Rirection of causality is } \\
\text { from construct to items }\end{array}$ \\
$\begin{array}{l}\text { Are the indicators (items) (a) } \\
\text { defining characteristics or } \\
\text { (b) manifestations of the } \\
\text { construct? }\end{array}$ & $\begin{array}{l}\text { Indicators are defining } \\
\text { characteristics of the } \\
\text { construct }\end{array}$ & $\begin{array}{c}\text { Indicators are } \\
\text { manifestations of the } \\
\text { construct }\end{array}$ \\
\end{tabular}




\begin{tabular}{|c|c|c|}
\hline & Formative model & Reflective model \\
\hline $\begin{array}{l}\text { Would changes in the } \\
\text { indicators/items cause } \\
\text { changes in the construct or } \\
\text { not? }\end{array}$ & $\begin{array}{l}\text { Changes in the } \\
\text { indicators should } \\
\text { cause changes in the } \\
\text { construct }\end{array}$ & $\begin{array}{l}\text { Changes in the } \\
\text { indicator should not } \\
\text { cause changes in the } \\
\text { construct }\end{array}$ \\
\hline $\begin{array}{l}\text { Would changes in the construct } \\
\text { cause changes in the } \\
\text { indicators? }\end{array}$ & $\begin{array}{l}\text { Changes in the construct } \\
\text { do not cause changes } \\
\text { in the indicators }\end{array}$ & $\begin{array}{l}\text { Changes in the } \\
\text { construct do cause } \\
\text { changes in the } \\
\text { indicators }\end{array}$ \\
\hline $\begin{array}{l}\text { 2. Interchangeability of the } \\
\text { indicators/items }\end{array}$ & $\begin{array}{l}\text { Indicators need not be } \\
\text { interchangeable }\end{array}$ & $\begin{array}{l}\text { Indicators should be } \\
\text { interchangeable }\end{array}$ \\
\hline $\begin{array}{l}\text { Should the indicators have the } \\
\text { same or similar content? Do } \\
\text { the indicators share a } \\
\text { common theme? }\end{array}$ & $\begin{array}{l}\text { Indicators need not have } \\
\text { the same or similar } \\
\text { content/ indicators } \\
\text { need not share a } \\
\text { common theme }\end{array}$ & $\begin{array}{l}\text { Indicators should have } \\
\text { the same or similar } \\
\text { content/ indicators } \\
\text { should share a } \\
\text { common theme }\end{array}$ \\
\hline $\begin{array}{l}\text { Would dropping one of the } \\
\text { indicators alter the } \\
\text { conceptual domain of the } \\
\text { construct? }\end{array}$ & $\begin{array}{l}\text { Dropping an indicator } \\
\text { may alter the } \\
\text { conceptual domain of } \\
\text { the construct }\end{array}$ & $\begin{array}{l}\text { Dropping an indicator } \\
\text { should not alter the } \\
\text { conceptual domain of } \\
\text { the construct }\end{array}$ \\
\hline $\begin{array}{l}\text { 3. Covariation among the } \\
\text { indicators }\end{array}$ & $\begin{array}{l}\text { Not necessary for } \\
\text { indicators to covary with } \\
\text { each other }\end{array}$ & $\begin{array}{l}\text { Indicators are expected } \\
\text { to covary with each } \\
\text { other }\end{array}$ \\
\hline $\begin{array}{l}\text { Should a change in one of the } \\
\text { indicators be associated with } \\
\text { changes in the other } \\
\text { indicators? }\end{array}$ & Not necessarily & Yes \\
\hline $\begin{array}{l}\text { 4. Nomological net of the } \\
\text { construct indicators }\end{array}$ & $\begin{array}{l}\text { Nomological net for the } \\
\text { indicators may differ }\end{array}$ & $\begin{array}{l}\text { Nomological net for the } \\
\text { indicators should not } \\
\text { differ }\end{array}$ \\
\hline $\begin{array}{l}\text { Are the indicators/items } \\
\text { expected to have the same } \\
\text { antecedents and } \\
\text { consequences? }\end{array}$ & $\begin{array}{l}\text { Indicators are not } \\
\text { required to have the } \\
\text { same antecedents and } \\
\text { consequences }\end{array}$ & $\begin{array}{l}\text { Indicators are required } \\
\text { to have the same } \\
\text { antecedents and } \\
\text { consequences }\end{array}$ \\
\hline
\end{tabular}

(Jarvis et al., 2003, p. 203)

\subsubsection{Appropriateness of higher order constructs}

The latent constructs can be unidimensional or multidimensional. A unidimensional construct refers to a single theoretical concept (Hattie, 1985), whereas a multidimensional construct is used when its definition is specified at a more abstract level which has multiple dimensions (Jarvis et al., 2003) and when "it is theoretically meaningful and parsimonious to use this overall abstraction as a representation of the 
dimensions" (Law, Wong, \& Mobley, 1998, p. 741). Multidimensional constructs are also considered as high order constructs (Diamantopoulos et al., 2008).

According to MacKenzie, Podsakoff, and Podsakoff (2011) researchers can examine the essential characteristics of a construct to determine the dimensionality of the construct. A construct is multidimensional if the important characteristics of the construct represent its unique aspects, and removing any of them would restrict its conceptual domain. Conversely, if the important characteristics do not describe unique aspects, and dropping any of them would not restrict the conceptual domain of the construct, the construct is unidimensional.

The use of constructs with sub-dimensions is widely employed in IS studies (Shin \& Kim, 2011) and other disciplines (Diamantopoulos et al., 2008). Researchers use higher order-constructs because they allow the representation of complicated phenomena and support researchers in investigating the relationship between broad predictors and broad outcomes (Edwards, 2001).

Because the relationship between a first-order construct and its measures can be reflective or formative, a second-order construct (which has other latent constructs as indicators) can be classified into four categories: reflective first- and second-order, reflective first-order and formative second-order, formative first-order and reflective second-order, and formative first- and second-order (Jarvis et al., 2003).

Taking the aforementioned characteristics of a multidimensional construct, the current study specified two constructs, intellectual capital (IC) and organizational learning capability (OLC), as reflective first- and formative second-order constructs. IC is a concept which has three facets: human capital, organizational capital, and social capital. Depending on the research purpose, prior studies have examined these dimensions either separately (e.g. Bontis, Keow, \& Richardson, 2000; Cabrita \& Bontis, 2008) or in a combined form (e.g. Hsu \& Sabherwal, 2012). In the current study, with the purpose of investigating the effect of the scope of ERP implementation on IC at a broad level of relationship, IC was specified as a secondorder construct. Although IC might be conceptualized as a reflective first- and 
reflective second-order construct (Hsu \& Sabherwal, 2012), this study argues that IC is a reflective first- and formative second-order construct because the sub-dimensions of IC have the characteristics of the formative measures: the three dimensions of the focal construct IC describe unique aspects of the construct, they are not interchangeable, and if one dimension is dropped the conceptual domain of IC may be altered.

Similarly, organizational learning capability in this study is a reflective-formative construct. The construct is multidimensional and characterized by four measures: managerial commitment, systems perspective, openness and experimentation, and knowledge transfer and integration (Jerez-Gómez et al., 2005; Liao \& Wu, 2010; López-Cabrales, Real, \& Valle, 2011). Prior studies have specified these four dimensions as either reflective (Jerez-Gomez et al., 2005; Liao \& Wu, 2010) or formative (López-Cabrales et al., 2011) to the focal construct. This study argues that these four properties of OLC are not interchangeable, each of the properties features a different aspect of the totality of all facilitators for organizational learning capability. Therefore, in the same manner as López-Cabrales et al. (2011), the study views these four properties as formative measures of the focal construct OLC.

\subsection{Instrumentation design}

This study investigates the effect of ERP implementation on intellectual capital under the influence of the learning capability of organizations. The dependent variable is intellectual capital, the independent variable is the degree of ERP implementation, and the moderating variable is organizational learning capability. It is a requirement to have measurement scales for the latent variables. With the purpose of examining new relationships among pre-existing concepts, the study made use of the versions of the measurement scales already established in prior research.

\subsubsection{Measures of intellectual capital}

The definitions of intellectual capital vary depending on the field or background that researchers are interested in (Marr \& Chatzkel, 2004). Intellectual capital may refer to 
either knowledge or some kind of intangible assets that might produce economic value for organizations (Kaufmann \& Schneider, 2004). The current study used the view of knowledge-related intellectual capital. In this view, there are two measures of intellectual capital: those developed by Bontis (1998) and Youndt et al. (2004). These measures have been widely used in many studies (e.g. Ahmed \& Omar, 2011; Asiaei \& Jusoh, 2015; Bontis et al., 2000; Cabrita \& Bontis, 2008; Daud \& Yusoff, 2011; Hsu \& Sabherwal, 2012; Huang \& Wu, 2010). Although the measures focus on the same concept, they are distinct. While Bontis (1998)'s measure includes many scale items that are mainly associated with outcome measurement, that of Youndt et al. (2004) mainly reflects the state of intellectual capital (Isaac, Herremans, \& Kline, 2010). Because the current study considers intellectual capital as the sum of an organization's knowledge (Youndt et al., 2004), it adapted the scale items of these authors to measure the state of this capital. The items are presented in Table 4.2.

Table 4.2 Item measures of intellectual capital

\begin{tabular}{|l|l|l|}
\hline Dimension & Item code & Item wording \\
\hline Human capital & HC1 & Our employees are highly skilled \\
\cline { 2 - 3 } & HC2 & $\begin{array}{l}\text { Our employees are widely considered the best in our } \\
\text { industry }\end{array}$ \\
\cline { 2 - 3 } & HC3 & Our employees are creative and bright \\
\cline { 2 - 3 } capital & HC4 & $\begin{array}{l}\text { Our employees are experts in their particular jobs } \\
\text { and functions }\end{array}$ \\
\cline { 2 - 3 } & HC5 & Our employees develop new ideas and knowledge \\
\cline { 2 - 3 } & OC2 & $\begin{array}{l}\text { Our organization uses patents and licenses as a way } \\
\text { to store knowledge }\end{array}$ \\
\cline { 2 - 3 } & OC3 & $\begin{array}{l}\text { Much of our organization's knowledge is contained } \\
\text { in manuals, databases, etc. }\end{array}$ \\
& $\begin{array}{l}\text { Our organization's culture (behaviours, stories, } \\
\text { rituals) contains valuable ideas and ways of doing } \\
\text { business, etc. }\end{array}$ \\
\cline { 2 - 3 } & OC4 & $\begin{array}{l}\text { Our organization embeds much of its knowledge } \\
\text { and information in structure, systems, and processes }\end{array}$ \\
\hline Social capital & SC1 & $\begin{array}{l}\text { Our employees are skilled at collaborating with each } \\
\text { other to diagnose and solve problems }\end{array}$ \\
\cline { 2 - 3 } & &
\end{tabular}




\begin{tabular}{|l|l|l|}
\hline Dimension & Item code & Item wording \\
\hline \multirow{7}{*}{} & SC2 & $\begin{array}{l}\text { Our employees share information and learn from } \\
\text { one another }\end{array}$ \\
\cline { 2 - 3 } & SC3 & $\begin{array}{l}\text { Our employees interact and exchange ideas with } \\
\text { people from different areas of the company }\end{array}$ \\
\cline { 2 - 3 } & SC4 & $\begin{array}{l}\text { Our employees partner with customers, suppliers, } \\
\text { alliance partners, etc., to develop solutions }\end{array}$ \\
\cline { 2 - 3 } & SC5 & $\begin{array}{l}\text { Our employees apply knowledge from one area of } \\
\text { the company to problems and opportunities that } \\
\text { arise in another }\end{array}$ \\
\hline
\end{tabular}

(Youndt et al., 2004, p. 358)

As previously explained, intellectual capital is a focal construct that consists of three sub-constructs: human capital, organizational capital, and social capital. The current study specified these sub-constructs as formative dimensions of the focal construct. The sub-constructs of intellectual capital are measured on reflective perception-based items using seven-point Likert scales anchored by 1 (strongly disagree) and 7 (strongly agree). There are fourteen items used to measure intellectual capital.

\subsubsection{Measures of organizational learning capability}

For the measure of organizational learning capability, this study applied the measures established by Jerez-Gómez et al. (2005). The authors said that organizational learning capability is a focal construct that consists of four dimensions demonstrating the attributes of a learning organization, which they called managerial commitment, systems perspective, openness and experimentation, and knowledge transfer and integration. Although the authors conceptualized these dimensions as reflective indicators of the focal construct, this study considered the four dimensions as formative variables. The sub-dimensions of organizational learning capability are measured with reflective perception-based items using seven-point Likert scales from 1 (strongly disagree) to 7 (strongly agree). As illustrated in Table 4.3, sixteen items are used to measure organizational learning capability. 
Table 4.3 Item measures of organizational learning capability

\begin{tabular}{|c|c|c|}
\hline Dimension & Item code & Item wording \\
\hline \multirow[t]{5}{*}{$\begin{array}{l}\text { Managerial } \\
\text { commitment }\end{array}$} & MC1 & $\begin{array}{l}\text { The managers frequently involve their staff in } \\
\text { important decision making processes }\end{array}$ \\
\hline & $\mathrm{MC} 2$ & $\begin{array}{l}\text { Employee learning is considered more of an } \\
\text { expense than an investment }\end{array}$ \\
\hline & MC3 & $\begin{array}{l}\text { The firm's management looks favourably on } \\
\text { carrying out changes in any area to adapt to and/or } \\
\text { keep ahead of new environmental situations }\end{array}$ \\
\hline & MC4 & $\begin{array}{l}\text { Employee learning capability is considered a key } \\
\text { factor in this firm }\end{array}$ \\
\hline & MC5 & $\begin{array}{l}\text { In this firm, innovative ideas that work are } \\
\text { rewarded }\end{array}$ \\
\hline \multirow[t]{3}{*}{$\begin{array}{l}\text { Systems } \\
\text { perspective }\end{array}$} & SP1 & $\begin{array}{l}\text { All employees have generalized knowledge } \\
\text { regarding this firm's objectives }\end{array}$ \\
\hline & SP2 & $\begin{array}{l}\text { All parts that make up this firm (departments, } \\
\text { sections, work teams, and individuals) are well } \\
\text { aware of how they contribute to achieving the } \\
\text { overall objectives }\end{array}$ \\
\hline & SP3 & $\begin{array}{l}\text { All parts that make up this firm are interconnected, } \\
\text { working together in a coordinated fashion }\end{array}$ \\
\hline \multirow[t]{4}{*}{$\begin{array}{l}\text { Openness and } \\
\text { experimentation }\end{array}$} & OP1 & $\begin{array}{l}\text { This firm promotes experimentation and innovation } \\
\text { as a way of improving the work processes }\end{array}$ \\
\hline & OP2 & $\begin{array}{l}\text { This firm follows what other firms in the sector are } \\
\text { doing, adopting those practices and techniques it } \\
\text { believes to be useful and interesting }\end{array}$ \\
\hline & OP3 & $\begin{array}{l}\text { Experiences and ideas provided by external sources } \\
\text { (advisors, customers, training firms, etc.) are } \\
\text { considered a useful instrument for this firm's } \\
\text { learning }\end{array}$ \\
\hline & OP4 & $\begin{array}{l}\text { Part of this firm's culture is that employees can } \\
\text { express their opinions and make suggestions } \\
\text { regarding the procedures and methods in place for } \\
\text { carrying out tasks }\end{array}$ \\
\hline $\begin{array}{l}\text { Knowledge } \\
\text { transfer and }\end{array}$ & KW1 & $\begin{array}{l}\text { Errors and failures are always discussed and } \\
\text { analyzed in this firm, on all levels }\end{array}$ \\
\hline
\end{tabular}


Chapter 4: Research Methods

\begin{tabular}{|l|l|l|}
\hline Dimension & Item code & Item wording \\
\hline integration & KW2 & $\begin{array}{l}\text { Employees have the chance to talk among } \\
\text { themselves about new ideas, programs, and } \\
\text { activities that might be of use to the firm }\end{array}$ \\
\cline { 2 - 3 } & KW3 & In this firm, teamwork is not the usual way to work \\
\cline { 2 - 3 } & KW4 & $\begin{array}{l}\text { The firm has instruments that allow what has been } \\
\text { learnt in past situations to remain valid, although } \\
\text { the employees are no longer the same }\end{array}$ \\
\hline
\end{tabular}

(Jerez-Gomez et al., 2005, p. 724)

\subsubsection{Measures of ERP implementation scope}

With the purpose of estimating the influence of ERP implementation on intellectual capital, this study employed the measure of Barki et al. (2005) to gauge the extent of scope of ERP implementation. The scope of ERP implementation has been conceptualized to include three dimensions: breadth, depth, and magnitude. There are seven items to measure the scope of ERP implementation. The detailed scales are featured in Table 4.4.

Table 4.4 Item measures of ERP implementation scope

\begin{tabular}{|c|c|c|c|}
\hline Dimension & Item code & Item wording & Scale \\
\hline \multirow[t]{2}{*}{ Breadth } & BRE1 & ERP breadth & $\begin{array}{l}1=\text { single site } \\
2=\text { multiple sites in one region } \\
3=\text { multiple sites in multiple } \\
\text { regions } \\
4=\text { multiple regions, international }\end{array}$ \\
\hline & BRE2 & $\begin{array}{l}\text { Business process } \\
\text { reengineering } \\
(\mathrm{BPR}) \text { breadth }\end{array}$ & $\begin{array}{l}1=\text { small number of people within } \\
\text { a department } \\
2=\text { a department } \\
3=\text { more than one department } \\
4=\text { a region } \\
5=\text { more than one region }\end{array}$ \\
\hline Depth & DEP1 & ERP depth & $\begin{array}{l}\text { Number of users of the ERP } \\
\text { software }\end{array}$ \\
\hline
\end{tabular}




\begin{tabular}{|l|l|l|l|}
\hline Dimension & Item code & Item wording & Scale \\
\hline & DEP2 & $\begin{array}{l}\text { Business process } \\
\text { reengineering } \\
\text { (BPR) depth }\end{array}$ & $\begin{array}{l}\text { Number of employees whose } \\
\text { activities changed }\end{array}$ \\
\hline Magnitude & MAG1 & $\begin{array}{l}\text { Business process } \\
\text { automation (BPA) }\end{array}$ & $\begin{array}{l}\text { (\% of processes that are automated } \\
\text { after ERP) }-(\% \text { of processes that } \\
\text { were automated before ERP) }\end{array}$ \\
\cline { 2 - 4 } & MAG2 & $\begin{array}{l}\text { Business process } \\
\text { reengineering } \\
\text { (BPR) magnitude }\end{array}$ & $\begin{array}{l}\text { (\% of activities in reengineered } \\
\text { processes that were modified) } \\
\text { (extent of modification of } \\
\text { activities 1-10) }\end{array}$ \\
\cline { 2 - 5 } & MAG3 & ERP customization & $\begin{array}{l}\text { Extent of modification done to } \\
\text { ERP to customize the software } \\
\text { (from 1-10) }\end{array}$ \\
& & &
\end{tabular}

(Barki et al., 2005, p. 3)

\subsubsection{Questionnaire construction}

The current study employed a measurement scale established in prior studies and developed a questionnaire that was consolidated into two parts: part A for the scope of ERP implementation and part B for organizational learning capability and intellectual capital.

a) Part $\mathrm{A}$ of the questionnaire.

This part was related to the scope of ERP implementation of the organization and general information about the respondent and the firm. The target respondents for this part of the questionnaire are managerial people who are responsible for the IT or IS activities of the firm. Beside the questions that reflect the measures of ERP implementation scope, other questions were added to obtain other necessary information. First, empirical studies have shown that firms can only experience the impacts of an ERP system after at least nine months when the phase of system stabilization starts (Deloitte, 1998). Therefore, the questionnaire included information 
about the time-frame during which the firm had started to implement and to use the ERP system to ensure the firm had enough duration of ERP system use to make a useful contribution to the data. Second, general information about the ERP package, respondent, and the firm was also added: job title, how long they has held that position, a self-evaluation of the respondent's ERP implementation knowledge; ERP package name, any ERP modules that have been used or not, ownership, operating industry, and number of employees in the firm.

b) Part B of the questionnaire

Part B was related to the assessment of learning capability and intellectual capital of the firm. The respondents for this part are managerial people working in departments not directly involved with IT or IS activities; they are knowledgeable about their firm and the impact of ERP implementation on their firm. The respondents were asked to indicate a degree of agreement or disagreement with a variety of statements relating to their organization's intellectual capital and learning capability. This part also asked the respondents general information including their job position, job area, how long they had held that position, and self-evaluation of their knowledge about what they answered.

As indicated previously, learning capability and intellectual capital are specified as higher-order reflective-formative constructs. To be able to assess the convergent validity of the constructs, one global item measuring the essence of each of these two constructs was included in the questionnaire (Hair, Hult, Ringle, \& Sarstedt, 2014, p. 122).

\subsubsection{Back-translation and pre-test}

Because most previous measures for this type of research have been written in the English language, a major concern is the ability to transfer the content of English language measurements to other cultures and languages. The data for this study were collected in the author's home country, thus the measures were translated into Vietnamese. In order to ensure the accuracy and minimize interpretation as much as 
possible, this study followed Brislin (1980)'s guidelines on the back-translation method. Firstly, the English questionnaire was translated into Vietnamese by three independent researchers: the author of this study; a researcher who is a Vietnamese $\mathrm{PhD}$ student at the School of International Business \& Marketing, Victoria University of Wellington (New Zealand); and an academic in the School of Industrial Management, Ho Chi Minh City University of Technology (Vietnam) who has a MBA degree from an English-speaking institution. The final Vietnamese version of the questionnaire was agreed upon through a discussion between the three researchers. The Vietnamese version of the questionnaire then was translated back to English by two Vietnamese lecturers with PhDs who majored in English. Throughout this process, the inconsistencies or ambiguities in translation and re-translation were discussed and resolved among the translators and it is believed that the Vietnamese version of the questionnaire is equivalent to the English version.

A pre-test was conducted to investigate all aspects of the questionnaire: question content, wording, clarity, sequence, format and time spent on filling in the questionnaire. The questionnaire pre-test was administered to seven respondents: five MBA students at the School of Industrial Management (Ho Chi Minh City University of Technology, Vietnam) who were also in employment, and two ERP implementation consultants from an ERP provider in Ho Chi Minh City, Vietnam. The respondents were asked to answer the questions and were free to make comments. The results of the pre-test were incorporated in the final questionnaire. A number of modifications of wording and the sequence of questions were made. In terms of the question content, there were two significant suggestions from the two ERP implementation consultants. The first was related to the measure of the breadth of ERP implementation. According to the consultants, the geographical scope of an ERP project can be multiple sites but only in several regions (such as cities or provinces); however, other ERP projects can be deployed at multiple sites in multiple regions nationwide or across nation. Therefore, one more scale was added to the measure of the breadth of ERP implementation, taking the total for ERP breadth item scales to five (see Table 4.5). 
Table 4.5 Modifications of ERP implementation scope measurement

\begin{tabular}{|c|c|c|c|}
\hline & Item code & Item wording & Scale \\
\hline Breadth & BRE1 & ERP breadth & $\begin{array}{l}1=\text { single site } \\
2=\text { multiple sites in one region } \\
3=\text { multiple sites in several regions } \\
4=\text { multiple sites in multiple } \\
\quad \text { regions across nation } \\
5=\text { multiple regions, international }\end{array}$ \\
\hline Depth & DEP1 & ERP depth & $\begin{array}{l}\text { Ratio of number of users of the } \\
\text { ERP software to number of } \\
\text { employees }\end{array}$ \\
\hline & DEP2 & $\begin{array}{l}\text { Business process } \\
\text { reengineering } \\
(\mathrm{BPR}) \text { depth }\end{array}$ & $\begin{array}{l}\text { Ratio of number of employees } \\
\text { whose activities changed to } \\
\text { number of employees }\end{array}$ \\
\hline
\end{tabular}

The second suggestion from the two consultants was related to the depth of ERP implementation. They believed that the number of users of an ERP package could be a factor that determines the cost of the ERP project as it affects the number of licensing accounts, however for the comparison of the depth of implementation among ERP projects the ratio of number of users to number of employees should be used. The same suggestion applied to the depth of business process reengineering. As a result, two modified scales measuring the depth of ERP implementation were used (see Table 4.5) for the data analysis. They are the ratio of the original scale to the number of employees of the organization. In the questionnaire, the original questions regarding the scales did not need to be modified. Because information on the number of employees was also requested, the modified scales were calculated based on available information.

The final English and Vietnamese versions of the survey questionnaire are presented in Appendix A and Appendix B respectively. 


\subsection{Survey}

\subsubsection{Sample size and informants}

Prior to data collection, it is important to determine the minimum sample size required to provide a sufficient level of statistical power for the research model. As stated by Barlett, Kotrlik, and Higgins (2001), the number of observations for one independent variable or question should be from five to ten. Additionally, a critical sample size of 200 was proposed by Hoelter (1983, p. 331). The research model in this study contains ten constructs that have a total of thirty-seven observable items. Thus, the sample size for this study should be from 200 to 370 . In reality, due to a limited size of the sampling frame, the total number of collected responses was 226. This sample size is considered as adequate, being within the recommended range.

In order to acquire valid information for the study, the informants need to be appropriately identified. For this study, the information is related to three aspects: ERP implementation, intellectual capital, and organizational learning capability of organizations. This study used two sources of information. The information on ERP implementation (part A of the questionnaire) is mainly factual and was provided by the personnel who are responsible for IT/IS activities in the organizations. For the information on the remaining aspects (part B of the questionnaire), the appropriate respondents were managerial people working in non-IT/IS departments. They are knowledgeable about the organization and the impact of the implementation of ERP. Accordingly, for each organization, there were two key informants: one for part A and one for part B of the questionnaire.

Although researchers have argued that using the key informant or single respondent method to collect data may lead to response bias or selection bias and make data unreliable (Bowman \& Ambrosini, 1997; Ramanujam, Venkatraman, \& Camillus, 1986), a multiple informant method is not always feasible. The key informant method and multiple informant method each have their own advantages and disadvantages as shown in Table 4.6. For example, while the multiple informant method may be used to help researchers record the actual picture of the event in an organization and avoid 
systematic bias and random error effects, the method may be associated with a number of problems such as the dissimilarity in responses, aggregation of multiple responses, selection of appropriate respondents, and the cost and time to collect data from multiple respondents (Wagner, Rau, \& Lindemann, 2010). In contrast, although the key informant method can overcome the disadvantages of the multiple informant method, it has the drawbacks of informant bias and random error that may distort the true value of organizational constructs (Kumar, Stern, \& Anderson, 1993). Therefore, due to the fact that the multiple respondent method has a number of practical constraints, key informants were used to collect data for both parts of the questionnaire in this study. Two key informants from each organization in the sample were required to answer the questionnaire.

Table 4.6 Key informants and multiple informants

\begin{tabular}{|c|c|c|}
\hline & Advantages & Disadvantages \\
\hline $\begin{array}{l}\text { Key } \\
\text { informants }\end{array}$ & $\begin{array}{l}\text { - Response rate is higher than } \\
\text { multiple respondent method's } \\
\text { - Easy to ensure anonymity of } \\
\text { the respondent, thus avoiding } \\
\text { creating potential bias } \\
\text { - Avoid the disadvantages of } \\
\text { multiple informant } \\
\text { methodology }\end{array}$ & $\begin{array}{l}\text { - Informant bias (different role or } \\
\text { position holds different viewpoint } \\
\text { on an event, idiosyncratic sources } \\
\text { of error) } \\
\text { - Random error (hindsight bias, } \\
\text { attributional bias, subconscious } \\
\text { attempts to maintain self-esteem, } \\
\text { or impression management) }\end{array}$ \\
\hline $\begin{array}{l}\text { Multiple } \\
\text { informants }\end{array}$ & $\begin{array}{l}\text { - Provide actual picture of the } \\
\text { event in the organization } \\
\text { - Reduce the systematic bias } \\
\text { and random error effects } \\
\text { - Multiple informant } \\
\text { methodology is often a } \\
\text { recommendation in the } \\
\text { limitation section of the } \\
\text { studies using key informant } \\
\text { methodology }\end{array}$ & $\begin{array}{l}\text { - More cost and time to collect data } \\
\text { from multiple people. Cost and } \\
\text { time can be saved to collect data } \\
\text { on more organizations (larger } \\
\text { sample size) } \\
\text { - Redundant data may exist } \\
\text { - Respondents feel that they are not } \\
\text { key informants } \\
\text { - Problem of selecting appropriate } \\
\text { respondents } \\
\text { - Issues of dealing with perceptual } \\
\text { disagreement (dissimilarity in } \\
\text { responses) } \\
\text { - Issues of aggregation of multiple } \\
\text { responses }\end{array}$ \\
\hline
\end{tabular}

(Kumar et al., 1993; Wagner et al., 2010) 


\subsubsection{Population and sampling frame}

The population is represented by "a large group of many cases from which a researcher draws a sample and to which results from a sample are generalized" (Neuman, 2011, p. 241). Because a population is too large to observe directly, an option for researchers is to select a sample of cases to examine in detail and the results from the sample can be generalized if the sample correctly represents the population. The objective of the current study is to examine the influence of ERP implementation scope on the intellectual capital of organizations; thus the target population in this study ideally covers all companies that have implemented and used ERP in Vietnam. However, due to limitations of time and financial resources the target population is defined as the manufacturing companies located in Ho Chi Minh City and Dong Nai province that have implemented ERP. There are two reasons for the selection.

First, because ERP packages may have various characteristics for specific industries, covering various industries in the study may lead to the problem of confounding effects. Moreover, as compared with other industries, the manufacturing sector has a greater number of companies implementing ERP. Second, according to the report on the e-business index published by the Vietnam E-Commerce Association (VECOM) in 2013, the five areas of Vietnam that have the highest e-business index are Ho Chi Minh City, Hanoi, Da Nang, Hai Phong, and Dong Nai (VECOM, 2013, p. 13). The index is used to measure the degree to which companies apply e-commerce and it covers four aspects: human resources and infrastructure for ICT, transactions between businesses and consumers (B2C), transactions between businesses (B2B), and online public services (G2B). The application of management software package such as ERP, CRM, and SCM is classified into the B2B aspect. It follows that the regions with a high e-business index are likely to have more companies using ERP systems. Ho Chi Minh City and Dong Nai are both in the southern part of Vietnam. Ho Chi Minh City is the biggest economic centre in Vietnam where business activities are concentrated, hence the majority of ERP providers are located here. Dong Nai province is one of the key southern economic regions of Vietnam, and is adjacent to Ho Chi Minh City. 
After determining the geographical regions for the target survey companies, a major issue for the study was the establishment of a list of companies that have implemented ERP. In Vietnam, there was no such data source from prior surveys available for this study. Therefore, in this study, the list of companies that have implemented ERP was built from two sources: business customers of ERP providers, and companies identified from the Vietnam business directory. The author of the study recruited twelve assistants to support the survey work. They are senior undergraduate students of a university in Ho Chi Minh City. The group first, identified a list of key ERP software companies from the Vietnam Information and Communication Technologies Directory. Then a list of the business customers that have implemented ERP systems from these software companies was identified based on the websites of these companies and announcements in online newspapers. In this step, 28 ERP software companies (see Appendix C) were identified and 341 typical manufacturing business customers of these companies were found.

In the next step, the survey group examined the Business Directory issued in 2013 by the Vietnamese Chamber of Commerce and Industry (VCCI). A total of 18,856 companies located in Ho Chi Minh City and Dong Nai province were found in the directory, of which 4,357 were reported to be manufacturing companies with complete contact information. From this list, after removing 341 companies that were identified in the previous step, 2000 companies were randomly chosen. The survey group contacted these companies by phone and email to check quickly whether they had implemented and used an ERP package or similar business system for at least one year. After this step, 286 companies were identified. In total, a list of 627 companies was established and was taken as the sampling frame for the study.

\subsubsection{Data collection}

For the survey approach, there are four methods of data collection: mail questionnaire, telephone interview, face-to-face interview, and web survey (Neuman, 2011, p. 338). Researchers choose the method of data collection by considering many factors such as the characteristics of the sample, available people and facilities, and 
Chapter 4: Research Methods

survey costs (Fowler, 2002, p. 58). Neuman (2011) indicates the features of survey methods in Table 4.7.

Table 4.7 Types of surveys and their features

\begin{tabular}{|c|c|c|c|c|}
\hline Features & $\begin{array}{l}\text { Mail } \\
\text { questionnaire }\end{array}$ & $\begin{array}{l}\text { Telephone } \\
\text { interview }\end{array}$ & $\begin{array}{l}\text { Face-to-face } \\
\text { interview }\end{array}$ & $\begin{array}{l}\text { Web-page } \\
\text { survey }\end{array}$ \\
\hline \multicolumn{5}{|l|}{ Administrative issues } \\
\hline Cost & Cheap & Moderate & Expensive & Cheapest \\
\hline Speed & Slowest & Fast & $\begin{array}{l}\text { Slow to } \\
\text { moderate }\end{array}$ & Fastest \\
\hline $\begin{array}{l}\text { Length (number of } \\
\text { questions) }\end{array}$ & Moderate & Short & Longest & Moderate \\
\hline Response rate & Lowest & Moderate & Highest & Moderate \\
\hline \multicolumn{5}{|l|}{ Research control } \\
\hline Probes possible & No & Yes & Yes & No \\
\hline Specific respondent & No & Yes & Yes & No \\
\hline Question sequence & No & Yes & Yes & Yes \\
\hline Only one respondent & No & Yes & Yes & No \\
\hline Visual observation & No & No & Yes & Yes \\
\hline \multicolumn{5}{|c|}{ Success with different questions } \\
\hline Visual aids & Limited & None & Yes & Yes \\
\hline Open-ended questions & Limited & Limited & Yes & Yes \\
\hline Contingency questions & Limited & Yes & Yes & Yes \\
\hline Complex questions & Limited & Limited & Yes & Yes \\
\hline Sensitive questions & Some & Limited & Limited & Yes \\
\hline \multicolumn{5}{|l|}{ Sources of bias } \\
\hline Social desirability & No & Some & Worse & No \\
\hline Interviewer bias & No & Some & Worse & No \\
\hline $\begin{array}{l}\text { Respondent's reading } \\
\text { skill level }\end{array}$ & Yes & No & No & Some \\
\hline
\end{tabular}

(Neuman, 2011, p. 338)

The mail questionnaire and web-based survey methods were considered for this study due to limitations of time and financial resources. A web-based survey has a number of advantages over mail questionnaire such as speed of data collection, cost saving, and entered data ready for processing. However, in this study the mail questionnaire method was used for two main reasons. First, the study needs information provided by two informants for each organization in the sample, therefore the two parts of the 
questionnaire could be matched if using a mail questionnaire. Second, the email addresses of potential respondents could not be determined in advance for sending the link to a web-based questionnaire. Additionally, the mail questionnaire method has the ability to reach the widely dispersed sampling frame in Ho Chi Minh City and Dong Nai province. In this method, the respondents have complete control over their anonymity as they are not required to provide their personal details on mailed questionnaires.

To overcome the major drawbacks of the mail questionnaire method, which are its low response rate and its slow return speed, the questionnaire was designed to have an acceptable length and clear contents, and the survey group conducted the data collection carefully. Mail packages were sent to the IT departments of the companies in the sampling frame. Each mail package included an invitation letter; the questionnaire with two parts and attached information sheet (see Appendix A \& B), a pre-paid self-addressed envelope for return of the completed questionnaire, and an introduction letter from the Business Research \& Training Centre (Ho Chi Minh City University of Technology) emphasizing the importance of the project and its significant contribution to the ERP implementation knowledge of companies. In the invitation letter, the company was required to assign two informants to answer the two parts of the questionnaire. Part A was designed to be answered by a manager who is responsible for the IT or IS activities of the company. Then the questionnaire with the remaining part $\mathrm{B}$ was to be moved to another manager working in a non IT/IS department, who has knowledge about the company and the impact of the implementation of ERP on the company.

As an incentive for participants, they could choose to receive a summary of the survey results in return for their completion of the questionnaire. Additionally, the information sheet emphasized the protection of respondents' privacy, confidentiality, and the proposed use of the survey results.

Moreover, to ensure a high response rate within the planned time frame for collecting data, follow-up reminders were given via telephone and mail. Two weeks after the first mailing, a phone call was made to confirm the receipt of the questionnaire and 
remind the IT department to do the survey. Six weeks after the first mailing, a replacement questionnaire package was sent saying that the initial questionnaire had not been received and to emphasize the important contribution of each completed and returned questionnaire to the overall survey results. The letter also asked the respondents to ignore it if they had already completed and returned the questionnaire from the previous mailing. Two weeks after the second mailing, a polite phone call was made to remind the respondents to complete and return the questionnaire.

The mail survey was conducted in Ho Chi Minh City and Dong Nai province between April and early June 2014. The assistants who were recruited to establish the sampling frame were also engaged to support the survey under the supervision of the author. The first mailing of 627 questionnaires led to 114 returned responses, 81 questionnaires were received after the first reminder and 47 after the second. Consequently 242 responses were received making a response rate of $38.6 \%$. After performing necessary data checking, 226 usable questionnaires were retained for data analysis. Sixteen questionnaires were excluded because they had a significant number of incomplete items and/or less than one year of ERP use. Fifteen questionnaires with missing values in the descriptive part were kept because the omissions had no effect on the regression analysis results.

\subsection{Data analysis techniques}

After data collection was completed, the returned questionnaires were checked for data entry accuracy and missing values. Next, the software package SPSS version 22 was used to analyze the data set for descriptive and summary statistics, missing data assessment, non-response bias, common method bias, and data normality. Finally, SmartPLS software version 2.0 (Ringle, Wende, \& Will, 2005) was used to determine if relationships exist between the variables in the research model and whether the relationships are statistically significant.

The following subsections first present more details on the approaches used for structural equation analysis and the reason for choosing the partial least square 
technique, then the steps for evaluating the measurement models and the structural model with moderating effect are explained.

\subsubsection{Covariance-based SEM and Partial Least Squares (PLS)}

Structural equation modelling (SEM) has become a popular and powerful multivariate technique in social sciences (Hair, Ringle, \& Sarstedt, 2013). SEM allows researchers to estimate a series of dependence relationships at the same time. There are two different statistical approaches to estimate structural equation models: covariance-based SEM and variance-based partial least squares (PLS) modelling (Haenlein \& Kaplan, 2004).

In the covariance-based SEM approach, an estimation function is used to minimize the difference between the sample covariance matrix and the hypothesized covariance matrix of the theoretical model (Chin \& Newsted, 1999; Hair, Ringle, \& Sarstedt, 2012). In contrast, the PLS approach focuses on target dependent variables in the model and attempts to maximize the variance of the dependent variables explained by the independent variables (Haenlein \& Kaplan, 2004).

Although the covariance-based approach is broadly used for the assessment of SEM, PLS is also an appropriate technique for SEM-based analysis under certain circumstances (Chin \& Newsted, 1999). According to Gefen, Straub, and Boudreau (2000), the choice of the suitable SEM approach depends on the research objectives, the underlying statistical assumptions, and the nature of the fit statistics (e.g. the fit between the observed and the hypothesized covariance matrix or the fit between the approximated values of the dependent variables and the value predicted by the model in question). Chin and Newsted (1999, p. 337) mentioned that the PLS approach is suitable when the following situations are encountered:

- The objective of analysis emphasizes prediction rather than obtaining optimal parameter accuracy.

- The phenomenon in question is relatively new or changing and the theoretical model or measures are not well formed.

- The model is relatively complex with large numbers of indicators. 
- There is an epistemic need to model the relationship between latent variables and indicators in different modes (i.e., formative and reflective measures).

- The data conditions relating to normal distributions, independence, and/or sample size are not met.

Based on the properties of the data and the research model, the current study views the PLS approach (variance-based structural equation modelling) as the most suitable method for two main reasons. First, the data set of the study had a number of items that were found to lack normality. Second, the structural model is relatively complex with the presence of higher-order and formative constructs and moderating effects.

\subsubsection{Structural equation model assessment}

The analysis of a structural equation model is done through two major steps: analysis of the measurement model, and analysis of the structural model (Urbach \& Ahlemann, 2010). In the measurement model analysis, the relationships between the empirically observable variables and latent variables are assessed. In the structural model analysis, the hypothesized theoretical relationships between the latent variables are examined.

a) Assessment of measurement models

The current study has ten first-order reflective constructs, of which seven constructs are specified into two second-order constructs (reflective-formative category). To evaluate reflective measurement models, Hair et al. (2014, p. 97) and Henseler, Ringle, and Sinkovics (2009, p. 300) suggest four criteria as shown in Table 4.8. The details of these evaluation criteria are discussed along with the relevant results in the data analysis section.

Table 4.8 Evaluation of reflective measurement models using PLS

\begin{tabular}{|c|l|l|}
\hline \multicolumn{1}{|c|}{ Criterion } & \multicolumn{1}{|c|}{ Description } & \multicolumn{1}{c|}{ Literature } \\
\hline Composite reliability (CR) & $\begin{array}{l}\text { CR is a measure of internal } \\
\text { consistency and must not } \\
\text { be lower than 0.8 }\end{array}$ & $\begin{array}{l}\text { Nunnally and Bernstein } \\
(1994)\end{array}$ \\
\hline
\end{tabular}




\begin{tabular}{|c|c|c|}
\hline Criterion & Description & Literature \\
\hline Indicator reliability & $\begin{array}{l}\text { Measures how much of the } \\
\text { indicator's variance is } \\
\text { explained by the } \\
\text { corresponding latent } \\
\text { construct. Values should } \\
\text { be higher than } 0.7\end{array}$ & Chin (1998) \\
\hline Convergent validity & $\begin{array}{l}\text { Measures the amount of } \\
\text { variance that an LV } \\
\text { component captures from } \\
\text { its indicators relative to the } \\
\text { amount due to } \\
\text { measurement error. The } \\
\text { average variance extracted } \\
\text { (AVE) should be higher } \\
\text { than } 0.5\end{array}$ & $\begin{array}{l}\text { Fornell and Larcker } \\
\text { (1981) }\end{array}$ \\
\hline $\begin{array}{l}\text { Discriminant validity: } \\
\text { Fornell-Larcker criterion }\end{array}$ & $\begin{array}{l}\text { The AVE of each latent } \\
\text { variable should be higher } \\
\text { than the squared } \\
\text { correlations with all other } \\
\text { latent variables }\end{array}$ & $\begin{array}{l}\text { Fornell and Larcker } \\
\text { (1981) }\end{array}$ \\
\hline $\begin{array}{l}\text { Discriminant validity: } \\
\text { Cross-loadings }\end{array}$ & $\begin{array}{l}\text { If an indicator has a higher } \\
\text { correlation with its } \\
\text { corresponding construct } \\
\text { than with any other } \\
\text { construct, and each of the } \\
\text { constructs loads highest } \\
\text { with its own indicators, it } \\
\text { can be inferred that the } \\
\text { constructs differ } \\
\text { sufficiently from one } \\
\text { another }\end{array}$ & Chin (1998) \\
\hline
\end{tabular}


When using second-order reflective-formative constructs, because the formative constructs are expressed as a function of their dimensions (first-order constructs), the dimensions should not necessarily be highly correlated. Consequently, the measurements of validity and reliability associated with reflective measurement models have been shown to be inappropriate and illogical (Chin, 1998, p. 306). Hair et al. $(2014$, p. 97) propose a procedure to evaluate formative measurement models as shown in Table 4.9

Table 4.9 Evaluation of formative measurement models using PLS

\begin{tabular}{|l|l|l|}
\hline \multicolumn{1}{|c|}{ Criterion } & \multicolumn{1}{|c|}{ Description } & \multicolumn{1}{c|}{ Literature } \\
\hline Convergent validity & $\begin{array}{l}\text { The extent to which a } \\
\text { measure correlates } \\
\text { positively with other } \\
\text { measures of the same } \\
\text { construct. A redundancy } \\
\text { analysis is used and the } \\
\text { path coefficient should be } \\
\text { at least 0.8 }\end{array}$ & \\
\hline Collinearity among & $\begin{array}{l}\text { The extent to which two } \\
\text { indicators }\end{array}$ & $\begin{array}{l}\text { Hair et al. (2014) } \\
\text { indicators are correlated. } \\
\text { The variance inflation } \\
\text { factor (VIF) should be less } \\
\text { than 5 }\end{array}$ \\
\hline $\begin{array}{l}\text { Significance and relevance } \\
\text { of the formative indicators }\end{array}$ & $\begin{array}{l}\text { Path coefficients of } \\
\text { independent variables } \\
\text { (formative indicators) with } \\
\text { the dependent variable } \\
\text { (formative construct) are } \\
\text { significant }\end{array}$ & Hair et al. (2014) \\
\hline
\end{tabular}


Because these criteria are used to evaluate a formative measurement model specified in the form of a first-order construct, in the case of higher-order construct assessment, a repeated indicator approach and latent variable scores should be used (Hair et al., 2014, p. 233).

To evaluate convergent validity of a second-order reflective-formative construct, a redundancy analysis model is established (see Figure 4.1). In the model, all indicators of the first-order constructs (or components) are assigned to the corresponding second-order construct and a link between the second-order construct and a criterion item is established. The criterion item or global item is added to test whether the formatively measured construct is highly correlated with a reflective measure of the same construct. If the structural path coefficient is above 0.8 , the formative construct's convergent validity is supported (Chin, 1998; Hair et al., 2014).

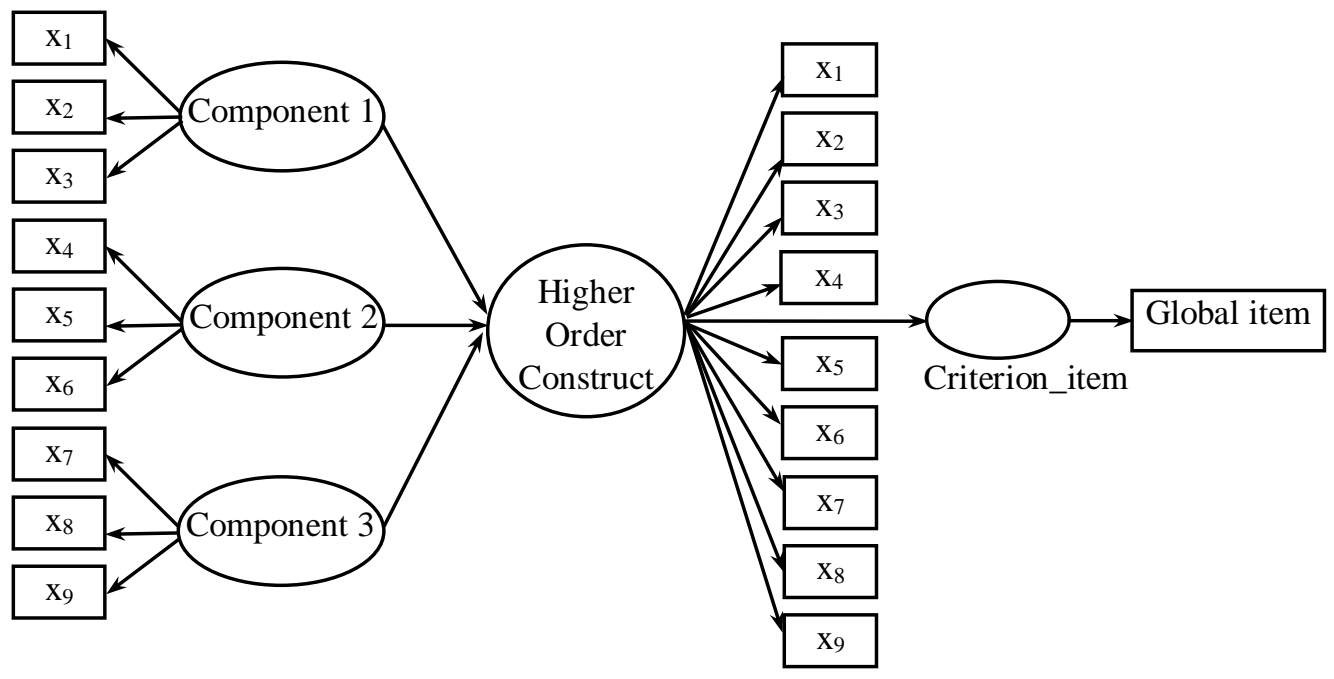

Figure 4.1 Redundancy analysis model

The second criterion for the assessment of a formative measurement model is multicollinearity. Formative dimensions of the focal construct should be relatively independent of one another (Chin, 1998) because a high collinearity among formative dimensions makes it difficult to ascertain the unique contribution from each dimension (Diamantopoulos \& Winklhofer, 2001). The multicollinearity of the formative dimensions are assessed using the variance inflation factor (VIF): the value of VIF should be lower than 5 to reach the conclusion that there is no potential collinearity problem (Hair, Ringle, \& Sarstedt, 2011). Because SmartPLS version 2.0 
does not support VIF calculation, the latent variable scores of formative dimensions are imported into SPSS software version 22 for the calculation. The latent variable scores are obtained by estimating the model in which all indicators of the first-order constructs are assigned to the corresponding second-order constructs.

The last rule for the evaluation of a formative measurement model is the significance of the paths linking the formative dimensions and the focal construct. The significance of path coefficients are assessed using the bootstrapping technique; the minimum number of bootstrap samples should be 5,000 and the number of cases for bootstrapping should be equal to the number of observations in the original sample (Hair et al., 2011).

b) Assessment of the structural model

The structural model of the study has three independent variables (breadth, depth, and magnitude of ERP implementation scope), one dependent variable (intellectual capital), and one moderating variable (organizational learning capability). The structural model will be tested to determine whether there is a positive relationship between the scope of ERP implementation and intellectual capital, and whether there is a moderating effect of organizational learning capability on this relationship.

According to Henseler and Fassott (2010), there are two common approaches for testing moderating effects in regression models: group comparison and product term. In the group comparison approach, a dataset is divided into groups using a dichotomy of the value of the moderator variable. Then, the coefficients or the slopes of the relationship between independent variable (or predictor variable) and dependent variable are compared among groups to test the moderating effect. In the product term approach, another variable is added to the regression model. This variable is the multiplication of independent variable and moderator variable. The moderating effect is assessed via the significant slope of the relationship between this variable and dependent variable. 
As recommended by Henseler and Fassott (2010), the product term approach should always be used if the moderator and predictor variables are continuous, because the analysis will take into account all moderator variable's variance (i.e. via the product term). The comparison approach should be used only when the moderator variable is categorical, or when the analyst wants to have a quick overview of a moderator effect. However, as remarked by Robinson, Tomek, and Schumacker (2013), simple slopes (i.e. group comparison) and interaction term (i.e. product term) approaches touch two different aspects of a moderating effect analysis. One aspect is that the group comparison approach is used to test whether there is a different relationship between predictor variable and dependent variable for each group of moderator variable. The other aspect is that the product term approach is used to test whether the interaction of predictor variable and moderator variable has a relationship on dependent variable, beside the effect of these variables on dependent variable. Furthermore, as suggested by Reinecke (1999, as cited in Henseler and Fassott, 2010) the group comparison approach is used first to obtain an insight into the analysis and after that the product term approach is conducted.

The current study applies both approaches to examine two aspects of the moderating effect in the research model: whether the relationship between ERP implementation scope and intellectual capital is different among the groups of firms with different level of learning capability, and whether the interaction between ERP implementation scope and learning capability has an effect on intellectual capital. This study applies the procedures suggested by Henseler and Fassott (2010).

In the group comparison approach, the data set is divided into two groups: high and low value of the moderator variable $(\mathrm{Z})$, and then the same model is assessed using these two subsets of data. In case the moderator variable has formative dimensions, the latent variable scores are used for the dichotomization by following these rules (Henseler \& Fassott, 2010, p. 720):

- If the moderator variable's latent variable score of an observation lies within the upper third, the grouping value is set to "high". 
- If the moderator variable's latent variable score of an observation lies within the lower third, the grouping value is set to "low".

- Otherwise, the observation is not assigned to any group.

\begin{tabular}{|c|c|c|}
\hline Group & Structural model & Moderating effect \\
\hline $\begin{array}{l}\text { Group } 1 \text { (high value of } \\
\text { moderator variable) }\end{array}$ & $b^{(1)}$ & $\mathrm{d}=\mathrm{b}^{(1)}-\mathrm{b}^{(2)}$ \\
\hline
\end{tabular}

Figure 4.2 Moderating effect using group comparison approach

After two groups are determined, a regression technique is used to estimate the parameters of the model for each group. Then the parameters are compared between two groups for the conclusion on the moderating effect (Henseler \& Fassott, 2010). As shown in Figure 4.2, two groups of data are determined based on the value of the moderator variable, then the direct relationship $b$ between independent variable (X) and dependent variable (Y) is estimated for each group. The difference in $b$ is interpreted as being caused by moderating effects.

In the product term approach, an additional variable representing the product of the independent variable and the moderator variable is included in the structural model. The product terms are built by multiplying the indicators of the latent independent variable and the indicators of the latent moderating variable, and these product terms are used as indicators of the interaction variable in the structural model (Henseler \& Fassott, 2010). In this study, because the moderator variable has formative indicators, a two-stage PLS approach will be used (Henseler \& Fassott, 2010; Hair et al., 2014, p. 263):

- Stage 1: In this stage, the PLS path model with main effects is estimated, the latent variable scores (LVS) are calculated and saved for further analysis.

- Stage 2: In this stage, the interaction term is built up as the pair multiplication of the latent variable scores of independent variable (X) and moderator 
variable $(\mathrm{Z})$. This interaction term and the latent variable scores of $\mathrm{X}$ and $\mathrm{Z}$ are used as independent variables in a multiple linear regression on the latent variable scores of the dependent variable (Y).

This two-stage approach is illustrated in Figure 4.3. In Stage 1, the main effects model without the interaction variable is estimated to obtain the latent variable scores for $\mathrm{X}, \mathrm{Z}$, and $\mathrm{Y}$, i.e., $\operatorname{LVS}(\mathrm{X}), \operatorname{LVS}(\mathrm{Z})$, and $\operatorname{LVS}(\mathrm{Y})$. Then the product term is created between the latent variable scores of $\mathrm{X}$ and $\mathrm{Z}$ and is used as the indicator for the interaction variable X.Z. In Stage 2, the interaction variable X.Z is included in the model. Each of the variables in Stage 2 is measured with a single item of the latent variable scores from Stage 1.

Stage 1

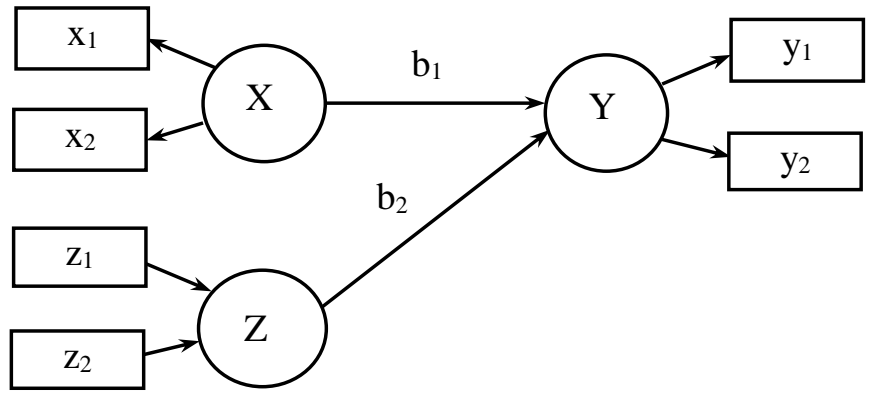

Stage 2

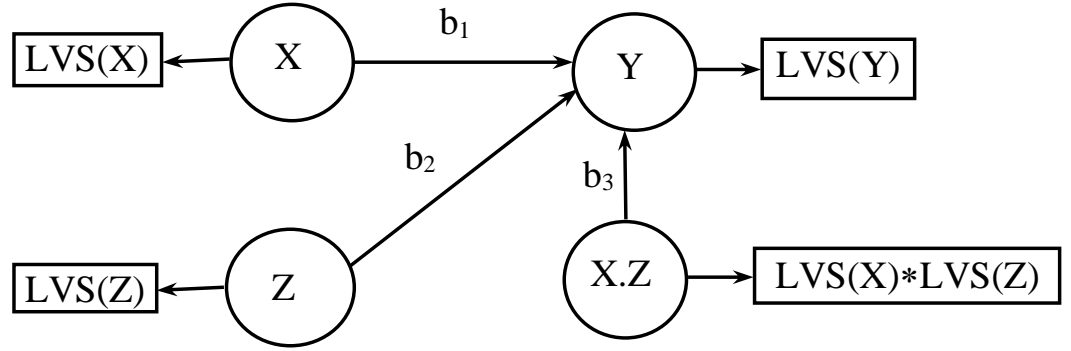

Figure 4.3 Two-stage approach for moderating effects analysis with formative constructs involved

In the product term approach, the moderating effects are detected through the examination of the relations of the independent, moderator, and interaction variables with the dependent variable. The significance of path coefficients is assessed by means of the bootstrapping technique (Hair et al., 2014, p. 127). If the path coefficient of the interaction variable is significant, the moderator hypothesis is supported (Baron \& Kenny, 1986). 
Additionally, the strength of moderating effects can be evaluated by a comparison between the determination coefficient $\left(\mathrm{R}^{2}\right)$ of the main effects model (without the interaction variable) and that of the interaction model (with the interaction variable) (Chin, Marcolin, \& Newsted, 2003). The overall effect size $\left(\mathrm{f}^{2}\right)$ is calculated from the determination coefficients, and the value of $0.02,0.15$, and 0.35 indicates small, moderate, and large interaction effects respectively (Cohen, 1988, p. 410). The formula for $\mathrm{f}^{2}$ calculation is as follows.

$$
\mathrm{f}^{2}=\frac{\mathrm{R}_{\text {interaction model }}^{2}-\mathrm{R}_{\text {main effect model }}^{2}}{1-\mathrm{R}_{\text {interaction model }}^{2}}
$$

Because the model has two higher-order formative constructs, the repeated indicator approach and two stage approach are used to support the analysis (Hair et al., 2014, p. 233). The repeated indicator approach is used to establish the second-order constructs in the structural model. In the two-stage approach, first the structural model is estimated to obtain the latent variable scores of the constructs, then the latent variable scores are used as the indicators for the constructs and are used to analyze moderating effects. The details of these procedures are presented along with the relevant results in Chapter 5.

\subsection{Chapter summary}

This chapter presented a justification of the quantitative research approach, measurement instrument development, methods of data collection, and data analysis techniques through which this study was carried out. It focused on the explanation of using formative dimensions in the measurement models, then described the process of questionnaire construction based on employing a previously established measurement scale, back-translation, pretest, and refinement. The survey design used to collect data, the criteria for data assessment, and data analysis techniques that employed PLS were described. The next chapter reports on the results of the data analysis. 


\section{CHAPTER 5}

\section{DATA ANALYSIS}

This chapter reports the results and findings of the statistical analysis. First, the description of the respondent and firm profile is presented, the construct validity and measurement model are assessed, and the structural model is then examined to test the significance of theoretical relationships. Finally, the moderating effect of organizational learning capability on the relationship between the scope of ERP implementation and intellectual capital is assessed

\subsection{Sample profile}

\subsubsection{Respondent profile}

As previously mentioned, the data for the study were collected from two sources in each firm. The first source is for the scope of ERP implementation. The people who provided this information are the managers who are responsible for the IT or IS activities of the firm. The job titles of these respondents vary depending on the organizational structure of their firms; the summary is shown in Table 5.1. Most of the respondents (over 70\%) keep a managerial position in IT/IS activities, in which they are at least an IT team leader. About $28 \%$ of the respondents are senior IT staff, thus they are also likely to provide sufficient information about the ERP implementation in their organizations.

Table 5.1 Job titles of respondents answering part A

\begin{tabular}{|l|c|c|}
\hline Job title & Frequency & Percentage \\
\hline Head of IT department & 21 & 9.3 \\
\hline IT manager & 94 & 41.6 \\
\hline IT team leader & 47 & 20.8 \\
\hline Senior IT staff & 64 & 28.3 \\
\hline Total & 226 & 100 \\
\hline
\end{tabular}

As for how long the respondents had been working in their current organizations, as illustrated in Table 5.2, nearly $43 \%$ of surveyed IT staff had been working in their 
organizations from 3 to 5 years. Around $28 \%$ had been working for 2 years or less, and $30 \%$ had been working for 6 years or more. It can be seen that, on average, respondents had been working at their present organization for nearly three to five years.

Table 5.2 Years in current organization of respondents answering part A

\begin{tabular}{|l|c|c|}
\hline Years in current organization & Frequency & Percentage \\
\hline 2 years or less & 63 & 27.9 \\
\hline $3-5$ years & 96 & 42.5 \\
\hline 6 - 10 years & 51 & 22.6 \\
\hline More than 10 years & 16 & 7.1 \\
\hline Total & 226 & 100 \\
\hline
\end{tabular}

The self-rating of the respondents' knowledge about the scope of ERP implementation in their company is depicted in Table 5.3. The evaluation was based on a seven-point scale; 1 stands for little knowledge and 7 is for expert knowledge. Given that part A of the survey targeted IT/IS managers as key informants, it is not surprising that all of the respondents provided a score of 4 and above, indicating that they had adequate knowledge about the ERP system in their organization.

Table 5.3 Self-rating of respondents answering part A

\begin{tabular}{|c|c|c|}
\hline \multicolumn{3}{|c|}{$\begin{array}{l}\text { Self-rating of ERP implementation knowledge (1 for little knowledge, } 7 \text { for expert } \\
\text { knowledge) }\end{array}$} \\
\hline & Frequency & Percentage \\
\hline 1 & 0 & 0 \\
\hline 2 & 0 & 0 \\
\hline 3 & 0 & 0 \\
\hline 4 & 14 & 6 \\
\hline 5 & 104 & 46 \\
\hline 6 & 77 & 34 \\
\hline 7 & 31 & 14 \\
\hline Total & 226 & 100 \\
\hline
\end{tabular}

The second source of information for the study is from managerial people working in other departments; hence they are knowledgeable about the learning capability and 
intellectual capital of their firms. Table 5.4 summarizes the respondents' job functions or work areas. The table shows that respondents had worked in various work areas. The work areas that include a high proportion of the respondents are production (16.4\% of the total), human resources $(13.3 \%)$, and accounting and finance $(11.5 \%)$.

Table 5.4 Job functions/work areas of respondents answering part B

\begin{tabular}{|l|c|c|}
\hline & Frequency & Percentage \\
\hline Planning/Strategy & 14 & 6.2 \\
\hline Finance/Accounting & 26 & 11.5 \\
\hline Engineering/Technology & 21 & 9.3 \\
\hline Production & 37 & 16.4 \\
\hline Human Resources & 30 & 13.3 \\
\hline Sales & 17 & 7.5 \\
\hline Marketing & 13 & 5.8 \\
\hline Logistics/Inventory & 9 & 4.0 \\
\hline Quality Management & 11 & 4.9 \\
\hline R\&D & 12 & 5.3 \\
\hline Information Technology/Systems & 21 & 9.3 \\
\hline Others & 8 & 3.5 \\
\hline Missing & 7 & 3.1 \\
\hline Total & 226 & 100 \\
\hline
\end{tabular}

Table 5.5 depicts the information provided by the respondents regarding their job positions. Most of the respondents were in a managerial position, in which they were at least a team leader. Half of the respondents hold a middle managerial position. Only a small number of respondents missed this question (2.2\%), thus the quality of the whole sample is probably not affected.

Table 5.5 Job positions of respondents answering part B

\begin{tabular}{|l|c|c|}
\hline & Frequency & Percentage \\
\hline Top management & 33 & 14.6 \\
\hline Middle management & 115 & 50.9 \\
\hline Low-level management & 57 & 25.2 \\
\hline Team leaders & 16 & 7.1 \\
\hline Missing & 5 & 2.2 \\
\hline Total & 226 & 100 \\
\hline
\end{tabular}


As regards the number of years the respondents had been with their current organization, Table 5.6 shows that a majority of respondents (over $75 \%$ ) had 3 or more years of working at the present organization. Nearly $24 \%$ of respondents have been with their present firm for 2 years or less. On average, respondents answering part B had been working at their present organization for nearly three to five years.

Table 5.6 Years in current organization of respondents answering part B

\begin{tabular}{|l|c|c|}
\hline & Frequency & Percentage \\
\hline 2 years or less & 53 & 23.5 \\
\hline 3 - 5 years & 102 & 45.1 \\
\hline 6 - 10 years & 41 & 18.1 \\
\hline More than 10 years & 26 & 11.5 \\
\hline Missing & 4 & 1.8 \\
\hline Total & 226 & 100 \\
\hline
\end{tabular}

The respondents provided their self-rating of their knowledge about the intellectual capital and learning capability of their organizations as shown in Table 5.7. Most respondents marked this with a score from 4 to 7 . Only two respondents $(0.9 \%)$ provided a score of 3 , slightly below the average score. This small proportion does not affect the whole sample, hence these cases were included in the analysis.

Table 5.7 Self-rating of respondents answering part B

\begin{tabular}{|c|c|c|}
\hline (1 for little knowledge, 7 for expert knowledge) \\
\hline & Frequency & Percentage \\
\hline 1 & 0 & 0 \\
\hline 2 & 0 & 0.9 \\
\hline 3 & 2 & 11.1 \\
\hline 4 & 25 & 42.5 \\
\hline 5 & 96 & 35.8 \\
\hline 6 & 81 & 8.4 \\
\hline 7 & 19 & 1.3 \\
\hline Missing & 3 & 100 \\
\hline Total & 226 & \\
\hline
\end{tabular}


In short, for part A of the survey, the typical respondent was an IT manager who had been working at his or her current organization for from 3 to 5 years and gave a selfrating of knowledge of ERP implementation in his or her organization at the average score or above. As for part B of the survey, the typical key informant was a middle manager who had been working at the present organization for 3 to 5 years in the field of production, human resources, accounting and finance, or engineering and technology. Most of the respondents answering part B provided an adequate selfrated knowledge score about the learning capability and intellectual capital of their firm.

\subsubsection{Company profile}

As shown in Table 5.8, the majority of organizations in the sample fall into the business category of limited liability (42\%) and shareholding or joint-stock company (36.7\%). The percentage of organizations with a number of employees from 100 to 299 employees accounts for $42.5 \%$, while the next largest groups are organizations with 300 to 499 employees (27\%) and 500 or more (23.9\%). Four industries that have the highest proportion of companies in the sample are electrical products (14.6\%), food and beverage (13.7\%), construction materials (11.5\%), and furniture and wooden products $(9.3 \%)$.

Table 5.8 Profile of surveyed companies

\begin{tabular}{|l|l|c|c|}
\hline \multirow{5}{*}{ Business types } & & Frequency & Percentage \\
\cline { 2 - 4 } & $\begin{array}{l}\text { Limited liability company } \\
\text { stock company }\end{array}$ & 95 & 42.0 \\
\cline { 2 - 4 } & Partnership & 83 & 36.7 \\
\cline { 2 - 4 } & $\begin{array}{l}\text { Private enterprise or sole } \\
\text { proprietorship }\end{array}$ & 16 & 6.6 \\
\cline { 2 - 4 } & Others & 10 & 7.1 \\
\cline { 2 - 4 } & Missing & 7 & 4.4 \\
\hline \multirow{3}{*}{$\begin{array}{l}\text { Firm size } \\
\text { emumber of }\end{array}$} & Less than 100 & 15 & 3.1 \\
\cline { 2 - 4 } & 100 to less than 300 & 96 & 6.6 \\
\cline { 2 - 4 } & 300 to less than 500 & 61 & 27.5 \\
\cline { 2 - 4 } & 500 and above & 54 & 23.9 \\
\hline
\end{tabular}




\begin{tabular}{|c|c|c|c|}
\hline & & Frequency & Percentage \\
\hline \multirow[t]{16}{*}{ Industry } & $\begin{array}{l}\text { Agricultural \& Aquatic } \\
\text { products }\end{array}$ & 17 & 7.5 \\
\hline & Automobile & 3 & 1.3 \\
\hline & $\begin{array}{l}\text { Chemical \& } \\
\text { Pharmaceutical }\end{array}$ & 10 & 4.4 \\
\hline & Construction materials & 26 & 11.5 \\
\hline & Electrical products & 33 & 14.6 \\
\hline & Electronics & 18 & 8 \\
\hline & Food \& Beverage & 31 & 13.7 \\
\hline & Footwear & 3 & 1.3 \\
\hline & $\begin{array}{l}\text { Furniture \& Wooden } \\
\text { products }\end{array}$ & 21 & 9.3 \\
\hline & Garment \& Textile & 15 & 6.6 \\
\hline & Machinery \& Equipment & 4 & 1.8 \\
\hline & $\begin{array}{l}\text { Metallic Processing, } \\
\text { Assembly }\end{array}$ & 15 & 6.6 \\
\hline & Paper \& Carton & 16 & 7.1 \\
\hline & Rubber \& Plastic & 5 & 2.2 \\
\hline & Stationery & 4 & 1.8 \\
\hline & Missing & 5 & 2.2 \\
\hline
\end{tabular}

As regards ERP implementation characteristics, all of the firms in the sample have used an ERP system or a number of the modules of an unfinished ERP system implementation for one year or more. About $94 \%$ said they have finished the implementation and nearly $6 \%$ have not finished but have started to use a number of modules.

In more detail, as shown in Table 5.9 the firms that have implemented ERP packages from SAP, Microsoft, and Oracle form a significant proportion of the sample (more than $10 \%$ for each). The percentage of firms that have implemented other ERP packages ranged between $3.5 \%$ and $8.4 \%$. Nearly $24 \%$ of firms have implemented ERP packages whose names were not listed in the questionnaire (see Appendix D for more details). About $26 \%$ of firms have used an ERP system for less than 2 years, more than $50 \%$ of firms have used an ERP system for 2 to almost 3.5 years, and $19 \%$ 
Chapter 5: Data Analysis

of firms have used an ERP system for 3 years or more. Regarding the duration of ERP implementation, approximately $20 \%, 42 \%$, and $38 \%$ of firms have implemented an ERP system less than 2 years ago, from 2 to less than 3.5 years ago, and 3.5 or more years ago respectively.

Table 5.9 ERP implementation characteristics

\begin{tabular}{|c|c|c|c|}
\hline & & Frequency & Percentage \\
\hline \multirow{10}{*}{ ERP package } & SAP & 27 & 11.9 \\
\hline & Oracle & 38 & 16.8 \\
\hline & Microsoft & 30 & 13.3 \\
\hline & SS4U & 15 & 6.6 \\
\hline & Pythis & 11 & 4.9 \\
\hline & Vietsoft & 8 & 3.5 \\
\hline & FastBusiness & 19 & 8.4 \\
\hline & LacViet & 9 & 4.0 \\
\hline & Others & 54 & 23.9 \\
\hline & Missing & 15 & 6.6 \\
\hline \multirow{8}{*}{ Time to start to use } & Less than one year & 0 & - \\
\hline & 1 year to $<1.5$ years & 39 & 17.3 \\
\hline & 1.5 years to $<2$ years & 21 & 9.3 \\
\hline & 2 years to $<2.5$ years & 47 & 20.8 \\
\hline & 2.5 years to $<3$ years & 34 & 15.0 \\
\hline & 3 years to $<3.5$ years & 42 & 18.6 \\
\hline & 3.5 years to $<4$ years & 16 & 7.1 \\
\hline & 4 years or above & 27 & 11.9 \\
\hline \multirow{8}{*}{$\begin{array}{l}\text { Time to start to } \\
\text { implement }\end{array}$} & Less than one year & 0 & - \\
\hline & 1 year to $<1.5$ years & 17 & 7.5 \\
\hline & 1.5 years to $<2$ years & 28 & 12.4 \\
\hline & 2 years to $<2.5$ years & 21 & 9.3 \\
\hline & 2.5 years to $<3$ years & 32 & 14.2 \\
\hline & 3 years to $<3.5$ years & 41 & 18.1 \\
\hline & 3.5 years to $<4$ years & 35 & 15.5 \\
\hline & 4 years or above & 52 & 23.0 \\
\hline \multirow[b]{2}{*}{ Completion } & Have finished & 213 & 94.2 \\
\hline & $\begin{array}{l}\text { Have not finished } \\
\text { (but have used some } \\
\text { modules) }\end{array}$ & 13 & 5.8 \\
\hline
\end{tabular}


In short, the typical surveyed organization was a limited liability or joint-stock company, more than $50 \%$ of which had 300 or more employees. The typical ERP package implemented was from SAP, Oracle, or Microsoft. Most of the organizations have used their ERP system between 2 to almost 3.5 years.

\subsection{Data assessment}

\subsubsection{Missing values and outliers}

The question items in the questionnaire were coded and the questionnaire responses were entered into Excel and SPSS applications. With the dataset built, examination and exploratory procedures were implemented to screen the data for possible outliers and the pattern of missing values. Fifteen cases with missing values in the descriptive part of the questionnaire were kept because they had no effect on the regression results. The variables involved in regression analysis also had incomplete items that accounted for less than $10 \%$ on any single variable. According to Hair et al. (2010, p. 47 ) and Kline (2010, p. 55), if the proportion of missing responses is low, any of the imputation methods can be applied. This study used the mean substitution method.

In order to examine the possible univariate outliers, all numeric variables were converted to standard z scores. As a common rule of thumb, the outliers are identified with an absolute value of z-score over 3 (Hair et al., 2010; Kline, 2010). The results show that the $\mathrm{z}$ scores of all measurement items were within a range of \pm 3 thus indicating no serious univariate outliers in the dataset (see Appendix E).

Because multivariate outliers may exist when some variables are combined, the multivariate assessment should be conducted using the Mahalanobis distance (D) statistic (Kline, 2010, p. 54). The Mahalanobis distance statistic indicates the difference in standard deviation units between a set of scores for an individual case and the sample means for all variables, with the correction for intercorrelations (Kline, 2010). For this study, the measurement items for each of ten latent variables were combined to determine $\mathrm{D}$ statistics and the associated p-values. The results 
show that all p-values were above 0.001 (see Appendix E), therefore no multivariate outliers was found in the dataset.

\subsubsection{Non-response bias}

Non-response is an important problem because the representativeness of the sample is influenced by the absence of respondents who are not willing to answer the questionnaire (Bryman, 2003, p. 92). In order to check the presence of non-response bias, a "time trend extrapolation test" (Armstrong \& Overton, 1977) was performed. The sample of this study was divided into three sub-groups according to early and late responding time. The late responding companies were assumed to be similar to non-response companies. The three sub-groups were compared in pair using an independent sample t-test at the 5\% significance level. The results show that there are no significant differences in any of the measurement items of the scope of ERP implementation, intellectual capital, and organizational learning capability ( $\mathrm{p}$-values ranged from 0.058 to 0.992 ). Therefore, although the problem of non-response bias could not be completely removed, this comparison gave confidence that the sample was representative.

\subsubsection{Possibility of common method bias}

Common method bias refers to a bias in the dataset that is attributed to the measurement method rather than to the constructs the measurement items represent (Podsakoff, MacKenzie, Lee, \& Podsakoff, 2003). Because all measurement items were presented in the same questionnaire, correlations among these variables may be relatively high. As a result, the responses were possibly inflated or deflated. This study follows the procedure of Zhuang and Lederer (2003) using Harman's singlefactor test to check for common method bias. The assumption of this technique is that if a considerable value of common method variance exists, either (a) a single factor will appear from the factor analysis or (b) one general factor will represent the majority of the covariance among the measures.

For this study, the questionnaire has two parts that were answered separately by two different respondents in each organization. Part A of the questionnaire covers the 
scope of ERP implementation, and the managerial people who provided this information responsible for the IT or IS activities of the organization. Part B deals with the evaluation of intellectual capital and organizational learning capability, and the respondents are supposed to be managers working in other departments and knowledgeable about the learning capability and intellectual capital of their organizations. However, in reality around $9.3 \%$ of the respondents to part B were involved in job positions related to information technology/systems (see Table 5.4). This means that $9.3 \%$ of the respondents might have answered both part A and B. Although the use of different sources for data collection can help to mitigate common method bias (Podsakoff et al., 2003), the problem of common method bias could happen for each part of the questionnaire. To examine this possibility, this study used three exploratory factor analysis (EFA) tests: the first test only used the items measuring ERP implementation scope (i.e. part A of the questionnaire), the second test only used the items measuring intellectual capital and organizational learning capability (i.e. part B of the questionnaire), and the third used all items of ERP implementation scope, intellectual capital, and organizational learning capability. All three EFA tests show that there are at least three "unrotated" factors, of which no single factor is found to explain more than $50 \%$ of the variance. Therefore, the tests suggest that no significant common method variance is present in the dataset.

\subsubsection{Normality assessment}

In order to use an appropriate estimation method in SEM, the normality of distribution of all interval variables need to be assessed. According to Hair et al. (2010, p. 71), both univariate and multivariate normality are needed for statistical methods, however it is sufficient to assess and achieve univariate normality for all variables. Multivariate normality is required only when it is especially critical (Hair et al., 2010).

There are various criteria for assessing data normality. As suggested by West, Finch, and Curran (1995), variables with absolute values of skewness and kurtosis greater than 2 and 7 respectively are considered to be non-normal. Hair et al. (2014, p. 54) recommend a more restricted criterion that absolute skewness and kurtosis values of 
larger than 1 signal non-normal data. Moreover, z statistics of skewness and kurtosis values can be used to assess data normality (Hair et al., 2010, p. 73), if the calculated $\mathrm{Z}$ values are outside the range of \pm 2.58 (for the 0.01 significance level) and \pm 1.96 (for the 0.05 level), then the distribution of the variables is non-normal.

In this study, a descriptive analysis was conducted for the dataset. The results show that all measurement items of ten latent variables have absolute values that do not exceed 2 for skewness and 7 for kurtosis indices thus meeting the level recommended by West et al. (1995). However, in more restricted criteria suggested by Hair et al. (2014) and Hair et al. (2010), among 37 items 3 were found with absolute kurtosis values larger than 1 (DEP1, DEP2, OC3) and 13 were found with $\mathrm{z}$ statistics of skewness and kurtosis values outside the range of \pm 2.58 (see Appendix F). Given that the dataset has a number of items that were non-normal, the study considered the Partial Least Squares (PLS) technique for the analysis because it makes no assumptions about data distribution (Chin, 1998; Gefen et al., 2000; Hair et al., 2014).

\subsection{Assessment of measurement models}

After the data quality was evaluated, the measurement models of the study were assessed. The structural model of the study includes ten reflective first-order constructs and two formative second-order constructs (intellectual capital and organizational learning capability). Reflective measurement models were assessed using different criteria of internal consistency reliability, indicator reliability, convergent validity, and discriminant validity (Hair et al., 2014; Henseler et al., 2009). Formative measurement models were evaluated via convergent validity, the path coefficient significance, and multi-collinearity among first-order constructs forming the second-order constructs (Hair et al., 2014, p. 121).

\subsubsection{Reflective measurement models}

Internal consistency reliability refers to the consistency among the variables measuring a single concept. The variables used to measure a single concept should be coherent or homogeneous, and thus highly intercorrelated (Bryman, 2003, p. 42; Hair et al., 2010, p. 125). According to Hair et al. (2010), researchers must rely on a series 
of diagnostic measures to assess the internal consistency. The first group of measures relates to each separate item and includes the item-to-total correlation and inter-item correlation. Rules of thumb suggest that the item-to-total correlations exceed 0.5 and that the inter-item correlations exceed 0.3 (Robinson, Shaver, \& Wrightsman, 1991). For the second type of diagnostic measure, researchers tend to use Cronbach's alpha as a reliability coefficient indicating how well the items are positively correlated to one another. The generally agreed-upon lower limit for this coefficient is 0.7 , and it may decrease to 0.6 in exploratory research (Robinson et al., 1991). Another diagnostic measure that can be derived from confirmatory factor analysis is the composite reliability. The composite reliability can be used as a better alternative to Cronbach's alpha; while Cronbach's alpha assumes that all indicators are equally reliable, the composite reliability takes into account that indicators have different loadings (Chin, 1998). Composite reliability with a value above 0.7 for exploratory research and values above 0.8 or 0.9 in more advanced stages of research is considered satisfactory (Nunnally \& Bernstein, 1994).

In addition to the internal consistency reliability of latent variables, the reliability of each indicator should be examined. Indicator reliability refers to the extent to which an indicator or set of indicators is consistent regarding what it intends to measure. Indicator reliability is assessed using indicator loadings. Indicator loadings should be at least significant at the 0.05 level and greater than 0.7 (Chin, 1998). An indicator is considered for removal only if its reliability is low and its elimination would lead to a substantial increase in composite reliability (Henseler et al., 2009).

Convergent validity assesses the degree to which a set of indicators represent the same underlying concept. High correlations among indicators indicate that the scale is measuring its intended concept (Hair et al., 2010, p. 126). Fornell and Larcker (1981) suggest using the average variance extracted (AVE) as a criterion of convergent validity. An AVE value of at least 0.5 indicates that a latent variable is able to explain more than half of the variance of its indicators on average; thus it satisfies convergent validity. 
Discriminant validity represents the degree to which a construct is distinct from other constructs (Hair et al., 2010, p. 687). Discriminant validity assesses whether the items unintentionally measure something else. Two measures of discriminant validity have been suggested: the Fornell-Larcker criterion and the cross-loadings. The FornellLarcker criterion (Fornell \& Larcker, 1981) requires a latent variable to share more variance with its assigned indicators that with any other latent variable, meaning the AVE of each latent variable should be greater than the latent variable's highest squared correlation with any other latent variable. For the second measure using the cross-loadings, it is required that the loading of each indicator on its designated latent variable is expected to be greater than all of its cross-loadings (Chin, 1998).

For this study, the constructs of the research model were initially checked with a confirmatory factor analysis. Except for two items - HC2 and SC4 - all items have loadings on their designated constructs greater than 0.7 and greater than their loadings on any other constructs (see Appendix G). Table 5.10 presents the factor loadings of the constructs after HC2 and SC4 were excluded. The results show that most of the measurement items satisfy the criteria of indicator reliability.

Table 5.10 Factor loadings of reflective constructs

\begin{tabular}{|l|l|l|l|l|l|l|l|l|l|l|}
\hline & BRE & DEP & MAG & HC & OC & SC & MC & SP & OP & KW \\
\hline BRE1 & $\mathbf{0 . 8 8 5}$ & 0.217 & 0.124 & 0.220 & 0.436 & 0.328 & 0.433 & 0.347 & 0.361 & 0.357 \\
\hline BRE2 & $\mathbf{0 . 8 9 8}$ & 0.221 & 0.101 & 0.277 & 0.417 & 0.349 & 0.423 & 0.398 & 0.411 & 0.331 \\
\hline DEP1 & 0.188 & $\mathbf{0 . 8 8 1}$ & 0.315 & 0.255 & 0.365 & 0.295 & 0.328 & 0.261 & 0.306 & 0.357 \\
\hline DEP2 & 0.251 & $\mathbf{0 . 9 3 0}$ & 0.343 & 0.327 & 0.422 & 0.423 & 0.378 & 0.316 & 0.355 & 0.368 \\
\hline MAG1 & 0.102 & 0.299 & $\mathbf{0 . 8 9 6}$ & 0.351 & 0.295 & 0.273 & 0.275 & 0.189 & 0.297 & 0.252 \\
\hline MAG2 & 0.122 & 0.354 & $\mathbf{0 . 8 5 0}$ & 0.290 & 0.261 & 0.230 & 0.312 & 0.207 & 0.282 & 0.243 \\
\hline MAG3 & 0.107 & 0.302 & $\mathbf{0 . 8 6 4}$ & 0.256 & 0.241 & 0.216 & 0.286 & 0.201 & 0.286 & 0.164 \\
\hline HC1 & 0.214 & 0.281 & 0.285 & $\mathbf{0 . 7 9 0}$ & 0.378 & 0.373 & 0.357 & 0.301 & 0.296 & 0.485 \\
\hline HC3 & 0.294 & 0.283 & 0.307 & $\mathbf{0 . 8 4 6}$ & 0.403 & 0.444 & 0.438 & 0.326 & 0.384 & 0.465 \\
\hline HC4 & 0.169 & 0.207 & 0.216 & $\mathbf{0 . 7 5 8}$ & 0.299 & 0.343 & 0.278 & 0.256 & 0.280 & 0.362 \\
\hline HC5 & 0.217 & 0.274 & 0.308 & $\mathbf{0 . 8 3 4}$ & 0.415 & 0.463 & 0.362 & 0.286 & 0.308 & 0.452 \\
\hline OC1 & 0.360 & 0.329 & 0.207 & 0.284 & $\mathbf{0 . 7 1 0}$ & 0.356 & 0.358 & 0.373 & 0.415 & 0.401 \\
\hline OC2 & 0.422 & 0.429 & 0.283 & 0.424 & $\mathbf{0 . 8 3 5}$ & 0.470 & 0.440 & 0.441 & 0.383 & 0.465 \\
\hline OC3 & 0.406 & 0.274 & 0.215 & 0.373 & $\mathbf{0 . 8 3 1}$ & 0.457 & 0.410 & 0.433 & 0.431 & 0.428 \\
\hline
\end{tabular}


Chapter 5: Data Analysis

\begin{tabular}{|l|l|l|l|l|l|l|l|l|l|l|}
\hline & BRE & DEP & MAG & HC & OC & SC & MC & SP & OP & KW \\
\hline OC4 & 0.380 & 0.396 & 0.294 & 0.428 & $\mathbf{0 . 8 8 9}$ & 0.529 & 0.466 & 0.415 & 0.474 & 0.459 \\
\hline SC1 & 0.315 & 0.298 & 0.245 & 0.414 & 0.472 & $\mathbf{0 . 8 1 9}$ & 0.312 & 0.404 & 0.287 & 0.334 \\
\hline SC2 & 0.285 & 0.385 & 0.232 & 0.383 & 0.472 & $\mathbf{0 . 8 1 5}$ & 0.277 & 0.335 & 0.236 & 0.309 \\
\hline SC3 & 0.288 & 0.346 & 0.251 & 0.423 & 0.447 & $\mathbf{0 . 8 3 5}$ & 0.300 & 0.377 & 0.293 & 0.297 \\
\hline SC5 & 0.362 & 0.303 & 0.187 & 0.447 & 0.447 & $\mathbf{0 . 8 2 3}$ & 0.347 & 0.318 & 0.282 & 0.329 \\
\hline MC1 & 0.428 & 0.276 & 0.265 & 0.347 & 0.410 & 0.359 & $\mathbf{0 . 8 2 6}$ & 0.475 & 0.519 & 0.479 \\
\hline MC2 & 0.299 & 0.331 & 0.304 & 0.308 & 0.403 & 0.228 & $\mathbf{0 . 7 7 0}$ & 0.373 & 0.435 & 0.423 \\
\hline MC3 & 0.372 & 0.311 & 0.315 & 0.405 & 0.438 & 0.284 & $\mathbf{0 . 8 2 2}$ & 0.471 & 0.448 & 0.429 \\
\hline MC4 & 0.423 & 0.335 & 0.266 & 0.316 & 0.403 & 0.332 & $\mathbf{0 . 8 2 6}$ & 0.411 & 0.434 & 0.464 \\
\hline MC5 & 0.435 & 0.356 & 0.222 & 0.451 & 0.449 & 0.329 & $\mathbf{0 . 8 5 1}$ & 0.494 & 0.450 & 0.536 \\
\hline SP1 & 0.379 & 0.215 & 0.152 & 0.322 & 0.436 & 0.363 & 0.476 & $\mathbf{0 . 8 3 1}$ & 0.349 & 0.397 \\
\hline SP2 & 0.404 & 0.268 & 0.227 & 0.349 & 0.419 & 0.416 & 0.493 & $\mathbf{0 . 8 7 5}$ & 0.415 & 0.435 \\
\hline SP3 & 0.274 & 0.335 & 0.197 & 0.245 & 0.434 & 0.321 & 0.409 & $\mathbf{0 . 8 3 0}$ & 0.365 & 0.406 \\
\hline OP1 & 0.363 & 0.304 & 0.340 & 0.323 & 0.429 & 0.242 & 0.448 & 0.382 & $\mathbf{0 . 8 5 4}$ & 0.391 \\
\hline OP2 & 0.347 & 0.369 & 0.305 & 0.380 & 0.459 & 0.329 & 0.491 & 0.407 & $\mathbf{0 . 8 6 6}$ & 0.449 \\
\hline OP3 & 0.360 & 0.252 & 0.214 & 0.297 & 0.409 & 0.272 & 0.404 & 0.368 & $\mathbf{0 . 8 1 3}$ & 0.350 \\
\hline OP4 & 0.395 & 0.310 & 0.256 & 0.329 & 0.452 & 0.282 & 0.534 & 0.352 & $\mathbf{0 . 8 4 4}$ & 0.478 \\
\hline KW1 & 0.294 & 0.372 & 0.170 & 0.448 & 0.428 & 0.279 & 0.488 & 0.391 & 0.430 & $\mathbf{0 . 8 5 6}$ \\
\hline KW2 & 0.310 & 0.345 & 0.216 & 0.461 & 0.478 & 0.349 & 0.520 & 0.461 & 0.454 & $\mathbf{0 . 8 9 2}$ \\
\hline KW3 & 0.384 & 0.262 & 0.192 & 0.454 & 0.412 & 0.296 & 0.411 & 0.428 & 0.343 & $\mathbf{0 . 7 8 7}$ \\
\hline KW4 & 0.322 & 0.365 & 0.285 & 0.490 & 0.485 & 0.374 & 0.501 & 0.371 & 0.443 & $\mathbf{0 . 8 3 8}$ \\
\hline Note $A$ & 1947 & $0 r 10 a d i n g s$ & 5 & \\
\hline
\end{tabular}

Note: All indicator loadings were significant at the 0.05 level

The two items HC2 and SC4 were removed because their reliability was below 0.7 and the deletion makes composite reliability of the associated constructs increase while AVE still remained above 0.5 (Henseler et al., 2009). The removal of HC2 makes the composite reliability of construct $\mathrm{HC}$ increase from 0.871 to 0.882 . Similarly for the item SC4, the composite reliability of construct SC changes from 0.882 to 0.894 (see Table 5.11).

Table 5.11 AVE and reliability of constructs before and after items removal.

\begin{tabular}{|l|c|c|l|l|l|l|}
\hline & \multicolumn{3}{|c|}{ Before removal } & \multicolumn{3}{c|}{ After removal } \\
\hline & AVE & $\begin{array}{l}\text { Composite } \\
\text { reliability }\end{array}$ & $\begin{array}{l}\text { Cronbach's } \\
\text { alpha }\end{array}$ & AVE & $\begin{array}{l}\text { Composite } \\
\text { reliability }\end{array}$ & $\begin{array}{l}\text { Cronbach's } \\
\text { alpha }\end{array}$ \\
\hline BRE & 0.795 & 0.886 & 0.742 & & & \\
\hline
\end{tabular}


Chapter 5: Data Analysis

\begin{tabular}{|l|c|c|c|c|c|c|}
\hline & \multicolumn{3}{|c|}{ Before removal } & \multicolumn{3}{c|}{ After removal } \\
\hline & AVE & $\begin{array}{l}\text { Composite } \\
\text { reliability }\end{array}$ & $\begin{array}{l}\text { Cronbach's } \\
\text { alpha }\end{array}$ & AVE & $\begin{array}{l}\text { Composite } \\
\text { reliability }\end{array}$ & $\begin{array}{l}\text { Cronbach's } \\
\text { alpha }\end{array}$ \\
\hline DEP & 0.820 & 0.901 & 0.784 & & & \\
\hline MAG & 0.757 & 0.903 & 0.841 & & & \\
\hline HC & 0.578 & 0.871 & 0.814 & 0.653 & 0.882 & 0.822 \\
\hline OC & 0.671 & 0.890 & 0.834 & & & 0.841 \\
\hline SC & 0.601 & 0.882 & 0.831 & 0.678 & 0.894 & \\
\hline MC & 0.671 & 0.911 & 0.877 & & & \\
\hline SP & 0.715 & 0.882 & 0.800 & & & \\
\hline OP & 0.714 & 0.909 & 0.866 & & & \\
\hline KW & 0.712 & 0.908 & 0.865 & & & \\
\hline
\end{tabular}

The criteria for internal consistency reliability and convergent and discriminant validity of constructs are shown in Table 5.12. All constructs have composite reliability above 0.8 . The AVE values of all constructs are above 0.5 and the square root of AVE of each construct was greater than its highest correlation with any other construct; thus the Fornell-Larcker criterion was obtained. Moreover, as illustrated in Table 5.10 the higher loading of each indicator on its designated latent variable over all of its cross-loadings also demonstrates the discriminant validity.

Table 5.12 Correlation matrix, composite reliability, and AVE of constructs

\begin{tabular}{|c|c|c|c|c|c|c|c|c|c|c|c|c|}
\hline & AVE & CR & BRE & DEP & MAG & HC & OC & SC & MC & SP & OP & KW \\
\hline BRE & 0.795 & 0.886 & 0.891 & & & & & & & & & \\
\hline DEP & 0.820 & 0.901 & 0.246 & 0.906 & & & & & & & & \\
\hline MAG & 0.757 & 0.904 & 0.126 & 0.364 & 0.870 & & & & & & & \\
\hline HC & 0.653 & 0.882 & 0.279 & 0.325 & 0.348 & 0.808 & & & & & & \\
\hline OC & 0.671 & 0.890 & 0.478 & 0.437 & 0.307 & 0.466 & 0.819 & & & & & \\
\hline SC & 0.678 & 0.894 & 0.380 & 0.404 & 0.278 & 0.506 & 0.558 & 0.823 & & & & \\
\hline MC & 0.671 & 0.911 & 0.480 & 0.392 & 0.333 & 0.448 & 0.514 & 0.376 & 0.819 & & & \\
\hline SP & 0.715 & 0.882 & 0.419 & 0.321 & 0.228 & 0.363 & 0.508 & 0.435 & 0.545 & 0.845 & & \\
\hline OP & 0.714 & 0.909 & 0.434 & 0.367 & 0.331 & 0.394 & 0.519 & 0.334 & 0.558 & 0.446 & 0.845 & \\
\hline KW & 0.712 & 0.908 & 0.385 & 0.400 & 0.256 & 0.548 & 0.535 & 0.386 & 0.571 & 0.489 & 0.496 & 0.844 \\
\hline
\end{tabular}

Note: Diagonal values are the square root of a construct's AVE. All of the correlations are significant at the 0.01 level, except the correlation between BRE and MAG is at the 0.05 level. 


\subsubsection{Formative measurement models}

As discussed previously, the study specified intellectual capital and organizational learning capability as higher-order formative constructs. Accordingly, the intellectual capital (IC) construct is formed by three first-order constructs: human capital (HC), organizational capital (OC), and social capital (SC). The organizational learning capability (OLC) construct is established by four sub-dimensions: management commitment (MC), systems perspective (SP), openness and experimentation (OP), and knowledge transfer and integration (KW).

The formative constructs are unlike the reflective constructs, whose variables are required to have a high degree of covariance because they share a common theme (Jarvis et al., 2003). The formative constructs are established by a function of their variables; therefore it is not necessary for these variables to be correlated (Jarvis et al., 2003). For this attribute, the traditional measurements of validity and reliability are not appropriate (Chin \& Gopal, 1995). According to Chin (1988) and Diamantopoulos and Winklhofer (2001), an indicator could be considered relevant for a formative index if it is statistically significant and it does not show high multicollinearity with other indicators. The presence of multicollinearity makes it difficult to ascertain the unique contribution from each indicator.

In this study, the research model has two second-order formative constructs (OLC and IC); therefore a repeated indicator approach and latent variable scores were used (Hair et al., 2014, p. 230). First, the convergent validity of two second-order formative constructs was assessed using the redundancy analysis technique suggested by Hair et al. (2014, p. 121). Next, the second-order formative constructs were assessed to determine whether multicollinearity exists amongst their formative components. The variance inflation factors (VIF) of first-order factors were calculated; values of 5 or higher indicate multicollinearity (Hair et al., 2011). Finally, the coefficient and level of significance of the formative dimensions in relation to second-order constructs were evaluated. 
To assess the convergent validity of two formative constructs, this study used the redundancy analysis technique suggested by Hair et al. (2014). For each construct, a new model was created in which all items of the first-order constructs were assigned to the corresponding second-order construct and a path between the second-order construct and the global item was established. After that, the PLS algorithm was implemented to obtain the structural path coefficient. The analysis showed path coefficients of 0.874 and 0.824 for the OLC and IC constructs respectively. These values are above the threshold of 0.8 , thus providing support for the formative construct's convergent validity (Chin, 1998; Hair et al., 2014).

To calculate the value of VIF and the coefficients of first-order factors, a repeated indicators approach was used (Hair et al., 2014; Lohmöller, 1989, p. 131). In the model, the two second-order constructs OLC and IC were measured by the indicators of their first-order constructs, and then the PLS algorithm was implemented to obtain the regression coefficients and latent variable scores of formative dimensions of the second-order constructs. The significance of coefficients was assessed using the bootstrapping technique; the number of bootstrap samples was 5,000 and the number of cases for bootstrapping was the number of observations (i.e. 226) in the original sample. (Hair et al., 2011). The latent variable scores were used to calculate the value of VIF.

Table 5.13 Path coefficients and multicollinearity of formative dimensions

\begin{tabular}{|l|l|c|c|}
\hline Second-order construct & First-order construct & VIF & Coefficient \\
\hline \multirow{4}{*}{ IC } & Human capital (HC) & 1.439 & $0.381^{* *}$ \\
\cline { 2 - 4 } & Organizational capital (OC) & 1.554 & $0.410^{* *}$ \\
\cline { 2 - 4 } & Social capital (SC) & 1.636 & $0.426^{* *}$ \\
\hline OLC & Managerial commitment (MC) & 1.915 & $0.392^{* *}$ \\
\cline { 2 - 4 } & Systems perspective (SP) & 1.557 & $0.221^{* *}$ \\
\cline { 2 - 4 } & Openness and experimentation (OP) & 1.594 & $0.303^{* *}$ \\
\cline { 2 - 4 } & $\begin{array}{l}\text { Knowledge transfer and integration } \\
\text { (KW) }\end{array}$ & 1.669 & $0.326^{* *}$ \\
\hline
\end{tabular}

Note: ** Significant at 0.01

The results are shown in Table 5.13. VIF values for the first-order constructs of each second-order construct vary from 1.439 to 1.915 . No values are higher than 5 , 
therefore there is no multicollinearity among the first-order constructs of OLC and IC. All path coefficients of first-order dimensions were found to be significant. The results support the formation of second-order constructs OLC and IC by their firstorder constructs.

\subsection{Assessment of the structural model}

The structural model of this study shows the relationships among three dimensions of ERP implementation scope (ERP), intellectual capital (IC), and organizational learning capability (OLC). The main relationships are the ones between three dimensions of ERP implementation scope (BRE - breadth, DEP - depth, MAG magnitude) and IC; the moderating relationship is represented by the effect of OLC on the main relationships.

Analysis of the moderating effect can be performed by using either the group comparison or product term approaches (Henseler \& Fassott, 2010). As discussed in Chapter 4, the study used both approaches to investigate two aspects of the moderating effect in the regression model: whether the relationships between three dimensions of ERP implementation scope and IC are different among the groups of firms with different levels of OLC, and whether the interaction between each dimension of ERP implementation scope and OLC has an effect on IC.

\subsubsection{Group comparison approach}

In this approach, the data set was divided into two groups: a low level of OLC and a high level of OLC. OLC is a formative construct, therefore observations were split into two groups using the upper third and lower third rule suggested by Henseler and Fassott (2010). Accordingly, after the latent variable scores of the moderator variable (OLC construct) were calculated, observations whose moderator LVS lie within the upper third are specified as the high OLC group; observations whose moderator LVS are within the lower third belong to the low OLC group; the remaining observations are not assigned to any group. As a result of this division, the size of each sub-sample was reduced to 75 observations. 


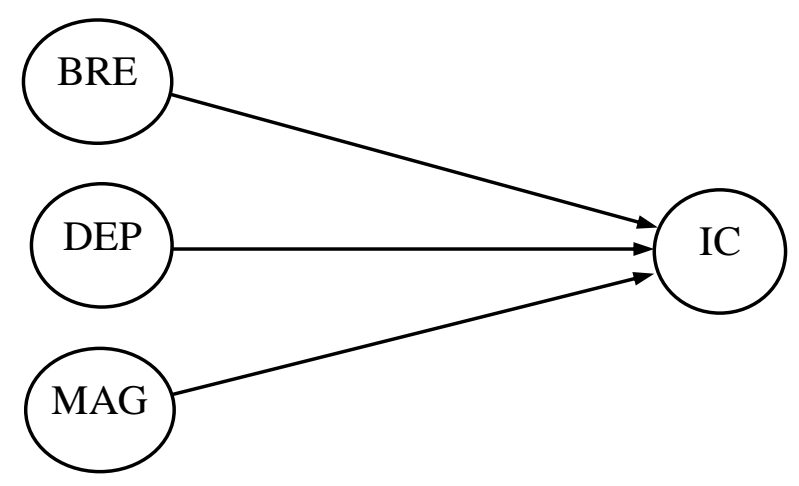

Figure 5.1 Structural model for moderating effect analysis using the group comparison approach

The direct relationships between the dimensions of ERP implementation scope and IC are illustrated in Figure 5.1. The path coefficients were calculated for the whole data set (baseline) and then for the two groups: low OLC and high OLC. The calculation was performed using the PLS algorithm and bootstrapping procedure with bootstrap samples of at least 5,000; each sample contains 75 observations to determine the coefficients' significance (Hair et al., 2014).The results are depicted in Table 5.14.

Table 5.14 Moderating effect analysis using the group comparison approach

\begin{tabular}{|l|c|c|c|}
\hline \multirow{2}{*}{ Path } & \multicolumn{3}{|c|}{ Path coefficient $(\beta)$} \\
\cline { 2 - 4 } & Baseline $(\mathrm{n}=226)$ & Low OLC $(\mathrm{n}=75)$ & High OLC $(\mathrm{n}=75)$ \\
\hline $\mathrm{BRE} \rightarrow \mathrm{IC}$ & $0.361^{*}$ & $-0.057 \mathrm{n} / \mathrm{s}$ & $0.200^{*}$ \\
\hline $\mathrm{DEP} \rightarrow \mathrm{IC}$ & $0.307^{*} *$ & $0.018 \mathrm{n} / \mathrm{s}$ & $0.163 \mathrm{n} / \mathrm{s}$ \\
\hline $\mathrm{MAG} \rightarrow \mathrm{IC}$ & $0.220^{* *}$ & $0.091 \mathrm{n} / \mathrm{s}$ & $0.268^{*}$ \\
\hline R-square (IC) & 0.396 & 0.013 & 0.168 \\
\hline
\end{tabular}

Note: * Significant at $0.05 * *$ Significant at $0.01 \quad \mathrm{n} / \mathrm{s}$ not significant

As can be seen in Table 5.14, for the whole sample all three dimensions of ERP implementation scope have positive significant effects on intellectual capital. However, while two dimensions - breadth and magnitude - positively significantly affected intellectual capital for the group representing high OLC ( $\beta=0.2$ and $\beta=0.268$ respectively), none of the ERP implementation dimensions showed any significant effects on intellectual capital for organizations with low OLC. The observed results 
support the main hypotheses ( $\mathrm{H} 1 \mathrm{a}, \mathrm{H} 1 \mathrm{~b}$, and $\mathrm{H} 1 \mathrm{c})$ and two of the three moderating hypotheses ( $\mathrm{H} 2 \mathrm{a}$ and $\mathrm{H} 2 \mathrm{c})$.

\subsubsection{Product term approach}

In the product term approach, instead of dividing the sample into subsamples, an additional variable is be added to the structural model. This variable represents the product of the independent variable and the moderator variable (Henseler \& Fassott, 2010). With the presence of second-order constructs in the model, the study followed the procedure suggested by Henseler and Fassott (2010) and Henseler and Chin (2010). A two-stage approach was used. The first stage was an analysis of the structural model in which two second-order constructs OLC and IC were measured by the indicators of their first-order constructs; then the PLS algorithm was implemented to obtain the latent variable scores (LVS) for the main constructs (BRE, DEP, MAG, OLC, and IC). In the second stage LVS obtained in stage 1 were used to estimate the parameters of the structural model. Then, to assess the contribution of OLC as a moderator, two models were used (see Figure 5.2).

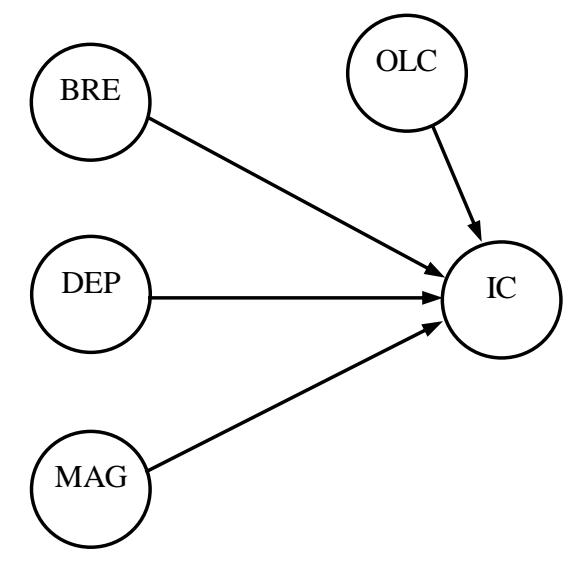

Main effects

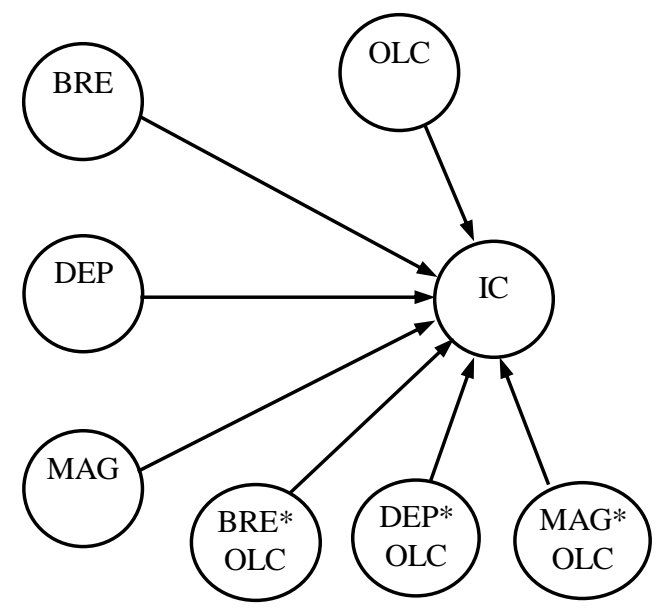

Moderation effects

Figure 5.2 Structural models for moderating effect analysis using the product term approach

The first model only included the direct effects of BRE, DEP, MAG, and OLC on IC. The second model additionally included product terms (i.e., BRE*OLC, DEP*OLC, 
and MAG*OLC). The product terms were calculated manually using MS Excel. They are the products of the scores of OLC with the scores of BRE, DEP, and MAG.

The path coefficients were calculated for the paths in the two models. The calculation was performed using the PLS algorithm and bootstrapping technique with bootstrap samples of at least 5,000; each sample contains 226 observations to determine the coefficients' significance (Hair et al., 2014).

Table 5.15 Moderating effect analysis using the product term approach

\begin{tabular}{|l|c|c|}
\hline \multirow{2}{*}{ Path } & \multicolumn{2}{|c|}{ Path coefficient } \\
\cline { 2 - 3 } & Model 1 (main effects) & Model 2 (interaction effects) \\
\hline $\mathrm{BRE} \rightarrow \mathrm{IC}$ & $0.155^{* *}$ & $0.144^{* *}$ \\
\hline $\mathrm{DEP} \rightarrow \mathrm{IC}$ & $0.175^{* *}$ & $0.164^{* *}$ \\
\hline $\mathrm{MAG} \rightarrow \mathrm{IC}$ & $0.124^{*}$ & $0.156^{* *}$ \\
\hline $\mathrm{OLC} \rightarrow \mathrm{IC}$ & $0.466^{* *}$ & $0.492^{* *}$ \\
\hline $\mathrm{BRE} * \mathrm{OLC} \rightarrow \mathrm{IC}$ & & $0.043 \mathrm{n} / \mathrm{s}$ \\
\hline $\mathrm{DEP} *$ OLC $\rightarrow$ IC & & $0.027 \mathrm{n} / \mathrm{s}$ \\
\hline $\mathrm{MAG}$ OLC $\rightarrow$ IC & & $0.117 *$ \\
\hline $\mathrm{R}-\mathrm{square}(\mathrm{IC})$ & 0.517 & 0.537 \\
\hline
\end{tabular}

Note: * Significant at $0.05 * *$ Significant at $0.01 \quad \mathrm{n} / \mathrm{s}$ not significant

The results in Table 5.15 show that for Model 1 all dimensions of ERP implementation scope and OLC had significant effects on IC. However, in Model 2 the results depict substantial differences in the patterns of interaction between ERP implementation scope and the organizational learning level. With the presence of the moderation effects, only the magnitude of ERP implementation has a significant moderation effect by OLC on IC. Therefore, while the results support all the main hypotheses (H1a, H1b, and H1c) only one of three moderating hypotheses $(\mathrm{H} 2 \mathrm{c})$ is supported by the results. For the strength of the moderating effect, the overall effect size $f^{2}$ was:

$$
\mathrm{f}^{2}=\frac{\mathrm{R}_{\text {interaction model }}^{2}-\mathrm{R}_{\text {main effect model }}^{2}}{1-\mathrm{R}_{\text {interaction model }}^{2}}=\frac{0.537-0.517}{1-0.537}=0.0432
$$


The values of effect size $\left(f^{2}\right) 0.02,0.15$, and 0.35 have been suggested as small, moderate, and large respectively (Cohen, 1988, p. 410). The result of the effect size in this study is in the range of small and moderate.

\subsection{Chapter summary}

This chapter reported the descriptive analyzes, assessment of data, assessment of measurement models, and assessment of the structural model. The analysis showed sufficient data quality and validity of the measurement models. The results of regression analysis supported the three main hypotheses (H1a, H1b, and $\mathrm{H} 1 \mathrm{c})$. As for moderating effect, when the group comparison approach is used, there is a different relationship between each of two dimensions of ERP implementation scope (i.e. BRE and MAG) and IC for each level of OLC (supported H2a and $\mathrm{H} 2 \mathrm{c}$ ). When the product term approach is used, only the interaction of MAG and OLC has a relationship on IC (supported $\mathrm{H} 2 \mathrm{c}$ ). The next chapter will provide further discussion on the findings and the answers to the research questions. 


\section{CHAPTER 6}

\section{DISCUSSION AND CONCLUSION}

This study examines the relationship between the extent or scope of ERP implementation, intellectual capital, and organizational learning capability. Having presented the research model and hypotheses and analyzed data in the preceding chapters, this chapter presents a discussion of the results, contributions of the study to theory and practice, limitations, suggestions for future research, and final conclusions.

\subsection{Discussion of the results}

\subsubsection{Summary of the results}

The analysis of the data showed that the three dimensions of ERP implementation scope (breadth, depth, and magnitude) have a positive effect on intellectual capital, which is the sum of all knowledge of a firm residing in human capital, organizational capital, and social capital (Youndt \& Snell, 2004). The findings showed that organizational learning capability has a partial moderating effect on the relationship between the scope of ERP implementation and intellectual capital. The moderating effect was analyzed using two approaches. By using the group comparison approach, the group of firms with a high level of organizational learning capability exhibit significant relationships between the breadth and magnitude of ERP implementation scope and intellectual capital, whereas the low-level group does not have any significant relationships between these variables. By using the product term approach, only the magnitude of ERP implementation scope has an interaction with organizational learning capability that in turn has an effect on intellectual capital. These results will be expanded in the next section.

\subsubsection{Discussion of the research questions}

This study has two research questions. This section presents a discussion of the results related to these questions 
Research question 1: To what extent does the scope of ERP implementation lead to the enhancement of intellectual capital?

Research question 2: What is the moderating effect of organizational learning capability on the relationship between the scope of ERP implementation and the enhancement of intellectual capital?

To what extent does the scope of ERP implementation lead to the enhancement of intellectual capital?

The findings addressing the original hypotheses presented in chapter 5 suggest that the three dimensions of the scope of ERP implementation have a positive relationship with intellectual capital. Thus, when the breadth, depth, and magnitude of an ERP implementation have greater scope, a firm is likely to accumulate more intellectual capital. These relationships are presented in turn as follows.

The breadth dimension reflects the geographical scope of ERP implementation including the system (hardware and software) and business process reengineering (Barki et al., 2005). It is posited that the breadth of ERP implementation is positively associated with intellectual capital. First, the breadth of ERP implementation positively influences the human capital of a firm. The geographical scope of business process reengineering and ERP system implementation is positively associated with enhancement of the understanding and skills of staff using the system because an ERP system facilitates the processes of capture, retention, and application of organizational knowledge (Perez \& Ramos, 2013) by means of central data storage, standardized business processes, and integrated functions (Davenport et al., 2004). In order to use the new system effectively the users need to grasp the best ways of exploiting the system's features, to understand the business data it can generate, and how to create appropriate and valuable reports. Second, organizational capital which consists of institutionalized knowledge and codified experience residing in databases, manuals, systems, structures, and processes - is affected by the breadth of 
ERP implementation because a wider geographical spread of system (hardware and software) installation increases the capturing, processing, storing, and sharing of information. The system enables the firm to build a repository of information in which organizational capital can be increased and improved, such as statistical documentation about customers, products, services, process capabilities, etc. The geographical range of business process reengineering, despite not reflecting the amount of business process reengineering, indicates the extent of the optimization of a firm's related business processes to perform a particular business objective (Davenport et al., 2004). Third, in terms of social capital, the breadth of ERP implementation enhances the value of the relationships among employees and with a firm's partners. A higher degree of breadth in an ERP implementation is associated with a wider spread of staff members who learn and use the system; therefore, in order for this to happen efficiently it requires the cooperation and exchange of information among individuals and workgroups. It also requires an extensive spread of knowledge exchange between the client firm and the system provider and any consultants who are involved with the ERP. They need to cooperate with each other to understand the firm's business requirements and to implement the appropriate system and business process reengineering across a wide geographical range. This should lead to improved ERP capabilities, including more extensive data capture, recording, processing and reporting. These capabilities facilitate better customer services and supplier relationships (Forslund, 2010).

For the second dimension of depth, the data analysis reported in Chapter 5 shows that a higher scope of ERP implementation is likely to lead to an increased accumulation of intellectual capital. The depth of ERP implementation is represented by the percentage of system users and the percentage of people whose activities changed due to the system implementation. First, human capital has a positive association with the depth of an ERP implementation. When people use a new system they must learn to change their activities to suit it, and as a result their knowledge, understanding, and job skills are consolidated and possibly enhanced. Second, the organizational capital of a firm is also improved with deeper ERP implementation. The system's users have more options to access the information stored in the system, and to use ERP system 
functionalities to perform various task routines. The firm's management has more flexibility in decision making and is able to make more timely decisions due to the reporting system. Therefore, because a higher number of users, including managers, have changed their activities it means that the amount of information, business transactions, and the flow of data processing stored in the system is greater than it was before. Third, because social capital is characterized in part by the relationships amongst employees, it is also enhanced because they need to cooperate while learning new features of the system and when dealing with difficulties as a result of changing their old work activities. The learning occurs not only in employees' heads; it occurs in the form of social processes in which people work and interact in groups or communities of practice (Brown \& Duguid, 1991).

For the third dimension of ERP implementation, the results show that magnitude is found to have a positive relationship with intellectual capital. Magnitude is determined by the amount of business process reengineering, the extent of business automation, and the extent of non-customization of the system (Barki et al., 2005). Magnitude represents neither the scope of ERP implementation in terms of geographical size nor the percentage of system users; it measures how much the system implementation changes a firm's business processes and staff work activities. It is posited that the intellectual capital of a firm is influenced by this dimension. Similar to the breadth and depth of ERP implementation, the magnitude of ERP implementation has a positive impact on human capital, organizational capital, and social capital. The change in business processes and work activities is associated with learning, as people have to unlearn what they already know in order to learn and understand the ERP system and new business processes associated with it (Robey et al., 2002). As a consequence, there is an improvement in people's understanding, knowledge and skills related to doing the tasks and as a result the human capital of the firm is affected positively. A higher degree of magnitude of ERP implementation leads to more seamless integration and improved efficiencies in business processes. The business automation is associated with the transformation of business processes from manual or early automation to later automation. An ERP system typically comprises standardized modules, which provide appropriate data and reports for 
decision making and controlling. The scale of business process reengineering and the degree of non-ERP customization reflect the extent to which the firm changes its old business processes to become more optimal. Due to these changes, the databases, manuals, and processes of the firm become more standardized and efficient. These standards become knowledge and thus part of organizational capital. The social capital of a firm also has a positive influence. The mutual coordination and cooperation among employees are enhanced when they learn to change their work activities during business process reengineering. A greater degree of change in business processes and work activities during the implementation means that the firm needs to maintain and manage the relationships with its ERP vendor and consultants. Moreover, the customer relationship is strengthened because the improved business processes makes the ERP system more capable both in delivering the firm's products and in meeting customer service (Forslund, 2010).

What is the moderating effect of organizational learning capability on the relationship between the scope of ERP implementation and the enhancement of intellectual capital?

The second research question of this study focuses on the role of organizational learning capability. It was argued in Chapter 3 that when a firm implements an ERP system, the firm is involved in learning, which comprises developing knowledge processes to overcome knowledge barriers. Therefore the organizational learning capability, which represents the conditions and learning facilitators of an organization, plays a critical role in fostering the result of this learning. In the research model, the study examined the moderating effect of organizational learning capability on the relationship between the scope of ERP implementation and intellectual capital. The moderating effect of organizational learning capability was examined using two approaches: group comparison and product term.

a) In the group comparison approach, organizational learning capability exhibits a moderating effect on the relationship between the scope of ERP implementation and intellectual capital. For firms with lower levels of 
organizational learning capability (see Chapter 5), the three dimensions of ERP implementation scope are found to have no significant relationship with intellectual capital. However, for firms with higher levels of organizational learning capability, the breadth and magnitude of ERP implementation are found to have a positive relationship with intellectual capital. Thus, for firms with a higher capability to learn, when the breadth or magnitude of an ERP implementation is greater, firms are more likely to accumulate intellectual capital. A higher degree in the breadth (i.e. the geographical range of business process reengineering and the installation of the system) and in the magnitude (i.e. the amount of business process reengineering and business process automation) means that a firm has to learn to absorb not only business process knowledge but also technical knowledge to implement the system successfully. Organizational learning capability is represented by the conditions and facilitators for effective learning including managerial commitment, systems perspective, openness and experimentation, and knowledge transfer and integration (Jerez-Gómez et al., 2005). These factors support the firm in implementing ERP. The findings are in line with previous studies, for example, the support of top management is crucial for the success of an ERP implementation (Dezdar \& Ainin, 2011). In addition, top management must have commitment and involvement in the ERP project, and create the conditions for their staff to learn and use the system. Also, a systems perspective is very important to an ERP implementation, all levels of a firm must work together to coordinate and integrate the diverse knowledge that is isolated in different places into business process knowledge embedded in the ERP system (Ke, Wei, Chau, \& Deng, 2003). The factor of "openness and experimentation" is also important; firms need to create an environment that encourages employees to develop novel and innovative suggestions for ERP implementation and business process optimization (Ke et al., 2003). In addition, knowledge transfer between a firm and its ERP consultants or vendors helps the firm to get a better understanding of the business processes and system functionality, which results in a better fit between organizational 
processes and the ERP system (Wang et al., 2007) and higher effectiveness of an ERP implementation (Maditinos et al., 2011).

As for the depth of ERP implementation, results of the analysis using the group comparison approach show that it has no significant relationship with intellectual capital for firms of any level of organizational learning capability. The depth of ERP implementation is characterized by the percentage of system users and the percentage of people whose activities are changed due to system implementation. The explanation for this lack of a significant relationship may be that learning at the individual level is different from learning at the organizational level. Organizational learning capability is defined as a construct at the organizational level (López-Cabrales et al., 2011), whereas the percentage of system users and the percentage of people whose activities have been changed are more likely to be associated with the individual level. According to Crossan, Lane, and White (1999), different processes exist at different levels of learning. For example, interpretation is the key process at the individual level, while integrating and institutionalizing are the key processes at the group and organizational levels. The percentage of system users and people whose activities have changed due to system implementation may not completely reflect the effectiveness of the whole learning process at an organizational level.

b) Unlike the group comparison approach, the product term approach considers organizational learning capability and its interactions with three dimensions of the scope of ERP implementation as the variables in the regression model. The results show that the three dimensions of the scope of ERP implementation and organizational learning capability have a positive impact on intellectual capital. Organizational learning capability represents the conditions and facilitators that support the learning process, leading to a broadening of organizational knowledge or intellectual capital. Moreover, the breadth, depth, and magnitude of the scope of ERP implementation also have a direct effect on intellectual capital. The extent of the installation of an ERP 
system, business process reengineering (in terms of scope and amount), business process automation, and the proportion of system users and people with changed activities positively affect the knowledge residing in a firm's people (human capital), the firm's structures, databases and processes (organizational capital), and the relationships among employees and with a firm's partners (social capital).

When the interaction effect of organizational learning capability is considered, of the three dimensions only the magnitude of ERP implementation interacts with organizational learning capability to have a significant effect on intellectual capital. The breadth and depth of ERP implementation reflect the horizontal and vertical diffusion of technology and business process reengineering across the firm; they appear to have minimal interaction with organizational learning capability. The magnitude represents the amount of business process reengineering, the change in staff work activities, and the degree of business process automation. Therefore, in comparison with the other two dimensions, this dimension is mostly associated with organizational change and transformation and thus significantly interacts with learning capability to create intellectual capital.

In short, the two research questions of this study were answered through the development and validation of a model. The relationships between the scope of ERP implementation and intellectual capital under the moderating effect of organizational learning capability were investigated. Specifically, the three dimensions of ERP implementation scope (breadth, depth, and magnitude) in general were found to be positively related to intellectual capital. However, group comparison analysis reveals that without an adequate level of organizational learning capability, firms do not gain any benefit from ERP implementation on intellectual capital. When considering the interaction of organizational learning capability with the three dimensions, it was found that only the magnitude of ERP implementation interacting with organizational learning capability will have a significant effect on intellectual capital. 


\subsection{Theoretical implications}

The area of concern is this study is placed around the ability of ERP to produce competitive advantage. In this study, it is argued that ERP can become strategically valuable through the interaction with and the enhancement of other organizational resources. This study attempts to link the scope of ERP implementation and other organizational resources in the forms of organizational learning capability and intellectual capital. By doing so, this study provides significant evidence to contribute to the literature on the effects of ERP on organizations.

Existing studies on the effects of ERP at the organizational level express concern about the ability of ERP to produce competitive advantage. Competitive advantage is measured along with a range of other measures in organizational impact of IS-impact model (Ifinedo, 2006); in learning and growth aspect of the balanced scorecard approach (Chang et al., 2011); and in strategic benefit of the five-category framework (Shang \& Seddon, 2002). Drawing on the literature on IT business value, the current study argues that it is inadequate to measure the direct relationship between ERP and competitive advantage, another aspect of the effect of ERP on organizations needs to be explicitly examined, which is the relationship between ERP and organizational resources.

The consensus in the literature on IT business value has is that IT resources alone are not enough to help firms to achieve better performance. IT resources do not have the traits of strategic resources according to the RBV. In order for IT resources to become valuable firm-specific assets and help firms achieve superior performance, other organizational resources need to exist too (Melville et al., 2004; Wade \& Hulland, 2004; Zhang \& Lado, 2001). IT resources can help firms improve their capability and other resources (Zhang \& Lado, 2001). Extending on this literature, the current study provides results showing that ERP implementation can help firms enhance intellectual capital, which is an important resource for business (Youndt et al., 2004). The results also indicate the importance of the presence of organizational learning capability. Firms should have a certain level of learning capability to achieve improvement in the intellectual capital created by an ERP implementation. The 
results confirm the notion that the relationship between ERP and other organizational resources should be explicitly examined in the literature on the effects of ERP, and should be considered prior to any attempt to identify the ability of ERP to produce competitive advantage.

Beside the effects of ERP implementation, the current study makes a contribution to the literature on ERP in general. First, recent surveys of the ERP literature have shown that research on ERP mainly focuses on the areas of the implementation of ERP and ERP usage, and there is a limited number of studies in the area of ERP value (Addo-Tenkorang \& Helo, 2011; Moon, 2007). The current study provides a contribution to this area when it investigates the strategic value of ERP in terms of the impact of the scope of ERP implementation on firms' intellectual capital. Second, this study contributes by providing evidence on the success of ERP systems. Many studies have emphasized the importance of ERP use and used it as a dependent variable. According to Hwang, Al-Arabiat, and Shin (2015, July) and Robey (1979), when the use of an information system is mandatory, it provides little information about the system's success. In the context of ERP implementation, the decision to implement ERP systems comes from top management staff, therefore the use of ERP systems in organizations is mostly mandatory, thus ERP use does not reflect the system's success. This study concentrates on post use of ERP and examines the impact of ERP implementation on intellectual capital. The empirical outcomes provide an additional measure for the success of the system.

Looking at the relationship between IT and intellectual capital, the results of this study propose that any technology, which includes a change in business processes, can create intellectual capital. In this study, the results show that ERP implementation scope has a positive impact on intellectual capital. ERP implementation is related to business process reengineering, which requires learning and knowledge and skill formation within a firm. Similarly, intellectual capital of a firm is likely to have a positive impact when it implements a technology that involves changes to business processes. 
Finally, in terms of the research model's constructs, this study attempts to explore the relationship between the constructs that have been established in prior studies: ERP implementation scope, organizational learning capability, and intellectual capital. The findings help to consolidate the practical use of these constructs.

\subsection{Managerial implications}

A great concern for managers is how investment in IT (e.g. ERP) can help firms achieve competitive advantage or superior performance. This study provides additional insights into the possibility that ERP implementation can improve intellectual capital within a firm, which is an important resource for competitive advantage. The results from this study suggest that investment in all three dimensions of ERP implementation (breadth, depth, and magnitude) can improve intellectual capital. However, managers should pay careful attention to the learning capability of the firm in order to obtain greater impact of the scope of ERP implementation on intellectual capital.

ERP implementation requires some learning in a firm, therefore managers should pay attention to building the conditions and facilitators for learning throughout the firm, namely managerial commitment, openness and experimentation, system perspective, and knowledge integration and sharing. The management team should provide support for learning as well as create a supportive learning environment. They should have a commitment to learning during an ERP implementation. As an ERP implementation is considered an IT innovation, managers should have policies to foster openness and experimentation with new ideas for business processes embedded in the ERP system. During an ERP implementation, firms should have a systems perspective to support the integration of many departmental functions. In other words, firms should have the ability to identify a shared goal and consider the interdependency of organizational factors during ERP implementation. Finally, managerial people should consider creating the conditions for knowledge transfer and integration in order to obtain the maximum effectiveness from ERP implementation. These conditions are important because in ERP projects, employees in different 
organizational functions need to share their knowledge on how business is done using the relevant processes embedded in the ERP.

As for the scope of ERP implementation, among the three dimensions of ERP implementation, managers should pay particular attention to the magnitude dimension. This dimension is most closely associated with organizational change and transformation. It requires learning capability to deal with and embrace the change necessary for the enhancement of intellectual capital.

\subsection{Limitations of the research}

As in any empirical research, there are some limitations that need to be mentioned.

First, it is stated that many organizational factors and environmental factors (e.g. characteristics of industry and country) have relationships with IT resources to shape business activities and influence a firm's ability to achieve competitive advantage and business performance (Melville et al., 2004). ERP systems use IT, therefore, it is expected that their business value is influenced by many factors. Within the scope of this study, the focus is only on examining the relationship between ERP implementation and only two organizational factors: organizational learning capability and intellectual capital. They are two key attributes of any firm when a firm is considered a learning entity (McElyea, 2002; Nevis et al., 1995; Nonaka et al., 2000). Additionally, with such a focus the study does not attempt to identify all possible effects of ERP that have been identified in prior studies.

Furthermore, the factor of time or response lag was not taken into account in this study. The validity of the findings regarding the relationship between the scope of ERP implementation and organizational learning capability as well as intellectual capital may not be enhanced by the fact that data on these aspects were collected at the same point in time. Although all the sampled firms had experienced at least one year of ERP operation, data collection at the same point in time may not reveal the complete phenomenon. A longitudinal study may be an alternative approach to gain more insights into this phenomenon. 
Second, the research findings may not reflect the effectiveness of a particular brand name of ERP system because the scope of ERP implementation used in this study was measured by the three generic dimensions (breadth, depth, and magnitude). It could be argued that different types of ERP may have different impacts on a firm. Nevertheless, because this study is a quantitative exploration of the relationship between the scope of ERP implementation and two organizational factors, it is adequate to apply these three generic dimensions that represent the implementation scope of any type of ERP.

Third, the results of this study may suffer from informant bias (see Chapter 4). This study used separate informants for the two parts of the questionnaire. The first part is about the scope of ERP implementation. Most of the measurement scales in this part are ordinal or ratio, therefore using a single respondent for this part was unlikely to create informant bias. However, the second part may incur this bias. In this part, perceptual measurement scales were used to measure organizational learning capability and intellectual capital. Although the respondent for this part was a manager who exhibited knowledge about what she or he answered through the selfevaluation question, the use of only one respondent may not completely provide true information about these organizational constructs.

Finally, as is the case in any research, a completely random sample is difficult to achieve. This study could not research firms in all regions of Vietnam, it only took manufacturing firms located in Ho Chi Minh City and Dong Nai province as the target population. Additionally, this study could not identify all manufacturing firms having implemented ERP, instead, a list of firms was established from two sources: ERP providers and the 2013 Vietnam Business Directory. These issues may have produced a lack of generalizability of the results to the whole population to which the sample belongs. 


\subsection{Future research}

The aforementioned limitations of the study reveal a number of opportunities that would be worthwhile for further research to expand and supplement the current body of knowledge in the literature of ERP business value creation.

First, future research could further examine this phenomenon to achieve a deeper insight. In this study, a quantitative approach is used to provide an initial view on the relationship between the scope of ERP implementation and two important organizational factors: organizational learning capability and intellectual capital. Future research can expand the results based on two themes, both illustrated in the lower half of Figure 6.1: the virtuous circle of the relationship between ERP implementation and learning capability, and the mediation effect of learning capability within that circle.

\section{THIS RESEARCH}

Moderation effect of organizational learning capability

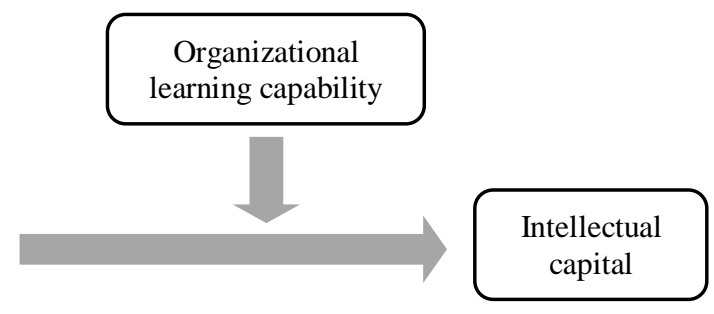

FUTURE RESEARCH

Mediation effect of organizational learning capability in a virtuous circle of strategic ERP implementation

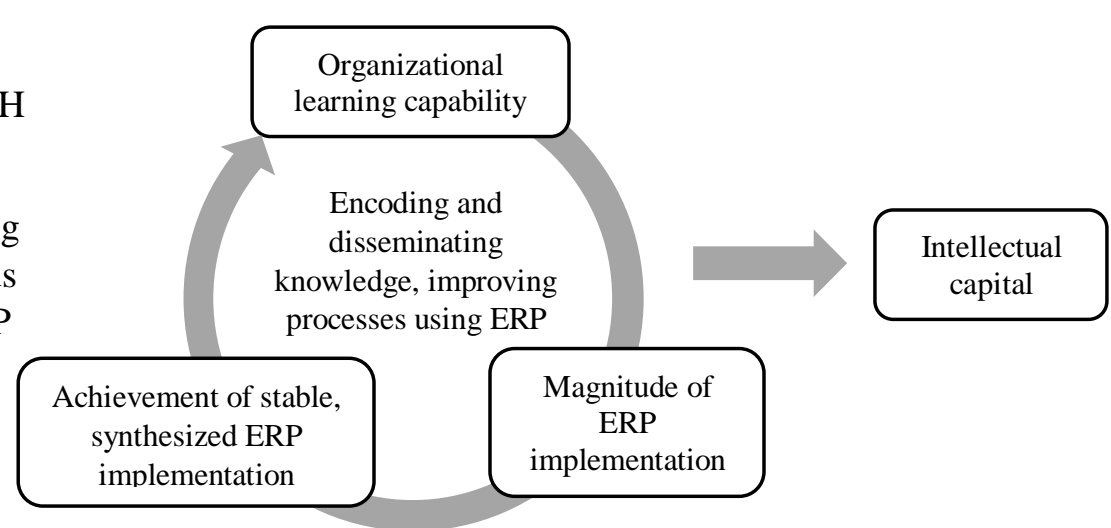

Figure 6.1 The virtuous circle of strategic ERP implementation

As presented in Chapter 3, informed by the relationship between organizational learning and information technology (Robey et al., 2000), the relationship between organizational learning and ERP implementation can be investigated within two 
themes: organizational learning occurs during ERP implementation and use, and organizational learning is supported by ERP implementation. This study is positioned in the former theme, it considers an ERP implementation as learning and examines the role of organizational learning capability (i.e. conditions and learning facilitators) as a factor that fosters this learning, and as a result a firm accumulates intellectual capital. The study does not examine the impact of ERP implementation on learning capability.

Furthermore, according to Baron and Kenny (1986) and Venkatraman (1989), a moderator is a variable that influences the strength of an effect or relationship between two variables, while a mediator is a variable that intervenes in or accounts for the relationship between two variables. In other words, moderator variables indicate when or under what conditions an effect can be expected. Mediator variables explain how or why an effect or relationship occurs. In this study, organizational learning capability is examined as a condition for the effect of ERP implementation scope on intellectual capital to happen, the study has not provided the information on how and why the effect can occur.

Given these points, a direction for future research is proposed in the lower half of Figure 6.1. In this, organizational learning capability affects and is affected by ERP implementation and improve intellectual capital. In a firm, some level of organizational learning capability is a pre-condition for the ability to change and improve business processes, which is measured in the magnitude of ERP implementation. In turn, as ERP implementation is completed and the firm goes through the stable and synthesized stage, the learning capability to carry out process improvement is supported, reinforced and embedded by the ERP. A continuation of this circle leads to the ERP system improving organizational learning capability as business processes are improved; knowledge is encoded and disseminated through the firm. This in turn adds to the value of the intellectual capital of the firm.

For such future research, there may be a need for longitudinal data. Therefore a qualitative and/or quantitative study with longitudinal data collection could provide an explanation in detail of how learning facilitators can capitalize upon ERP 
implementation in terms of fostering intellectual capital. The results of such research can help to supplement this study's results.

Second, in a broader view of the relationship between ERP and competitive advantage, further research could include other organizational factors into a more comprehensive model to explain how an ERP implementation leads to superior organizational performance or competitive advantage. Such research will provide a better and fuller understanding of the mechanism through which ERP systems bring value to firms.

Third, the characteristics of environmental factors could be considered in a comparative study in the future. In this present study, the three constructs of the research model are generalizable concepts, therefore the research model can be applied in other countries to understand the relationship between the scope of ERP implementation, intellectual capital, and organizational learning capability. However, more insights could be obtained in a comparative study conducted in several countries with different characteristics, such as IT maturity, IT/IS knowledge, and business process reengineering experience. For example, the studies comparing ERP implementation between developed and developing countries have found that companies in developing countries are more dependent on ERP vendors (Moohebat, Asemi, \& Jazi, 2010), have a lack of business process reengineering experience, and have limited level of IT/IS knowledge (Huang \& Palvia, 2001). In countries that vary on these characteristics there might be a significant difference in the strength of the relationships between the variables in the research model, especially the role of learning capability in leveraging ERP implementation to obtain the value of intellectual capital. The Vietnam context could be used in this type of study to compare it with other contexts, however the criteria to select the contexts need to be examined so that they represent typical differences and not unusual ones.

Fourth, future research could utilize a dynamic capability perspective to investigate the relationship between ERP implementation and the dynamic capabilities of firms. This study investigated the ability of ERP implementations to enhance firms' resources (i.e. intellectual capital) that can help the firms produce competitive 
advantage. However, owning resources does not guarantee that firms have a competitive advantage in the long term (Priem \& Butler, 2001). Present markets are highly dynamic, so firms need to respond constantly to market changes. In this view, the dynamic capabilities of firms are important. Dynamic capabilities refer to the capacity of firms to integrate and reconfigure internal and external resources and functional competencies to deal with a constantly changing environment (Teece, Pisano, \& Shuen, 1997). Future research could, for example, examine whether ERP implementations hinder or facilitate firms' dynamic capabilities, whether ERP implementations and firms' dynamic capabilities are complementary, and if the relationship between ERP implementation and the firms' resources produces competitive advantage over the long term.

Finally, to be able to generalize the results of this study, future research might be extended to other industries in the services and/or non-manufacturing sectors.

\subsection{Conclusion}

Based on the literature on IT business value creation and the effects of ERP (particularly the possibility that ERP implementation leads to competitive advantage of a firm), this study investigated the relationship between the scope of ERP implementation and two other organizational resources: organizational learning capability and intellectual capital. The study answers two research questions: (1) to what extent does the scope of ERP implementation lead to the enhancement of intellectual capital; and (2) what is the moderating effect of organizational learning capability on the relationship between the scope of ERP implementation and the enhancement of intellectual capital? The rationale for the research questions of this study is twofold. First, ERP implementation is considered an opportunity for organizational learning and through which the sum of knowledge or intellectual capital is accumulated. Second, the examination of the relationship between ERP and other organizational resources (e.g. organizational learning capability and intellectual capital) is necessary for future studies on the achievement of competitive advantage due to ERP implementation. 
The empirical results of regression analysis of data collected from a sample of 226 firms revealed that the breadth, depth, and magnitude of the scope of ERP implementation leads to the enhancement of intellectual capital and that organizational learning capability more or less moderates the relationship between ERP implementation scope and intellectual capital. In the group comparison approach for moderation analysis, firms with low levels of organizational learning capability are likely to experience no effect of ERP implementation on intellectual capital but for firms with a high learning capability level the breadth and magnitude of ERP implementation have a positive effect on intellectual capital. In the product term approach, only the magnitude of ERP implementation shows an interaction effect with organizational learning capability on intellectual capital, but the breadth and depth of ERP implementation appear to have minimal interaction with organizational learning capability.

The study, relying on the literature of IT business value, provides significant evidence to contribute to the literature on the effects of ERP on organizations by demonstrating that an ERP system can become a strategic asset as its implementation has a positive effect on organizational resources (e.g. intellectual capital) especially with the presence of the capability to learn. The study also provides a variety of practical recommendations for business executives on how to utilize organizational learning capability to capture the potential knowledge creation inherent in ERP systems. Finally, the study suggests some opportunities for future research. 
Appendices

APPENDICES

APPENDIX A. English Version of the questionnaire 


\section{Participant Information Sheet for Part A}

Research Project Title: The relationship between enterprise resource planning (ERP) implementation and intellectual capital under the moderating effect of organizational learning capability

\section{Researcher: Nguyen Vu Quang, School of Information Management, Victoria University of Wellington}

Dear Survey Participants

Regarding the implementation of ERP in your organization, you may be interested in the following questions:

- How does the extent of ERP implementation affect the sum of all knowledge (or intellectual capital) of your organization?

- To what extent does the degree of your organizational learning capability influence the effect that ERP implementation has on the intellectual capital of your organization?

To help you address such important questions, I am conducting a PhD research project to evaluate the relationships between the implementation of ERP, intellectual capital, and learning capability in organizations. If you request a copy you will receive an executive summary report of this study, which will provide profiles and suggestions on how the scale of ERP implementation influences the intellectual capital in your organization and the role of organizational learning capability on the extent of this effect.

The questionnaire seeks information on the scale of ERP implementation. It should be filled in by the senior manager in charge of IT/IS or ERP governance in the organization. The survey will take about 20 minutes to complete.

The research is approved by Victoria University of Wellington of Wellington that requires, and has granted, approval from the School's Human Ethics Committee.

Participation is voluntary. You will not be identified personally in any written report produced as a result of this research, including possible publication in academic conferences and journals. Also, no information will be released that makes it possible to identify specific organizations. All material collected will be kept confidential, and will be viewed only by myself and my supervisor Dr Philip Calvert. The thesis will be submitted for marking to the School of Information Management, and subsequently deposited in the University Library. All collected data will be destroyed within two years after the completion of the project.

Your contribution to the success of this research project is deeply appreciated. We look forward to receiving your completed survey. Thank you very much in advance for your time and your support. If you have any questions or would like to receive further information about the project, please contact me at quang.v.nguyen@vuw.ac.nz or telephone (+64 4 4635528), or you may contact my supervisor Dr Philip Calvert at philip.calvert@vuw.ac.nz or telephone (+64 4 4636629).

Mr. Nguyen Vu Quang 
PART A - A SURVEY ON SCOPE OF ENTERPRISE RESOURCE PLANNING (ERP) IMPLEMENTATION

This questionnaire is for IT/IS manager. It will take about 20 minutes to complete the questionnaire.

\section{Definition of key terms}

Organization: an independent company, a parent company, a wholly owned subsidiary or a division of a company where the respondent works at, is most familiar with, and knows best. An organization is an entity that has own financial statements

ERP: an enterprise-wide information system of an organization that utilizes information technology with the promise of integrating and optimizing all of business processes and departmental functions. An ERP package may or may not include functions of customer relationship management (CRM), supply chain management (SCM), and E-commerce

Please respond to all questions or statements in this questionnaire to the best of your knowledge.

1. Your job title:

2. How long have you been in this organization:

3. Which ERP package has your organization implemented? (Please tick ONLY ONE box, the main ERP package)
$\square$ SAP
$\square$ SS4U (ERP B4U)
$\square$ Oracle
$\square$ Pythis (PERP)
Fast Business
$\square$ Microsoft
$\square$ Vietsoft ERP
$\square$ LacViet
$\square$ Other, please specify:

4. How long ago did your organization start the implementation of the ERP package?
$\square$ Less than one year
$\square 2.5$ years to $<3$ years
$\square$ one year to $<1.5$ years
$\square 3$ years to $<3.5$ years
$\square 1.5$ years to $<2$ years
$\square 3.5$ years to $<4$ years
$\square 2$ years to $<2.5$ years
$\square 4$ years or above

5. Has your organization finished the implementation of the ERP package?
$\square$ Yes
$\square$ No

6. Has your organization started to use some modules of the ERP package?
$\square$ Yes
$\square$ No

7. How long ago did your organization start to use the ERP package or some its modules?
$\square$ Less than one year
$\square 2.5$ years to $<3$ years
$\square$ one year to $<1.5$ years
$\square 3$ years to $<3.5$ years
$\square 1.5$ years to $<2$ years
$\square 3.5$ years to $<4$ years
$\square 2$ years to $<2.5$ years
$\square 4$ years or above

8. Please indicate the extent to which the ERP system currently in-use (including hardware and software) is diffused horizontally across your organization:

$\begin{array}{cccc}\text { Single site } & \text { Multiple sites in } & \text { Multiple sites in } & \text { Multiple sites in } \\ \text { one region } & \text { several regions } & \text { multiple regions } & \text { Multiple sites } \\ \text { across nation } & & \text { internationally }\end{array}$

9. How large in terms of geographical size is your organization?

Single site

\section{Multiple sites in one region}

Multiple sites in

several regions
Multiple sites in multiple regions across nation
Multiple sites

internationally 
10. Please indicate the extent to which the implementation of Business Process Reengineering (BPR) is diffused horizontally across your organization when the ERP package is implemented:

Small number of
people within a $\quad \begin{gathered}\text { Mopartment than one } \\ \text { department }\end{gathered} \quad \begin{gathered}\text { A region } \\ \begin{array}{c}\text { More than one } \\ \text { region }\end{array}\end{gathered}$
department

11. Please estimate the number of users of the ERP package in your organization: (users)

12. Please indicate the number of employees whose activities have changed due to the implementation of ERP? (employees).

13. The percentage of organizational processes that have been changed, automated or standardized before the implementation of ERP is: $\%$

14. The percentage of organizational processes that have been changed, automated or standardized after the implementation of ERP is: $\%$

15. Please indicate your perception of the degree to which the ERP package is modified to conform to your organizational processes $(0=$ no modification; $10=$ complete modification $)$

$$
\begin{array}{lllllllllll}
0 & 1 & 2 & 3 & 4 & 5 & 6 & 7 & 8 & 9 & 10
\end{array}
$$

16. On average, what is the percentage of the organizational processes that are modified to align with the ERP package? $\%$

17. Please indicate the overall extent that represents how the extent of the modification of organizational processes required to align with the ERP package $(0=$ no modification; $10=$ complete modification $)$

$\begin{array}{lllllllllll}0 & 1 & 2 & 3 & 4 & 5 & 6 & 7 & 8 & 9 & 10\end{array}$

18. Overall, please rate the comprehensiveness of the implementation of ERP at your organization $(0=$ not comprehensive at all; $10=$ completely comprehensive)

$$
\begin{array}{lllllllllll}
0 & 1 & 2 & 3 & 4 & 5 & 6 & 7 & 8 & 9 & 10
\end{array}
$$

19. In general, to what extent do you believe that you are knowledgeable about the scope of ERP implementation at your organization? ( 1 = little knowledge; 7 = expert knowledge)

$$
\begin{array}{lllllll}
1 & 2 & 3 & 4 & 5 & 6 & 7
\end{array}
$$

Following are some general questions about your organization.

20. What is the type of business of your organization? (Please tick ONLY ONE box for the main type)
$\square$ Limited liability company (LLC)
$\square$ Shareholding or joint stock company (JSC)

$\square$ Partnership

$\square$ Private enterprise or sole proprietorship

$\square$ Other, please specify:

21. Your industry is seen primarily as:

22. How many employees are there in your organization?

23. If you would like to receive a copy of the research results, please provide your email address:

Thank you very much for responding to this survey 


\section{Participant Information Sheet for Part B}

Research Project Title: The relationship between enterprise resource planning (ERP) implementation and intellectual capital under the moderating effect of organizational learning capability

\section{Researcher: Nguyen Vu Quang, School of Information Management, Victoria University of Wellington}

Dear Survey Participants

Regarding the implementation of ERP in your organization, you may be interested in the following questions:

- How does the extent of ERP implementation affect the sum of all knowledge (or intellectual capital) of your organization?

- To what extent does the degree of your organizational learning capability influence the effect that ERP implementation has on the intellectual capital of your organization?

To help you address such important questions, I am conducting a PhD research project to evaluate the relationships between the implementation of ERP, intellectual capital, and learning capability in organizations. If you request a copy you will receive an executive summary report of this study, which will provide profiles and suggestions on how the scale of ERP implementation influences the intellectual capital in your organization and the role of organizational learning capability on the extent of this effect.

The questionnaire seeks information on the learning capability and intellectual capital of the organization. It should be filled in by management people working at the departments different from IT or IS. They are knowledgeable about the organization and the impact of the implementation of ERP. The survey will take about 25 minutes to complete.

The research is approved by Victoria University of Wellington that requires, and has granted, approval from the School's Human Ethics Committee.

Participation is voluntary, you will not be identified personally in any written report produced as a result of this research, including possible publication in academic conferences and journals. Also, no information will be released that makes it possible to identify specific organizations. All material collected will be kept confidential, and will be viewed only by myself and my supervisor Dr Philip Calvert. The thesis will be submitted for marking to the School of Information Management, and subsequently deposited in the University Library. All collected data will be destroyed within two years after the completion of the project.

Your contribution to the success of this research project is deeply appreciated. We look forward to receiving your completed survey. Thank you very much in advance for your time and your support. If you have any questions or would like to receive further information about the project, please contact me at quang.v.nguyen@vuw.ac.nz or telephone 022124 0349, or you may contact my supervisor Dr Philip Calvert at philip.calvert@vuw.ac.nz or telephone +64 44636629 .

Mr. Nguyen Vu Quang 


\section{PART B - A SURVEY ON ORGANIZATIONAL LEARNING CAPABILITY AND INTELLECTUAL CAPITAL.}

This questionnaire is for management people working at the departments different from IT or IS. They are knowledgeable about the organization and the impact of ERP implementation. It takes about 25 minutes to answer the questionnaire.

\section{Definitions of key terms}

Organization: an independent company, a parent company, a wholly owned subsidiary or a division of a company where the respondent works at, is most familiar with, and knows best. An organization is an entity that has own financial statements

ERP: an enterprise-wide information system of an organization that utilizes information technology with the promise of integrating and optimizing all of business processes and departmental functions. An ERP package may or may not include functions of customer relationship management (CRM), supply chain management (SCM), and E-commerce

Learning capability: are the conditions for or facilitators of effective organizational learning

Intellectual capital: the sum of all knowledge an organization is able to leverage in the process of conducting business to gain competitive advantage

There are no right or wrong answers to any of the questions or statements below. Please respond to all questions or statements in this questionnaire to the best of your knowledge.

Part 1. Consider the effect in terms of the sum of all knowledge that the implementation of ERP brings to your organization. Please indicate the extent to which you agree with the following items describing your organizational intellectual capital due to the implementation of ERP ( $1=$ strongly disagree; $4=$ neutral; 7 = strongly agree).

\begin{tabular}{|c|c|c|c|c|c|c|c|}
\hline The employees of my organization ... & \multicolumn{2}{|c|}{$\begin{array}{l}\text { Strongly } \\
\text { Disagree }\end{array}$} & & & & \multicolumn{2}{|c|}{$\begin{array}{r}\text { Strongly } \\
\text { agree }\end{array}$} \\
\hline 1. are highly skilled & 1 & 2 & 3 & 4 & 5 & 6 & 7 \\
\hline 2. are widely considered the best in our industry & 1 & 2 & 3 & 4 & 5 & 6 & 7 \\
\hline 3. are creative and bright & 1 & 2 & 3 & 4 & 5 & 6 & 7 \\
\hline $\begin{array}{l}\text { 4. are experts in their particular jobs and } \\
\text { functions }\end{array}$ & 1 & 2 & 3 & 4 & 5 & 6 & 7 \\
\hline 5. develop new ideas and knowledge & 1 & 2 & 3 & 4 & 5 & 6 & 7 \\
\hline $\begin{array}{l}\text { 6. are skilled at collaborating with each other to } \\
\text { diagnose and solve problems }\end{array}$ & 1 & 2 & 3 & 4 & 5 & 6 & 7 \\
\hline 7. share information and learn from one another & 1 & 2 & 3 & 4 & 5 & 6 & 7 \\
\hline $\begin{array}{l}\text { 8. interact and exchange ideas with people from } \\
\text { different areas of the company }\end{array}$ & 1 & 2 & 3 & 4 & 5 & 6 & 7 \\
\hline $\begin{array}{l}\text { 9. partner with customers, suppliers, alliance } \\
\text { partners, etc., to develop solutions }\end{array}$ & 1 & 2 & 3 & 4 & 5 & 6 & 7 \\
\hline $\begin{array}{l}\text { 10. apply knowledge from one area of the } \\
\text { organization to problems and opportunities } \\
\text { that arise in another }\end{array}$ & 1 & 2 & 3 & 4 & 5 & 6 & 7 \\
\hline
\end{tabular}




\begin{tabular}{|c|c|c|c|c|c|c|c|}
\hline My organization... & \multicolumn{2}{|c|}{$\begin{array}{l}\text { Strongly } \\
\text { Disagree }\end{array}$} & & & & \multicolumn{2}{|c|}{$\begin{array}{r}\text { Strongly } \\
\text { agree }\end{array}$} \\
\hline $\begin{array}{l}\text { 11. uses patents and licenses as a way to store } \\
\text { knowledge }\end{array}$ & 1 & 2 & 3 & 4 & 5 & 6 & 7 \\
\hline $\begin{array}{l}\text { 12. has much of knowledge is contained in } \\
\text { manuals, databases, etc. }\end{array}$ & 1 & 2 & 3 & 4 & 5 & 6 & 7 \\
\hline $\begin{array}{l}\text { 13. has a culture (behaviours, stories, rituals) } \\
\text { containing valuable ideas and ways of doing } \\
\text { business, etc. }\end{array}$ & 1 & 2 & 3 & 4 & 5 & 6 & 7 \\
\hline $\begin{array}{l}\text { 14. embeds much of its knowledge and } \\
\text { information in structure, systems, and } \\
\text { processes }\end{array}$ & 1 & 2 & 3 & 4 & 5 & 6 & 7 \\
\hline $\begin{array}{l}\text { Overall, due to the implementation of } \\
\text { ERP... }\end{array}$ & \multicolumn{2}{|c|}{$\begin{array}{l}\text { Strongly } \\
\text { Disagree }\end{array}$} & & & & \multicolumn{2}{|c|}{$\begin{array}{l}\text { Strongly } \\
\text { agree }\end{array}$} \\
\hline $\begin{array}{l}\text { 15. My organization acquires the knowledge } \\
\text { necessary for doing business that resided in } \\
\text { people, mechanisms and structures, and } \\
\text { relationships }\end{array}$ & 1 & 2 & 3 & 4 & 5 & 6 & 7 \\
\hline
\end{tabular}

Part 2. Consider the organizational learning environment, to what extent do you agree with the following items describing the conditions for or/and facilitators of effective learning in your organization ( 1 = strongly disagree; 4 = neutral; 7 = strongly agree)?

The management people in my Strongly Strongly organization...

Disagree agree

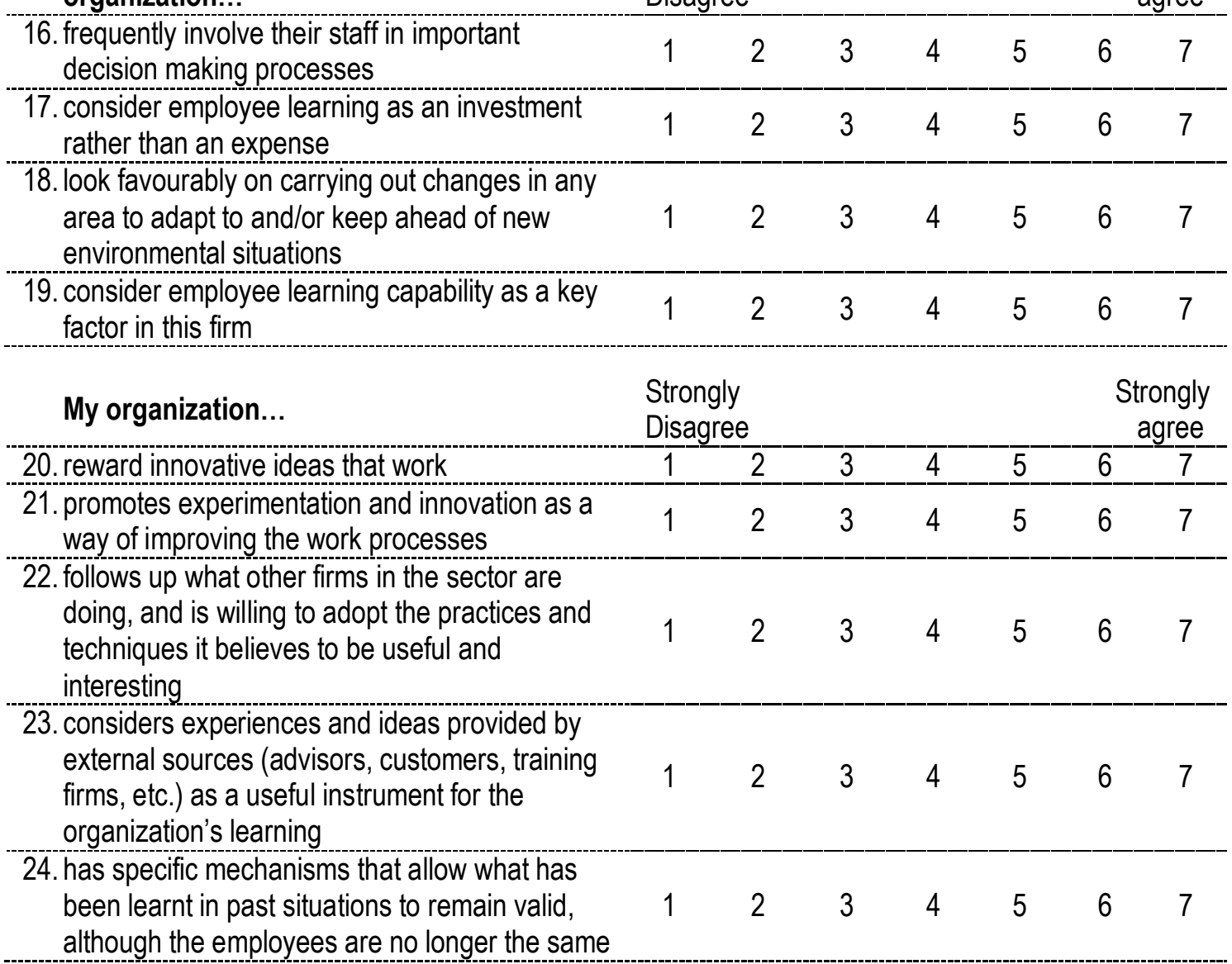




\begin{tabular}{|c|c|c|c|c|c|c|c|}
\hline In my organization, ... & \multicolumn{2}{|c|}{$\begin{array}{l}\text { Strongly } \\
\text { Disagree }\end{array}$} & & & & \multicolumn{2}{|c|}{$\begin{array}{l}\text { Strongly } \\
\text { agree }\end{array}$} \\
\hline $\begin{array}{l}\text { 25. all employees have generalized knowledge } \\
\text { regarding the organization's objectives }\end{array}$ & 1 & 2 & 3 & 4 & 5 & 6 & 7 \\
\hline $\begin{array}{l}\text { 26. all parts (departments, sections, work teams, } \\
\text { and individuals) are well aware of how they } \\
\text { contribute to achieving the overall objectives }\end{array}$ & 1 & 2 & 3 & 4 & 5 & 6 & 7 \\
\hline $\begin{array}{l}\text { 27. all parts are interconnected, working together in } \\
\text { a coordinated fashion }\end{array}$ & 1 & 2 & 3 & 4 & 5 & 6 & 7 \\
\hline $\begin{array}{l}\text { 28. employees can express their opinions and } \\
\text { make suggestions regarding the procedures } \\
\text { and methods in place for carrying out tasks }\end{array}$ & 1 & 2 & 3 & 4 & 5 & 6 & 7 \\
\hline $\begin{array}{l}\text { 29. errors and failures are always discussed and } \\
\text { analyzed, on all levels }\end{array}$ & 1 & 2 & 3 & 4 & 5 & 6 & 7 \\
\hline $\begin{array}{l}\text { 30. employees have the chance to talk among } \\
\text { themselves about new ideas, programs, and } \\
\text { activities that might be of use to the } \\
\text { organization }\end{array}$ & 1 & 2 & 3 & 4 & 5 & 6 & 7 \\
\hline 31. teamwork is the usual way to work & 1 & 2 & 3 & 4 & 5 & 6 & 7 \\
\hline Overall, my organization... & $\begin{array}{l}\text { Stro } \\
\text { Dis? }\end{array}$ & & & & & & $\begin{array}{l}\text { ongly } \\
\text { yree }\end{array}$ \\
\hline $\begin{array}{l}\text { 32. has adequate factors and conditions to facilitate } \\
\text { learning }\end{array}$ & 1 & 2 & 3 & 4 & 5 & 0 & 7 \\
\hline
\end{tabular}

Part 3. Please provide some personal information as follows.

33. Overall, to what extent do you believe that you are knowledgeable about your organization's people and learning capability? ( 1 = little knowledge; 7 = expert knowledge)

$$
\begin{array}{lllllll}
1 & 2 & 3 & 4 & 5 & 6 & 7
\end{array}
$$

34. What is your current area of work? (select ONE BOX only for the main area)
$\square$ Planning/strategy
$\square$ Finance/Accounting
$\square$ Engineering/Technology
$\square$ Production
Human resource
$\square$ Sales
$\square$ Marketing
$\square$ Logistic/lnventory
$\square$ Quality management
$\square R \& D$
$\square$ Information technology/systems
$\square$ Other, please specify:

35. Which of the following best represents your current position?

$\square$ Top management (e.g. general director, director, CEO, president, vice general director, vice director,...)

Middle management (e.g. head of department,...)

$\square$ Low level management (e.g. head of sub-department, head

Other, please specify: of workshop,...)

36. How long have you worked at your organization? years

\section{Thank you very much for responding to this survey}


Appendices

APPENDIX B. Vietnamese Version of the questionnaire 


\title{
Thông tin cho người trả lời phần A
}

\author{
Dự án nghiên cứu: Mối quan hệ giữa việc triển khai hệ thống hoạch định nguồn lực doanh \\ nghiệp (ERP) và vốn tri thức dước tác động của năng lực học tập tổ \\ chức
}

\section{Nghiên cứu sinh: Nguyễn Vũ Quang, Khoa Quản lý Thông tin, Đại học Victoria Wellington}

Kính gởi Quý Ông/Bà

Trong việc triển khai hệ thống ERP tại tổ chức, ông/bà có thể quan tâm các câu hỏi sau:

- Mức độ triển khai ERP ảnh hưởng thế nào đến vốn tri thức của tổ chức?

- Năng lực học tập của tổ chức của ông/bà có mức độ ảnh hưởng bao nhiêu đến mối quan hệ giữa việc triển khai ERP và vốn tri thức của tổ chức?

Để giúp làm rõ những điều trên, tôi đang thực hiện dự án nghiên cứu nhằm đánh giá các mối quan hệ giữa việc triển khai ERP, vốn tri thức, và năng lực học tập trong các tổ chức. Nếu ông/bà yêu cầu, ông/bà sẽ nhận một báo cáo kết quả của nghiên cứu này, bào cáo cung cấp các thông tin mô tả và các khuyến nghị về mức độ triển khai ERP tác động như thế nào đến vốn tri thức trong tổ chức và vai trò của năng lực học tập đối với mối tác động này.

Bản câu hỏi này thu thập thông tin về qui mô hay mức độ triển khai ERP. Đối tượng trả lời là nhà quản lý phụ trách hoạt động IT/IS hoặc hệ thống ERP trong tổ chức. Thời gian trả lời bản câu hỏi khoảng 20 phút.

Nghiên cứu này được trường đại học Victoria Wellington chấp thuận và được Ủy ban Đạo đức Con người của Khoa Quản lý Thông tin thông qua.

Việc tham gia là tự nguyện. Ông/Bà sẽ được giấu danh tánh trong mọi tài kiệu của kết quả nghiên cứu này, kể cả các bài viết xuất bản trong hội thảo và tờ báo khoa học. Tương tự, thông tin về tổ chức được bảo mật. Tất cả tư liệu thu thập sẽ được giữ bảo mật và chỉ được tham khảo bởi nghiên cứu sinh và người hướng dẫn tiến sỹ Philip Calvert. Luận văn sẽ được nộp cho Khoa Quản lý Thông tin để đánh giá, và sau đó được nộp vào Thư viện của Đại học. Tất cả dữ liệu thu thập sẽ được hủy trong vòng hai năm sau khi hoàn thành dự án.

Tôi rất cảm kích sự đóng góp của ông/bà cho sự thành công của dự án. Tôi mong nhận được bản trả lời đầy đủ từ ông/bà. Chân thành cảm ơn ông/bà dành thời gian và hỗ trợ. Nếu ông/bà có bất kỳ câu hỏi gì hoặc muốn biết thêm thông tin của dự án nghiên cứu, vui lòng liên hệ với tôi (email: quang.v.nguyen@vuw.ac.nz, ĐT: +64 4 4635528) hoặc người hướng dẫn tiến sỹ Philip Calvert (email: Philip.calvert@vuw.ac.nz, ĐT: +64 4 4636629).

Nguyễn Vũ Quang 


\section{PHÀN A - MỨC ĐỌ TRIẼN KHAI HẸ THỐNG ERP}

\section{Bản câu hỏi này dành cho Ông/Bà cấp quản lý phụ trách hoạt động IT/IS của tổ chức. Thời gian trả lời bản câu hỏi khoảng 20 phút.}

\section{Đinh nghĩa các thuât nqữ}

Tổ chức: là một công ty độc lập, một công ty mẹ, một công ty con hoàn toàn tự quản, hoặc một đơn vị của một công ty mà Ông/Bà đang công tác, quen thuộc và thông thạo nhất. Tổ chức là đơn vị hạch toán độc lập, có các báo cáo tài chính riêng.

ERP: còn gọi là hệ hoạch định nguồn lực doanh nghiệp. ERP là một hệ thống thông tin doanh nghiệp qui mô rộng của một tổ chức, nó tận dụng công nghệ thông tin nhằm tích hợp và tối ưu hóa các qui trình kinh doanh và các nhiệm vụ của phòng ban. Một gói phần mềm ERP có thể có hoặc không có các chức năng như quản lý quan hệ khách hàng (CRM), quản lý chuỗi cung ứng (SCM), và thương mại điện tử (E-commerce)

Vui lòng trả lời tất cả các phát biểu hoặc câu hỏi theo hiểu biết tốt nhất của Ông/Bà

1. Tên vị trí công việc của Ông/Bà:

2. Thời gian Ông/Bà làm việc tại tổ chức đến nay:

3. Tổ chức của Ông/Bà đã thực hiện gói phần mềm ERP của nhà cung cấp nào? (một chọn lựa chính)

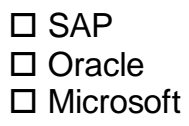

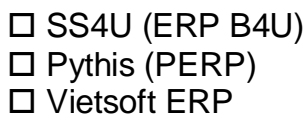

Vietsoft ERP
Fast Business

$\square$ LacViet

$\square$ Khác, vui lòng nêu rõ:

4. Tổ chức của Ông/Bà đã khởi công thực hiện ERP cách đây bao lâu?
$\square$ Ít hơn một năm
$\square 1$ năm đển $<1,5$ năm
$\square 2,5$ năm đến $<3$ năm
$\square$ 1,5 năm đến $<2$ năm
$\square 3$ năm đến $<3,5$ năm
$\square 2$ năm đến $<2,5$ năm
$\square$ 3,5 năm đến < 4 năm
$\square 4$ năm hoặc hơn

5. Tổ chức của Ông/Bà đã triển khai xong giải pháp ERP hay chưa?
$\square$ Rồi
$\square$ Chưa

6. Tổ chức của Ông/Bà đã bắt đầu sử dụng phân hệ nào của giải pháp ERP chưa?

口Rồi

$\square$ Chưa

7. Tổ chức của Ông/Bà đã bắt đầu sử dụng giải pháp ERP hoặc một vài phân hệ của nó cách đây bao lâu?
$\square$ İt hơn một năm
$\square 1$ năm đến $<1,5$ năm
$\square$ 2,5 năm đến < 3 năm
$\square 1,5$ năm đến $<2$ năm
$\square 3$ năm đến $<3,5$ năm
$\square 2$ năm đến $<2,5$ năm
$\square 3,5$ năm đến < 4 năm
$\square 4$ năm hoặc hơn

8. Vui lòng cho biết mức độ triển khai đưa vào sử dụng của hệ thống ERP hiện nay (gồm cả phần cứng và phần mềm) ở tổ chức của Ông/Bà
Một chỗ
Nhiều chỗ trong một vùng
Nhiều chỗ trong vài vùng
Nhiều chỗ trong
nhiều vùng khắp cả nước
Nhiều chỗ tại các nước

9. Tổ chức của Ông/Bà có độ lớn theo phương diện địa lý ra sao?

$\begin{array}{ccccc}\square & \square & \square & \square \\ \text { Một chỗ } & \text { Nhiều chỗ trong } & \text { Nhiều chỗ trong } & \text { Nhiều chỗ trong } \\ & \text { một vùng } & \text { vài vùng } & \text { nhiều vùng khắp } \\ & & \text { cả nước } & \text { Nhiều chố tại các } \\ & & \text { nước }\end{array}$


10. Ông/Bà vui lòng cho biết khi hệ thống ERP được triển khai, công việc tái cấu trúc qui trình nghiệp vụ (BPR) của tổ chức đã được thực hiện ở mức độ nào?

$\begin{array}{ccccc}\square & \square & \square & \text { M } \\ \text { Một lượng nhỏ } & \text { Một phòng ban } & \text { Nhiều hơn một } & \text { Trong cả một } & \text { Nhiều hơn một } \\ \text { nhâan viên trong } & & \text { phòng ban } & \text { vùng } & \text { vùng }\end{array}$
một phòng ban

11. Vui lòng ước lượng số lượng người sử dụng hệ thống ERP trong tổ chức: (người)

12. Vui lòng ước lượng số lượng nhân viên phải thay đổi qui trình công việc do thực hiện triển khai ERP: (nhân viên)

13. TRƯỚC KHI thực hiện ERP, qui trình công việc trong tổ chức được thay đổi, tụ động hóa hoặc chuẩn hóa với tỷ lệ ước khoảng là: $\%$

14. SAU KHI thực hiện ERP, qui trình công việc trong tổ chức được thay đổi, tụ̣ động hóa hoặc chuẩn hóa với tỷ lệ ước khoảng là: $\%$

15. Vui lòng đánh giá mức độ mà gói phần mềm ERP phải được điều chỉnh để thích ứng với các qui trình công việc trong tố chức của Ông/Bà $(0=$ không phải điều chỉnh; $10=$ điều chỉnh toàn bộ)

$$
\begin{array}{lllllllllll}
0 & 1 & 2 & 3 & 4 & 5 & 6 & 7 & 8 & 9 & 10
\end{array}
$$

16. Ông/Bà vui lòng cho biết, khi thực hiện tái cấu trúc, tỷ lệ phần trăm qui trình công việc của tổ chức được điều chỉnh để phù hợp với phần mềm ERP là: $\%$

17. Vui lòng cho biết mức độ điều chỉnh (về nội dung) các qui trình công việc của tổ chức để phù hợp với gói phần mềm ERP $(0=$ không phải điều chỉnh; $10=$ điều chỉnh toàn bộ)

$$
\begin{array}{lllllllllll}
0 & 1 & 2 & 3 & 4 & 5 & 6 & 7 & 8 & 9 & 10
\end{array}
$$

18. Nhìn chung, mức độ triển khai hệ thống ERP ở tổ chức của Ông/Bà là: $(0=$ không thực hiện; 10 = sâu rộng toàn diện)

$$
\begin{array}{lllllllllll}
0 & 1 & 2 & 3 & 4 & 5 & 6 & 7 & 8 & 9 & 10
\end{array}
$$

19. Nhìn chung, Ông/Bà tự đánh giá sự hiểu biết của mình về mức độ triển khai ERP tại tổ chức là: (1 = không hiểu biết, 7 = hiểu biết rất thấu đáo)

$$
\begin{array}{lllllll}
1 & 2 & 3 & 4 & 5 & 6 & 7
\end{array}
$$

Sau đây là một số câu hỏi về tổ chức

20. Loại hình tổ chức của Ông/Bà là gì? (một chọn lựa chính)
$\square$ Công ty trách nhiệm hữu hạn
$\square$ Công ty cổ phần
$\square$ Công ty hợp danh
$\square$ Công ty tư nhân/ một thành viên
$\square$ Khác, xin ghi rõ:

21. Ngành nghề kinh doanh chủ yếu của tổ chức của Ông/Bà là:

22. Tổ chức của Ông/Bà có bao nhiêu nhân viên?

23. Ông/Bà vui lòng ghi lại địa chỉ email nếu có ý muốn nhận bản tổng hợp kết quả khảo sát:

\section{Cảm ơn Ông/Bà đã trả lò̀i bản câu hỏi}




\section{Thông tin cho người trả lời phần $B$}

\section{Dự án nghiên cứu: Mối quan hệ giữa việc triển khai hệ thống hoạch định nguồn lực doanh nghiệp (ERP) và vốn tri thức dước tác động của năng lực học tập tổ chức}

\section{Nghiên cứu sinh: Nguyễn Vũ Quang, Khoa Quản lý Thông tin, Đại học Victoria Wellington}

Kính gởi Quý Ông/Bà

Trong việc triển khai hệ thống ERP tại tổ chức, ông/bà có thể quan tâm các câu hỏi sau:

- Mức độ triển khai ERP ảnh hưởng thế nào đến vốn tri thức của tổ chức?

- Năng lực học tập của tổ chức của ông/bà có mức độ ảnh hưởng bao nhiêu đến mối quan hệ giữa việc triển khai ERP và vốn tri thức của tổ chức?

Để giúp làm rõ những điều trên, tôi đang thực hiện dự án nghiên cứu nhằm đánh giá các mối quan hệ giữa việc triển khai ERP, vốn tri thức, và năng lực học tập trong các tổ chức. Nếu ông/bà yêu cầu, ông/bà sẽ nhận một báo cáo kết quả của nghiên cứu này, bào cáo cung cấp các thông tin mô tả và các khuyến nghị về mức độ triển khai ERP tác động như thế nào đến vốn tri thức trong tổ chức và vai trò của năng lực học tập đối với mối tác động này.

Bản câu hỏi này thu thập thông tin về năng lực học tập và vốn tri thức của tổ chức. Đối tượng trả lời là nhà quản lý làm việc trong các phòng ban khác với phòng ban phụ trách hoạt động IT/IS. Họ có hiểu biết về tình hình doanh nghiệp và ảnh hưởng của việc triển khai ERP. Thời gian trả lời bản câu hỏi khoảng 25 phút.

Nghiên cứu này được trường đại học Victoria Wellington chấp thuận và được Ủy ban Đạo đức Con người của Khoa Quản lý Thông tin thông qua.

Việc tham gia là tự nguyện. Ông/Bà sẽ được giấu danh tánh trong mọi tài kiệu của kết quả nghiên cứu này, kể cả các bài viết xuất bản trong hội thảo và tờ báo khoa học. Tương tự, thông tin về tổ chức được bảo mật. Tất cả tư liệu thu thập sẽ được giữ bảo mật và chỉ được tham khảo bởi nghiên cứu sinh và người hướng dẫn tiến sỹ Philip Calvert. Luận văn sẽ được nộp cho Khoa Quản lý Thông tin để đánh giá, và sau đó được nộp vào Thư viện của Đại học. Tất cả dữ liệu thu thập sẽ được hủy trong vòng hai năm sau khi hoàn thành dự án.

Tôi rất cảm kích sự đóng góp của ông/bà cho sự thành công của dự án. Tôi mong nhận được bản trả lời đầy đủ từ ông/bà. Chân thành cảm ơn ông/bà dành thời gian và hỗ trợ. Nếu ông/bà có bất kỳ câu hỏi gì hoặc muốn biết thêm thông tin của dự án nghiên cứu, vui lòng liên hệ với tôi (email: quang.v.nguyen@vuw.ac.nz, ĐT: +64 4 4635528) hoặc người hướng dẫn tiến sỹ Philip Calvert (email: Philip.calvert@vuw.ac.nz, ĐT: +64 4 4636629).

Nguyễn Vũ Quang 
Appendices

\section{PHÀN B - NĂNG LỰC HỌC TẠP VÀ VỐN TRI THỨC CỦA TỎ CHỨC}

Bản câu hỏi này dành cho Ông/Bà cấp quản lý làm việc trong các phòng ban khác với phòng ban phụ trách hoạt động IT/IS. Họ có hiểu biết về tình hình doanh nghiệp và ảnh hưởng của việc triển khai ERP. Thời gian trả lời bản câu hỏi khoảng 25 phút.

\section{Định nghĩa các thuật ngữ}

Tổ chức: một công ty độc lập, một công ty mẹ, một công ty con hoàn toàn tự quản, hoặc một phân bộ của một công ty mà Ông/Bà đang công tác, quen thuộc và thông thạo nhất. Tổ chức là đơn vị hạch toán độc lập, có các báo cáo tài chính riêng.

ERP: còn gọi là hệ hoạch định nguồn lực doanh nghiệp. ERP là một hệ thống thông tin doanh nghiệp qui mô rộng của một tổ chức, nó tận dụng công nghệ thông tin nhằm tích hợp và tối ưu hóa các qui trình kinh doanh và các nhiệm vụ của phòng ban. Một gói phần mềm ERP có thể có hoặc không có các chức năng như quản lý quan hệ khách hàng ( $\mathrm{CRM})$, quản lý chuỗi cung ứng (SCM), và thương mại điện tử (E-commerce).

Năng lực học tập: các điều kiện, nhân tố hỗ trợ cho sự học tập hiệu quả của tổ chức.

Vốn tri thức: tất cả dạng kiến thức mà tổ chức có thể đưa vào sử dụng trong quá trình hoạt động kinh doanh nhằm đạt được lợi thế cạnh tranh.

Sẽ không có câu trả lời đúng hay sai đối với bất kỳ câu hỏi hay phát biểu nào dưới đây. Xin vui lòng trả lời đầy đủ tất cả các câu hỏi hay phát biểu theo hiểu biết tốt nhất của Ông/Bà

Phần 1. Khi đánh giá tác động của việc triển khai ERP đến vốn tri thức trong tổ chức, Ông/Bà vui lòng cho biết mức độ đồng ý với các phát biểu sau. (1 = hoàn toàn không đồng ý; 4 = trung lập; 7 = hoàn toàn đồng ý)

\begin{tabular}{|c|c|c|c|c|c|c|c|}
\hline \multirow{3}{*}{$\begin{array}{l}\text { Nhân viên trong tổ chức của tôi ... } \\
\text { 1. có kỹ năng tông quát cao } \\
\text { 2. được mọi người thữa nhận là giói nhât } \\
\text { trong ngành }\end{array}$} & \multicolumn{3}{|c|}{$\begin{array}{l}\text { Hoàn toàn không } \\
\text { đồng ý }\end{array}$} & & & \multicolumn{2}{|c|}{$\begin{array}{c}\text { Hoàn toàn } \\
\text { đồng ý }\end{array}$} \\
\hline & 1 & 2 & 3 & 4 & 5 & 6 & 7 \\
\hline & 1 & 2 & 3 & 4 & 5 & 6 & 7 \\
\hline 3. có sức sáng tạo và hiếu biết & 1 & 2 & 3 & 4 & 5 & 6 & 7 \\
\hline $\begin{array}{l}\text { 4. có sự thành thạo trong công việc và nhiệm } \\
\text { vu của ho }\end{array}$ & 1 & 2 & 3 & 4 & 5 & 6 & 7 \\
\hline 5. phát triên y tường và kiên thức mới & 1 & 2 & 3 & 4 & 5 & 6 & 7 \\
\hline $\begin{array}{l}\text { 6. giôi phối hợp với nhau đê nhận diện và } \\
\text { giải quyết các vấn đề }\end{array}$ & 1 & 2 & 3 & 4 & 5 & 6 & 7 \\
\hline 7. chia sê thông tin và hoc hổ nhau & 1 & 2 & 3 & 4 & 5 & 6 & 7 \\
\hline $\begin{array}{l}\text { 8. tương tác và trao đôi ý kiên với nhân sự } \\
\text { trong các phòng ban khác với họ }\end{array}$ & 1 & 2 & 3 & 4 & 5 & 6 & 7 \\
\hline $\begin{array}{l}\text { 9. hợp tác với khách hàng, nhà cung câp, đồi } \\
\text { tác, v.v... để phát triển các giải pháp trong } \\
\text { hoạt động kinh doanh }\end{array}$ & 1 & 2 & 3 & 4 & 5 & 6 & 7 \\
\hline $\begin{array}{l}\text { 10. sữ dụng kiến thức cúa một phòng ban này } \\
\text { để giải quyết các vấn đề và nắm bắt các } \\
\text { cơ hôi phát sinh trong phòng ban khác }\end{array}$ & 1 & 2 & 3 & 4 & 5 & 6 & 7 \\
\hline Tổ chức của tôi ... & & & & & & & $\begin{array}{l}\text { toàn } \\
\text { hg ý }\end{array}$ \\
\hline $\begin{array}{l}\text { 11. sử dụng băng sáng chê và/hoặc giây phép } \\
\text { sử dưng sử dưng sáng chế như là cách để } \\
\text { lưu trữ tri thức }\end{array}$ & 1 & 2 & 3 & 4 & 5 & 6 & 7 \\
\hline $\begin{array}{l}\text { 12. có nhiều tri thức được lưu trứ trong văn } \\
\text { bản, tài liệu, cơ sớ dữ liêu, v.v... }\end{array}$ & 1 & 2 & 3 & 4 & 5 & 6 & 7 \\
\hline
\end{tabular}


Appendices

\begin{tabular}{|c|c|c|c|c|c|c|c|}
\hline $\begin{array}{l}\text { 13. có môi trướng văn hóa (những câu } \\
\text { chuyện, các nghi thức, quy tắc, quan } \\
\text { niệm, hành xử) chứa đựng các ý tưởng và } \\
\text { phương thức kinh doanh có giá tri, v.v... }\end{array}$ & 1 & 2 & 3 & 4 & 5 & 6 & 7 \\
\hline $\begin{array}{l}\text { 14. đưa tri thức và thông tin vào trong các câu } \\
\text { trúc, các hệ thống, và các qui trình hoạt } \\
\text { đông của tồ chức }\end{array}$ & 1 & 2 & 3 & 4 & 5 & 6 & 7 \\
\hline Nhìn tổng thể, nhờ triển khai ERP ... & \multicolumn{3}{|c|}{$\begin{array}{l}\text { Hoàn toàn không } \\
\text { đồng ý }\end{array}$} & & & \multicolumn{2}{|c|}{$\begin{array}{l}\text { Hoàn toàn } \\
\text { đồng ý }\end{array}$} \\
\hline $\begin{array}{l}\text { 15. tô chức tôi thu thập được kiên thức cần } \\
\text { thiết cho hoạt động kinh doanh ở mợ dạng } \\
\text { từ con người, cấu trúc và cơ chế, và các } \\
\text { mối quan hệ }\end{array}$ & 1 & 2 & 3 & 4 & 5 & 6 & 7 \\
\hline
\end{tabular}

Phần 2. Dưới góc độ của môi trường học tập của tổ chức. Ông/Bà vui lòng cho biết mức độ đồng ý với các phát biểu về những điều kiện, yếu tố hỗ trợ học tập hiệu quả trong tổ chức như sau đây. (1 = hoàn toàn không đồng ý; 4 = trung lập; 7 = hoàn toàn đồng ý)

Cấp quản lý trong tổ chức của tôi ...

Hoàn toàn không

Hoàn toàn đồng ý đồngý

\begin{tabular}{|c|c|c|c|c|c|c|c|}
\hline $\begin{array}{l}\text { 16. thường xuyên tham vân nhân sự của mình } \\
\text { trong các qui trình ra quyết định quan trong }\end{array}$ & 1 & 2 & 3 & 4 & 5 & 6 & 7 \\
\hline $\begin{array}{l}\text { 17. quan niệm sự học tập cúa nhân viên là một } \\
\text { sự đầu tư hơn là chi phí tốn kém }\end{array}$ & 1 & 2 & 3 & 4 & 5 & 6 & 7 \\
\hline $\begin{array}{l}\text { 18. có khuynh hướng tích cực thực hiện các } \\
\text { thay đổi trong bất kỳ bộ phận nào để thích } \\
\text { ứng và/hoặc đón đầu các tînh hình mới của } \\
\text { môi trường kinh doanh }\end{array}$ & 1 & 2 & 3 & 4 & 5 & 6 & 7 \\
\hline $\begin{array}{l}\text { 19. xem năng lực học hỏi của nhân viên là yêu } \\
\text { tố then chốt }\end{array}$ & 1 & 2 & 3 & 4 & 5 & 6 & 7 \\
\hline Tổ chức của tôi... & \multicolumn{3}{|c|}{$\begin{array}{l}\text { Hoàn toàn không } \\
\text { đồng ý }\end{array}$} & & & \multicolumn{2}{|c|}{$\begin{array}{l}\text { Hoàn toàn } \\
\text { đồng ý }\end{array}$} \\
\hline $\begin{array}{l}\text { 20. tướng thướng cho các ý tướng có tính đổi } \\
\text { mới khi ý tướng mang lai kêt quả }\end{array}$ & 1 & 2 & 3 & 4 & 5 & 6 & 7 \\
\hline $\begin{array}{l}\text { 21. khuyến khích việc thứ nghiềm và đồi mới } \\
\text { như một cách thức để cải thiện các qui } \\
\text { trình công viếc }\end{array}$ & 1 & 2 & 3 & 4 & 5 & 6 & 7 \\
\hline $\begin{array}{l}\text { 22. theo đuôi nhứng gì các công ty khác trong } \\
\text { ngành đang làm, và sắn sàng áp dụng } \\
\text { những hoạt động thực tiễn và các kỹ thuật } \\
\text { mà tổ chức thấy là hữu ích và đang được } \\
\text { ngành chú ý }\end{array}$ & 1 & 2 & 3 & 4 & 5 & 6 & 7 \\
\hline $\begin{array}{l}\text { 23. xem các kinh nghiệm và ý tướng của các } \\
\text { nguồn bên ngoài (cố vấn, đối tác, khách } \\
\text { hàng, dịch vụ huấn luyện, v.v..) là phương } \\
\text { tiện hữu ích cho sự học tập của tổ chức }\end{array}$ & 1 & 2 & 3 & 4 & 5 & 6 & 7 \\
\hline $\begin{array}{l}\text { 24. có các cơ chê cụ thế cho phép lưu giữ } \\
\text { những kinh nghiệm học hỏi trong các tình } \\
\text { huống trước đây, mặc dù nhân viên có thể } \\
\text { thay đổi }\end{array}$ & 1 & 2 & 3 & 4 & 5 & 6 & 7 \\
\hline
\end{tabular}


Trong tổ chức của tôi, ...

Hoàn toàn không Hoàn toàn đồngý đồngý

\begin{tabular}{|c|c|c|c|c|c|c|c|}
\hline $\begin{array}{l}\text { 25. nhân viên có hiếu biết tồng quát về các } \\
\text { mục tiêu của tổ chức }\end{array}$ & 1 & 2 & 3 & 4 & 5 & 6 & 7 \\
\hline $\begin{array}{l}\text { 26. tât cả các bộ phận (các phông ban, tồ, } \\
\text { nhóm, và cá nhân) đều biết được họ cần } \\
\text { làm gì để đóng góp vào việc đạt được mục } \\
\text { tiêu chung của tổ chức }\end{array}$ & 1 & 2 & 3 & 4 & 5 & 6 & 7 \\
\hline $\begin{array}{l}\text { 27. mọi bộ phận (các phòng ban, tô, nhóm, và } \\
\text { cá nhân) đều được liên kết và phối hợp } \\
\text { nhau trong một thể thống nhất }\end{array}$ & 1 & 2 & 3 & 4 & 5 & 6 & 7 \\
\hline $\begin{array}{l}\text { 28. nhân viên có thể bày tó ý kiến và đưa để } \\
\text { xuất về các qui trình và phương pháp để } \\
\text { thực hiên các công việc }\end{array}$ & 1 & 2 & 3 & 4 & 5 & 6 & 7 \\
\hline $\begin{array}{l}\text { 29. các sai sót và thất bại luôn được thảo luận } \\
\text { và phân tích, tai mọi cấp cấu trúc }\end{array}$ & 1 & 2 & 3 & 4 & 5 & 6 & 7 \\
\hline $\begin{array}{l}\text { 30. nhân viên có cơ hội trao đôi với nhau về } \\
\text { các ý tưởng, các chương trình, và các hoạt } \\
\text { động mới mẻ có thể ứng dụng được trong } \\
\text { tổ chức }\end{array}$ & 1 & 2 & 3 & 4 & 5 & 6 & 7 \\
\hline $\begin{array}{l}\text { 31. làm việc theo nhóm là hình thức làm việc } \\
\text { phố biến }\end{array}$ & 1 & 2 & 3 & 4 & 5 & 6 & 7 \\
\hline Nhìn chung, tổ chức của tôi ... & \multicolumn{3}{|c|}{$\begin{array}{l}\text { Hoàn toàn không } \\
\text { đồng ý }\end{array}$} & & & \multicolumn{2}{|c|}{$\begin{array}{l}\text { Hoàn toàr } \\
\text { đồng ! }\end{array}$} \\
\hline $\begin{array}{l}\text { 32. có đầy đủ các yếu tồ và điều kiện để hố trợ } \\
\text { học tập }\end{array}$ & 1 & 2 & 3 & 4 & 5 & 6 & 7 \\
\hline
\end{tabular}

Phần 3. Ông/Bà vui lòng cho biết một số thông tin cá nhân.

33. Tổng quát, Ông/Bà tự đánh giá sự hiểu biết của mình về con người và năng lực học tập của tổ chức của Ông/Bà như thế nào ( 1 = không hiểu biết; 7 = hiểu biết thấu đáo)

$\begin{array}{lllllll}1 & 2 & 3 & 4 & 5 & 6 & 7\end{array}$

34. Lĩnh vực công tác hiện tại của Ông/Bà là gì? (chọn MỌT lĩnh vực chính)
$\square$ Hoạch định/chiến lược
口 Tài chính/kế toán
$\square$ Kỹ thuật/công nghệ
$\square$ Sản xuất
प Nhân sự
$\square$ Bán hàng
$\square$ Tiếp thi
$\square$ Kho vận/thu mua
$\square$ Chất lượng sản phẩm/dịch vụ
Nghiên cứu \& phát triển sản phẩm, dịch vụ
$\square$ Công nghệ / hệ thống thông tin
$\square$ Khác, xin nêu rõ:

35. Chức vụ hiện nay của Ông/Bà là gì?

$\square$ Quản lý cấp cao (ví dụ: tổng giám đốc, phó tổng giám đốc, giám đốc, phó giám đốc, chủ tịch công ty, giám đốc điều hành, phó giám đốc điều

$\square$ Trưởng đội nhóm hành,...)

Nhân viên

Quản lý cấp trung (ví dụ: trưởng hoặc phó trưởng phòng, bộ phận...)

$\square$ Quản lý cấp thấp (ví dụ: trưởng hoặc phó trưởng phân ban thuộc phòng/bộ phận...)

36. Thời gian Ông/Bà đã làm việc tại tổ chức: năm 
Appendices

APPENDIX C. List of ERP software companies in Ho Chi Minh City

\begin{tabular}{|c|c|c|c|}
\hline Name & Address & website & Tel \\
\hline BRAVO & $\begin{array}{l}116 \text { - } 118 \text { Nguyen } \\
\text { Thi Minh Khai, } \\
\text { Dist.3, HCMC }\end{array}$ & www.bravo.com.vn & $\begin{array}{l}(+84) 83930 \\
3352\end{array}$ \\
\hline CDS Solution & $\begin{array}{l}\text { 69-71 Level 1, } \\
\text { Thach Thi Thanh, } \\
\text { Dist.1, HCMC }\end{array}$ & $\begin{array}{l}\text { www.cds- } \\
\text { solution.net/en.html }\end{array}$ & $\begin{array}{l}(+84) 83820 \\
3938\end{array}$ \\
\hline DiCentral & $\begin{array}{l}\text { DiCentral Building, } \\
\text { 50/13 Truong Son, } \\
\text { Tan Binh Dist., } \\
\text { HCMC }\end{array}$ & www.dicentral.com.vn & $\begin{array}{l}(+84) 83848 \\
5182\end{array}$ \\
\hline Diginet & $\begin{array}{l}\text { 341-343 Dien Bien } \\
\text { Phu, Binh Thanh } \\
\text { Dist., HCMC }\end{array}$ & www.vtdsoft.com.vn & $\begin{array}{l}(+84) 83512 \\
3878\end{array}$ \\
\hline $\begin{array}{l}\text { Electra } \\
\text { Vietnam }\end{array}$ & $\begin{array}{l}60 \text { Nguyen Dinh } \\
\text { Chieu, Dist.1, } \\
\text { HCMC }\end{array}$ & www.abeo-electra.com & $\begin{array}{l}(+84) 83911 \\
7254\end{array}$ \\
\hline Entersoft JSC & $\begin{array}{l}\text { 54A No Trang long, } \\
\text { Binh Thanh Dist., } \\
\text { HCMC }\end{array}$ & $\underline{\text { www.entersoft.com.vn }}$ & $\begin{array}{l}(+84) 85445 \\
3166\end{array}$ \\
\hline ERP FPT & $\begin{array}{l}\text { Level 1, } \\
\text { CentrePoint } \\
\text { Building, } 106 \\
\text { Nguyen Van Troi, } \\
\text { Phu Nhuan Dist., } \\
\text { HCMC }\end{array}$ & $\begin{array}{l}\text { www.fis.com.vn/cong-ty- } \\
\text { thanh-vien/fpt-erp }\end{array}$ & $\begin{array}{l}(+84) 83997 \\
7692\end{array}$ \\
\hline $\begin{array}{l}\text { Exact } \\
\text { Software } \\
\text { Vietnam }\end{array}$ & $\begin{array}{l}\text { Level 8, BITEXCO } \\
\text { Building, 19-25 } \\
\text { Nguyen Hue, } \\
\text { Dist.1, HCMC }\end{array}$ & $\underline{\text { www.exact.com }}$ & $\begin{array}{l}(+84) 83823 \\
6933\end{array}$ \\
\hline FAST & $\begin{array}{l}\text { Level 9, Section B, } \\
\text { Waseco Building, } \\
10 \text { Pho Quang, Tan } \\
\text { Binh Dist., HCMC }\end{array}$ & $\underline{\text { www.fast.com.vn }}$ & $\begin{array}{l}(+84) 83848 \\
6068\end{array}$ \\
\hline FBS Ltd. & $\begin{array}{l}\text { 47B Nguyen } \\
\text { Thuong Hien, Binh } \\
\text { Thanh Dist., HCMC }\end{array}$ & www.fbs.com.vn & $\begin{array}{l}(+84) 83550 \\
0116\end{array}$ \\
\hline $\begin{array}{l}\text { Fujinet } \\
\text { Vietnam }\end{array}$ & $\begin{array}{l}\text { ABC Building } \\
\text { (Airport Business } \\
\text { Centre), 10 Pho } \\
\text { Quang, Tan Binh } \\
\text { Dist., HCMC }\end{array}$ & www.fujinet.net & $\begin{array}{l}(+84) 83847 \\
7000\end{array}$ \\
\hline
\end{tabular}


Appendices

\begin{tabular}{|c|c|c|c|}
\hline Name & Address & website & Tel \\
\hline $\begin{array}{l}\text { Global } \\
\text { CyberSoft }\end{array}$ & $\begin{array}{l}\text { Helios Building, } \\
\text { Quang Trung } \\
\text { Software Park, } \\
\text { street 3, Dist. 12, } \\
\text { HCMC }\end{array}$ & www.globalcybersoft.com & $\begin{array}{l}(+84) 85437 \\
1199\end{array}$ \\
\hline Green Effect & $\begin{array}{l}\text { 173/9A Phan Huy } \\
\text { Ich, Tan Binh Dist., } \\
\text { HCMC }\end{array}$ & www.effect.com.vn & $\begin{array}{l}(+84) 83948 \\
3804\end{array}$ \\
\hline HPT & $\begin{array}{l}\text { Level 9, Paragon } \\
\text { Building, 03 } \\
\text { Nguyen Luong } \\
\text { Bang, Dist.7, } \\
\text { HCMC }\end{array}$ & www.hpt.vn & $\begin{array}{l}(+84) 85412 \\
3400\end{array}$ \\
\hline KMC Soft & $\begin{array}{l}\text { 275/8B Nguyen } \\
\text { Van Luong, Go Vap } \\
\text { Dist., HCMC }\end{array}$ & www.kmcsoft.com & $\begin{array}{l}(+84) 83984 \\
8818\end{array}$ \\
\hline Lac Viet & $\begin{array}{l}23 \text { Nguyen Thi } \\
\text { Huynh, Phu Nhuan } \\
\text { Dist., HCMC }\end{array}$ & www.lacviet.com.vn & $\begin{array}{l}(+84) 83842 \\
3333\end{array}$ \\
\hline MISA JSC & $\begin{array}{l}\text { 92-94, Street 9A, } \\
\text { KDC Trung Son, } \\
\text { Binh Chanh, } \\
\text { HCMC }\end{array}$ & $\underline{\text { www.amis.vn }}$ & $\begin{array}{l}(+84) 85431 \\
8318\end{array}$ \\
\hline Omega & $\begin{array}{l}32 \text { Street D5, Q. } \\
\text { Bình Thạnh, } \\
\text { TpHCM }\end{array}$ & phanmemerp.net & $\begin{array}{l}(+84) 918499 \\
343\end{array}$ \\
\hline $\begin{array}{l}\text { Perfect } \\
\text { Software }\end{array}$ & $\begin{array}{l}122 \text { Nguyen Sy } \\
\text { Sach, Tan Binh } \\
\text { Dist., HCMC }\end{array}$ & www.perfect.com.vn & $\begin{array}{l}(+84) 86674 \\
8561\end{array}$ \\
\hline $\begin{array}{l}\text { Phuc An } \\
\text { Thinh } \\
\text { (PATSOFT) }\end{array}$ & $\begin{array}{l}\text { CMC Plaza, 79B Ly } \\
\text { Thuong Kiet, Tan } \\
\text { Binh Dist., HCMC }\end{array}$ & www.patsoft.com.vn/ & $\begin{array}{l}(+84) 86265 \\
1172\end{array}$ \\
\hline $\begin{array}{l}\text { Phuc Hung } \\
\text { Thinh (SS4U) }\end{array}$ & $\begin{array}{l}\text { 5A, Green Star } \\
\text { Buidling, } 70 \text { Pham } \\
\text { Ngoc Thach, } \\
\text { Dist.3, HCMC } \\
\end{array}$ & www.ss $4 u-v n . c o m$ & $\begin{array}{l}(+84) 83715 \\
4067\end{array}$ \\
\hline PSC Ltd. & $\begin{array}{l}5 \text { Hoa Sua, Phu } \\
\text { Nhuan Dist., } \\
\text { HCMC }\end{array}$ & psctelecom.com.vn & $\begin{array}{l}(+84) 83517 \\
3655\end{array}$ \\
\hline Pythis & $\begin{array}{l}\text { Room 305, } 123 \\
\text { Truong Dinh , Dist. } \\
\text { 3, HCMC }\end{array}$ & $\underline{\text { www.perp.vn }}$ & $\begin{array}{l}(+84) 83848 \\
4796\end{array}$ \\
\hline $\begin{array}{l}\text { Tectura } \\
\text { Vietnam }\end{array}$ & $\begin{array}{l}\text { Level 4, Mirae } \\
\text { Business Centre, } \\
268 \text { To Hien Thanh } \\
\text {, Dist.10, HCMC }\end{array}$ & www.vn.tectura.com & $\begin{array}{l}(+84) 83868 \\
1420\end{array}$ \\
\hline
\end{tabular}


Appendices

\begin{tabular}{|l|l|l|l|}
\hline \multicolumn{1}{|c|}{ Name } & \multicolumn{1}{|c|}{ Address } & \multicolumn{1}{c|}{ website } \\
\hline Tinh Van & $\begin{array}{l}\text { Level 4, 168B Bui } \\
\text { Thi Xuan, Dist.1, } \\
\text { HCMC }\end{array}$ & $\begin{array}{l}\text { www.tinhvanconsulting.co } \\
\text { m }\end{array}$ & $\begin{array}{l}(+84) 86291 \\
6851\end{array}$ \\
\hline $\begin{array}{l}\text { Tri Nguyen } \\
\text { Software Ltd. }\end{array}$ & $\begin{array}{l}\text { 109/8B Binh Quoi, } \\
\text { Binh Thanh Dist., } \\
\text { HCMC }\end{array}$ & www.tringuyensoftware.vn & $\begin{array}{l}(+84) \\
914939095\end{array}$ \\
\hline Vietsoft & $\begin{array}{l}\text { 27/49 Hau Giang } \\
\text { Tan Binh Dist. }\end{array}$ & www.vietsoft.com.vn & $\begin{array}{l}(+84) 83811 \\
0770\end{array}$ \\
\hline $\begin{array}{l}\text { HCMC } \\
\text { Company }\end{array}$ & $\begin{array}{l}\text { 456 - 458 Hai Ba } \\
\text { Trung, Dist.1, }\end{array}$ & www.vtdsoft.com.vn & $\begin{array}{l}(+84) 83848 \\
1197\end{array}$ \\
\hline
\end{tabular}


Appendices

APPENDIX D. Other ERP packages

\begin{tabular}{|l|r|}
\hline ERP package & Frequency \\
\hline PATSOFT & 4 \\
\hline Omega & 2 \\
\hline EnterERP & 9 \\
\hline FESSOFT & 7 \\
\hline LEMON3_ERP & 5 \\
\hline Symphony & 3 \\
\hline KMC_ERP & 3 \\
\hline AMIS.VN & 6 \\
\hline Sage 300 ERP & 1 \\
\hline PSC-ERP & 3 \\
\hline BRAVO & 5 \\
\hline EXACT ERP & 1 \\
\hline Effect ERP & 4 \\
\hline BizForceOne & 1 \\
\hline Total & 54 \\
\hline
\end{tabular}

APPENDIX E. Outliers analysis

Univariate outlier analysis ( $\mathrm{Z}$ score of all numeric variables)

Descriptive Statistics

\begin{tabular}{|l|r|r|r|}
\hline & \multicolumn{1}{|c|}{$\mathrm{N}$} & Minimum & Maximum \\
\hline Zscore: BRE1 & 226 & -1.43409 & 1.71255 \\
Zscore: BRE2 & 226 & -1.57735 & 2.06021 \\
Zscore: DEP1 & 226 & -1.80581 & 1.66005 \\
Zscore: DEP2 & 226 & -1.82928 & 1.74377 \\
Zscore: MAG1 & 226 & -2.27652 & 1.68773 \\
Zscore: MAG2 & 226 & -2.34751 & 1.69007 \\
Zscore: MAG3 & 226 & -2.36515 & 2.32027 \\
Zscore: HC1 & 223 & -2.38945 & 1.63711 \\
Zscore: HC2 & 222 & -2.27709 & 1.89209 \\
Zscore: HC3 & 222 & -2.63390 & 1.58795 \\
Zscore: HC4 & 224 & -2.97960 & 1.49479 \\
Zscore: HC5 & 223 & -1.88955 & 1.67534 \\
Zscore: OC1 & 222 & -1.97540 & 2.71987 \\
Zscore: OC2 & 221 & -1.53120 & 2.00111 \\
Zscore: OC3 & 223 & -1.68120 & 2.00159
\end{tabular}


Appendices

Descriptive Statistics

\begin{tabular}{|l|l|l|r|}
\hline & $\mathrm{N}$ & Minimum & Maximum \\
\hline Zscore: OC4 & 223 & -1.73080 & 2.17576 \\
Zscore: SC1 & 221 & -2.26143 & 1.92079 \\
Zscore: SC2 & 223 & -2.28674 & 1.84236 \\
Zscore: SC3 & 224 & -2.40787 & 1.52430 \\
Zscore: SC4 & 223 & -2.32739 & 1.93551 \\
Zscore: SC5 & 224 & -2.39021 & 1.45702 \\
Zscore: MC1 & 222 & -2.15874 & 1.65686 \\
Zscore: MC2 & 223 & -2.08353 & 1.26714 \\
Zscore: MC3 & 224 & -2.97798 & 1.46914 \\
Zscore: MC4 & 224 & -2.42960 & 1.61973 \\
Zscore: MC5 & 223 & -2.48498 & 1.53060 \\
Zscore: SP1 & 221 & -2.53703 & 2.16801 \\
Zscore: SP2 & 224 & -1.78418 & 2.03662 \\
Zscore: SP3 & 225 & -2.22317 & 1.91767 \\
Zscore: OP1 & 224 & -2.22585 & 1.65423 \\
Zscore: OP2 & 224 & -2.41641 & 1.98421 \\
Zscore: OP3 & 222 & -2.74189 & 1.59049 \\
Zscore: OP4 & 224 & -2.48814 & 1.58502 \\
Zscore: KW1 & 224 & -2.41318 & 1.47568 \\
Zscore: KW2 & 223 & -2.53403 & 1.37933 \\
Zscore: KW3 & 224 & -2.92328 & 1.92720 \\
Zscore: KW4 & 224 & -2.85239 & 2.21049 \\
Valid N (listwise) & 142 & & \\
\hline
\end{tabular}

Multivariate outlier analysis

\begin{tabular}{|l|r|r|r|c|}
\hline Variable & \multicolumn{2}{|c|}{$\begin{array}{c}\text { D statistic of variables } \\
\text { min }\end{array}$} & \multicolumn{2}{c|}{$\begin{array}{c}\text { p-value of } \mathrm{D} \text { statistic } \\
\min \end{array}$} \\
\hline BRE & 0.449 & 4.660 & 0.097 & 0.799 \\
DEP & 0.013 & 9.780 & 0.008 & 0.994 \\
MAG & 0.006 & 9.115 & 0.028 & 0.999 \\
HC & 0.521 & 11.970 & 0.035 & 0.991 \\
OC & 0.048 & 15.679 & 0.004 & 0.999 \\
SC & 0.519 & 14.316 & 0.014 & 0.991 \\
MC & 0.123 & 15.506 & 0.008 & 0.999 \\
SP & 0.333 & 12.616 & 0.006 & 0.954 \\
OP & 0.281 & 17.381 & 0.002 & 0.991 \\
KW & 0.196 & 12.781 & 0.012 & 0.996 \\
\hline
\end{tabular}


Appendices

APPENDIX F. Normality assessment

Descriptive Statistics

\begin{tabular}{|c|c|c|c|c|c|c|c|c|c|}
\hline & $\mathrm{N}$ & Mean & $\begin{array}{c}\text { Std. } \\
\text { Deviation }\end{array}$ & Skev & wness & & rtosis & $\begin{array}{c}\text { Z } \\
\text { Skewness }\end{array}$ & $\begin{array}{c}\text { Z } \\
\text { Kurtosis }\end{array}$ \\
\hline & Statistic & Statistic & Statistic & Statistic & Std. Error & Statistic & Std. Error & & \\
\hline BRE1 & 226 & 2.37 & .953 & .044 & .162 & -.958 & .322 & 0.269 & -2.940 \\
\hline BRE2 & 226 & 2.73 & 1.100 & .280 & .162 & -.768 & .322 & 1.716 & -2.357 \\
\hline DEP1 & 226 & .32 & .124 & -.187 & .162 & -1.234 & .322 & -1.146 & -3.787 \\
\hline DEP2 & 226 & .29 & .108 & .014 & .162 & -1.279 & .322 & 0.087 & -3.924 \\
\hline MAG1 & 226 & 39.46 & 15.135 & -.520 & .162 & -.611 & .322 & -3.193 & -1.873 \\
\hline MAG2 & 226 & 6.91 & 1.238 & -.460 & .162 & -.236 & .322 & -2.820 & -0.725 \\
\hline MAG3 & 226 & 3.33 & 1.323 & -.123 & .162 & -.363 & .322 & -0.757 & -1.113 \\
\hline $\mathrm{HC1}$ & 223 & 4.56 & 1.490 & -.048 & .163 & -.898 & .324 & -0.295 & -2.738 \\
\hline $\mathrm{HC} 2$ & 222 & 3.18 & .959 & -.254 & .163 & -.597 & .325 & -1.544 & -1.816 \\
\hline $\mathrm{HC} 3$ & 222 & 4.74 & 1.421 & -.235 & .163 & -.661 & .325 & -1.426 & -2.011 \\
\hline HC4 & 224 & 5.00 & 1.341 & -.487 & .163 & -.014 & .324 & -2.977 & -0.044 \\
\hline HC5 & 223 & 4.65 & 1.403 & -.010 & .163 & -.846 & .324 & -0.062 & -2.579 \\
\hline OC1 & 222 & 3.10 & 1.065 & .381 & .163 & -.167 & .325 & 2.320 & -0.507 \\
\hline OC2 & 221 & 4.17 & 1.416 & .049 & .164 & -.984 & .326 & 0.300 & -2.986 \\
\hline OC3 & 223 & 4.28 & 1.358 & .064 & .163 & -1.017 & .324 & 0.389 & -3.100 \\
\hline OC4 & 223 & 4.22 & 1.280 & -.111 & .163 & -.943 & .324 & -0.675 & -2.875 \\
\hline SC1 & 221 & 4.24 & 1.435 & .206 & .164 & -.720 & .326 & 1.253 & -2.185 \\
\hline SC2 & 223 & 4.32 & 1.453 & -.062 & .163 & -.788 & .324 & -0.375 & -2.403 \\
\hline SC3 & 224 & 4.67 & 1.526 & -.292 & .163 & -.629 & .324 & -1.787 & -1.921 \\
\hline SC4 & 223 & 3.18 & .938 & -.276 & .163 & -.772 & .324 & -1.684 & -2.354 \\
\hline SC5 & 224 & 4.73 & 1.560 & -.383 & .163 & -.731 & .324 & -2.342 & -2.233 \\
\hline MC1 & 222 & 4.83 & 1.310 & -.264 & .163 & -.673 & .325 & -1.605 & -2.046 \\
\hline MC2 & 223 & 4.87 & .895 & -.378 & .163 & -.632 & .324 & -2.302 & -1.926 \\
\hline MC3 & 224 & 5.02 & 1.349 & -.364 & .163 & -.456 & .324 & -2.226 & -1.393 \\
\hline MC4 & 224 & 5.00 & 1.235 & -.577 & .163 & -.037 & .324 & -3.524 & -0.112 \\
\hline MC5 & 223 & 4.71 & 1.494 & -.300 & .163 & -.665 & .324 & -1.827 & -2.027 \\
\hline SP1 & 221 & 4.24 & 1.275 & .280 & .164 & -.372 & .326 & 1.699 & -1.128 \\
\hline SP2 & 224 & 4.33 & 1.309 & .184 & .163 & -.814 & .324 & 1.123 & -2.488 \\
\hline SP3 & 225 & 4.68 & 1.207 & -.033 & .162 & -.600 & .323 & -0.200 & -1.836 \\
\hline OP1 & 224 & 4.44 & 1.546 & -.298 & .163 & -.729 & .324 & -1.820 & -2.227 \\
\hline OP2 & 224 & 4.29 & 1.363 & -.140 & .163 & -.646 & .324 & -0.853 & -1.974 \\
\hline OP3 & 222 & 4.80 & 1.385 & -.456 & .163 & -.350 & .325 & -2.775 & -1.066 \\
\hline OP4 & 224 & 4.67 & 1.473 & -.281 & .163 & -.600 & .324 & -1.717 & -1.833 \\
\hline KW1 & 224 & 5.10 & 1.286 & -.423 & .163 & -.618 & .324 & -2.586 & -1.888 \\
\hline KW2 & 223 & 5.24 & 1.278 & -.389 & .163 & -.455 & .324 & -2.370 & -1.387 \\
\hline KW3 & 224 & 5.01 & 1.031 & -.300 & .163 & -.150 & .324 & -1.830 & -0.457 \\
\hline $\begin{array}{l}\text { KW4 } \\
\text { Valid N } \\
\text { (listwise) }\end{array}$ & 224 & 4.82 & .988 & -.189 & .163 & -.447 & .324 & -1.154 & -1.366 \\
\hline
\end{tabular}


Appendices

APPENDIX G. Factor loadings of reflective constructs

\begin{tabular}{|c|c|c|c|c|c|c|c|c|c|c|}
\hline & & $P$ & & C & & & & & & \\
\hline & 391 & 217 & 124 & 229 & 35 & 335 & 433 & & & \\
\hline & & 221 & & & & & & & & \\
\hline & & 380 & & & & & & & & \\
\hline$P$ & & 30 & & & 22 & 436 & & & & \\
\hline & & & & & & & & & & \\
\hline G2 & & 353 & & & & 220 & & & & \\
\hline G3 & & & & & & & & & & \\
\hline & & & & & & & & & & \\
\hline & & & & & & & & & & \\
\hline HC3 & & & & & & & & & & \\
\hline HC4 & 68 & 208 & 216 & 760 & 299 & 0.340 & 278 & & 28 & 36 \\
\hline HC5 & & 274 & 08 & 322 & & 462 & & & & \\
\hline C1 & & 329 & & & & 362 & & & & $4 C$ \\
\hline & & 429 & & & & .460 & & & & \\
\hline & & & & & & & & & & \\
\hline 24 & & 396 & & & & 531 & & & & .45 \\
\hline & & & & & & & & & & \\
\hline & & & & & & & & & & \\
\hline & & & & & & & & & & \\
\hline & & & & & & & & & & \\
\hline & 362 & 303 & & & & 0.808 & & & & 32 \\
\hline & & & & & & & & & & \\
\hline & & & & & & 220 & & & & $4 c^{2}$ \\
\hline & & & & & & & & & & \\
\hline & & & & & & & & & & \\
\hline C5 & & & & & & 325 & & & & \\
\hline & & & & & & & & & & \\
\hline & & & & & & & & & & \\
\hline & & & & & & & & & & \\
\hline & & & & & & & & & & \\
\hline & & & & & & 329 & & & 366 & \\
\hline & & & & & & & & & & \\
\hline & & & & & & & & & & \\
\hline & & & & & & & & & & \\
\hline & & & & & & & & & & \\
\hline & & & & & & & & & 43 & \\
\hline & & & & & & 0.05 & & . & & \\
\hline
\end{tabular}




\section{REFERENCES}

Addo-Tenkorang, R., \& Helo, P. (2011). Enterprise resource planning (ERP): A review literature report. Paper presented at the World Congress on Engineering and Computer Science, 19-21 October 2011. Retrieved from http://www.iaeng.org/publication/WCECS2011/WCECS2011 pp1126$\underline{1134 . p d f}$

Ahmed, A. S. S., \& Omar, E. M. K. (2011). Understanding the knowledge management-intellectual capital relationship: a two-way analysis. Journal of Intellectual Capital, 12(4), 586-614.

Argote, L. (2011). Organizational learning research: Past, present and future. Management Learning, 42(4), 439-446.

Argote, L., \& Ingram, P. (2000). Knowledge transfer: A basis for competitive advantage in firms. Organizational behavior and human decision processes, 82(1), 150-169.

Armstrong, J. S., \& Overton, T. S. (1977). Estimating nonresponse bias in mail surveys. Journal of Marketing research, 14(3), 396-402.

Asiaei, K., \& Jusoh, R. (2015). A multidimensional view of intellectual capital: the impact on organizational performance. Management Decision, 53(3), 668697.

Attewell, P. (1992). Technology diffusion and organizational learning: The case of business computing. Organization Science, 3(1), 1-19.

Babbie, E. (2010). The practice of social research (12 ${ }^{\text {nd }}$ ed.). Belmont, CA: Wadsworth, Cengage Learning.

Barki, H., Oktamis, S., \& Pinsonneault, A. (2005). Dimensions of ERP Implementations and their impact on ERP project outcomes. Journal of Information Technology Management, 16(1), 1-9.

Barlett, J. E., Kotrlik, J. W., \& Higgins, C. C. (2001). Organizational research: Determining appropriate sample size in survey research. Information Technology, Learning, and Performance Journal, 19(1), 43-50. 
Barney, J. B. (1991). Firm resources and sustained competitive advantage. Journal of Management, 17(1), 99-120.

Baron, R. M., \& Kenny, D. A. (1986). The moderator-mediator variable distinction in social psychological research: Conceptual, strategic, and statistical considerations. Journal of Personality and Social Psychology, 51(6), 11731182.

Beard, J. W., \& Sumner, M. (2004). Seeking strategic advantage in the post-net era: viewing ERP systems from the resource-based perspective. The Journal of Strategic Information Systems, 13(2), 129-150.

Becker, G. S. (1962). Investment in human capital: A theoretical analysis. Journal of Political Economy, 70(5), 9-49.

Besson, P., \& Rowe, F. (2001). ERP project dynamics and enacted dialogue: Perceived understanding, perceived leeway, and the nature of task-related conflicts. SIGMIS Database, 32(4), 47-66. doi:10.1145/506139.506145

Bharadwaj, A. S. (2000). A resource-based perspective on information technology capability and firm performance: An empirical investigation. MIS Quarterly, 24(1), 169-196.

Bontis, N. (1998). Intellectual capital: an exploratory study that develops measures and models. Management Decision, 36(2), 63-76.

Bontis, N. (1999). Managing organizational knowledge by diagnosing intellectual capital: Framing and advancing the state of the field. International Journal of Technology Management, 18(5,6,7,8), 433-462.

Bontis, N., Crossan, M. M., \& Hulland, J. (2002). Managing an organizational learning system by aligning stocks and flows. Journal of Management Studies, 39(4), 437-469.

Bontis, N., Dragonetti, N. C., Jacobsen, K., \& Roos, G. (1999). The knowledge toolbox: A review of the tools available to measure and manage intangible resources. European Management Journal, 17(4), 391-402. 
Bontis, N., Keow, W. C. C., \& Richardson, S. (2000). Intellectual capital and business performance in Malaysian industries. Journal of Intellectual Capital, $1(1), 85-85$.

Bowman, C., \& Ambrosini, V. (1997). Using single respondents in strategy research. British Journal of Management, 8(2), 119-131.

Brazel, J. F., \& Dang, L. (2008). The effect of ERP system implementations on the management of earnings and earnings release dates. Journal of Information Systems, 22(2), 1-21.

Brislin, R. W. (1980). Translation and content analysis of oral and written material. In H. C. Triandis \& J. W. Berry (Eds.), Handbook of cross-cultural psychology (Vol. 2, pp. 389-444). Boston, MA: Allyn and Bacon.

Brooking, A. (1996). Intellectual capital: Core assets of the third millennium enterprise. London, United Kingdom: Thomson Business Press.

Brown, J. S., \& Duguid, P. (1991). Organizational learning and communities-ofpractice: Toward a unified view of working, learning, and innovation. Organization Science, 2(1), 40-57.

Bryman, A. (2003). Research methods and organization studies. New York, NY: Routledge.

Brynjolfsson, E., \& Hitt, L. M. (1998). Beyond the productivity paradox. Communications of the ACM, 41(8), 49-55.

Brynjolfsson, E., Hitt, L. M., \& Yang, S. (2002). Intangible assets: Computers and organizational capital. Brookings Papers on Economic Activity, 2002(1), 137198.

Cabrita, M. D. R., \& Bontis, N. (2008). Intellectual capital and business performance in the Portuguese banking industry. International Journal of Technology Management, 43(1), 212-237.

Carr, N. G. (2005). The end of corporate computing. MIT Sloan Management Review, 46(3), 67-73. 
Chakraborty, S., \& Sharma, S. K. (2007). Enterprise resource planning: an integrated strategic framework. International Journal of Management and Enterprise Development, 4(5), 533-551.

Chand, D., Hachey, G., Hunton, J., Owhoso, V., \& Vasudevan, S. (2005). A balanced scorecard based framework for assessing the strategic impacts of ERP systems. Computers in Industry, 56(6), 558-572. doi:10.1016/j.compind.2005.02.011

Chang, S.-I., Yen, D. C., Ng, C. S.-P., Chang, I.-C., \& Yu, S.-Y. (2011). An ERP system performance assessment model development based on the balanced scorecard approach. Information Systems Frontiers, 13(3), 429-450.

Chang, S. C., Chen, S. S., \& Lai, J. H. (2008). The effect of alliance experience and intellectual capital on the value creation of international strategic alliances. Omega, 36(2), 298-316.

Chin, W. W. (1998). The partial least squares approach for structural equation modeling. In G. A. Marcoulides (Ed.), Modern methods for business research (pp. 295-336). Mahwah, NJ: Lawrence Erlbaum Associates.

Chin, W. W., \& Gopal, A. (1995). Adoption intention in GSS: Relative importance of beliefs. SIGMIS Database, 26(2-3), 42-64. doi:10.1145/217278.217285

Chin, W. W., Marcolin, B. L., \& Newsted, P. R. (2003). A partial least squares latent variable modeling approach for measuring interaction effects: Results from a Monte Carlo simulation study and an electronic-mail emotion/adoption study. Information Systems Research, 14(2), 189-217.

Chin, W. W., \& Newsted, P. R. (1999). Structural equation modeling analysis with small samples using partial least squares. In R. Hoyle (Ed.), Statistical strategies for small sample research (pp. 307-341). Thousand Oaks, CA: Sage Publications.

Chuang, M.-L., \& Shaw, W. H. (2008). An empirical study of enterprise resource management systems implementation: From ERP to RFID. Business Process Management Journal, 14(5), 675-693. 
Chung, S. H., \& Snyder, C. A. (2000). ERP adoption: a technological evolution approach. International Journal of Agile Management Systems, 2(1), 24-32.

Clemons, E. K., \& Row, M. C. (1991). Sustaining IT advantage: The role of structural differences. MIS Quarterly, 15(3), 275-292.

Cohen, J. (1988). Statistical power analysis for the behavioral sciences ( $2^{\text {nd }}$ ed.). New York, NY: Lawrence Erlbaum Associates.

Cooper, R. B., \& Zmud, R. W. (1990). Information technology implementation research: A technological diffusion approach. Management Science, 36(2), 123-139.

Creswell, J. W. (2009). Research design: Qualitative, quantitative, and mixed methods approaches ( $3^{\text {rd }}$ ed.). Thousand Oaks, CA: SAGE Publications.

Crossan, M. M., Lane, H. W., \& White, R. E. (1999). An organizational learning framework: From intuition to institution. Academy of Management Review, 24(3), 522-537.

Curado, C., Henriques, L., \& Bontis, N. (2011). Intellectual capital disclosure payback. Management Decision, 49(7), 1080-1098.

Cyert, R., \& March, J. G. (1963). A behavioral theory of the firm. N.J.: Prentice Hall.

Daft, R. L., \& Weick, K. E. (1984). Toward a model of organizations as interpretation systems. The Academy of Management Review, 9(2), 284-295.

Daud, S., \& Yusoff, W. F. W. (2011). How intellectual capital mediates the relationship between knowledge management processes and organizational performance? African Journal of Business Management, 5(7), 2607-2617.

Davenport, T. H. (1998). Putting the enterprise into the enterprise system. Harvard Business Review, 76(4), 121-131.

Davenport, T. H. (2000). The future of enterprise system-enabled organizations. Information Systems Frontiers, 2(2), 163-180.

Davenport, T. H., Harris, J. G., \& Cantrell, S. (2004). Enterprise systems and ongoing process change. Business Process Management Journal, 10(1), 16-26. 
Davern, M. J., \& Kauffman, R. J. (2000). Discovering potential and realizing value from information technology investments. Journal of Management Information Systems, 121-143.

Davern, M. J., \& Wilkin, C. L. (2010). Towards an integrated view of IT value measurement. International Journal of Accounting Information Systems, $11(1), 42-60$.

De Carolis, D. (2002). The role of social capital and organizational knowledge in enhancing entrepreneurial opportunities in high-technology environments. In Choo \& Bontis (Eds.), The strategic management of intellectual capital and organizational knowledge (pp. 699-709). New York, NY: Oxford University Press.

De Geus, A. P. (1988). Planning as learning. Harvard Business Review, 66(2), 70-74.

Deloitte. (1999). ERP's second wave - Maximizing the value of ERP-enabled processes. Retrieved from New York, NY: Retrieved from http://www.ctiforum.com/technology/CRM/wp01/download/erp2w.pdf

Dezdar, S., \& Ainin, S. (2011). The influence of organizational factors on successful ERP implementation. Management Decision, 49(6), 911-926.

Dezdar, S., \& Sulaiman, A. (2009). Successful enterprise resource planning implementation: Taxonomy of critical factors. Industrial Management \& Data Systems, 109(8), 1037-1052. doi:10.1108/02635570910991283

Diamantopoulos, A., Riefler, P., \& Roth, K. P. (2008). Advancing formative measurement models. Journal of Business Research, 61(12), 1203-1218.

Diamantopoulos, A., \& Winklhofer, H. M. (2001). Index construction with formative indicators: An alternative to scale development. Journal of Marketing Research, 269-277.

DiBella, A. J., \& Nevis, E. C. (1998). How organizations learn: An integrated strategy for building learning capability. San Francisco, CA: Jossey-Bass.

DiBella, A. J., Nevis, E. C., \& Gould, J. M. (1996). Understanding organizational learning capability. Journal of Management Studies, 33(3), 361-379. 
Drucker, P. F. (1993). Post-capitalist society. New York, NY: ButterworthHeinemann.

Duncan, R. B., \& Weiss, A. (1979). Organizational learning: Implications for organizational design. In B. Staw (Ed.), Research in organizational behavior (Vol. 1, pp. 75-123). Greewich, CT: JAI Press.

Dzinkowski, R. (2000). The measurement and management of intellectual capital: An introduction. Management Accounting, 78(2), 32-36.

Edvinsson, L. (1997). Developing intellectual capital at Skandia. Long Range Planning, 30(3), 320-373. doi:10.1016/S0024-6301(97)00016-2

Edvinsson, L., \& Sullivan, P. (1996). Developing a model for managing intellectual capital. European Management Journal, 14(4), 356-364.

Edwards, J. R. (2001). Multidimensional constructs in organizational behavior research: An integrative analytical framework. Organizational Research Methods, 4(2), 144-192.

Edwards, J. R., \& Bagozzi, R. P. (2000). On the nature and direction of relationships between constructs and measures. Psychological Methods, 5(2), 155-174. doi:10.1037//1082-989X.5.2.155

Elbanna, A. R. (2007). Implementing an integrated system in a socially dis-integrated enterprise. Information Technology \& People, 20(2), 121-139.

Esteves, J. (2009). A benefits realisation road-map framework for ERP usage in small and medium-sized enterprises. Journal of Enterprise Information Management, 22(1), 25-35.

Esteves, J., \& Pastor, J. (2001). Enterprise resource planning systems research: An annotated bibliography. Communications of the Association for Information Systems, 7(8), 1-52.

Fang, M.-Y., \& Lin, F. (2006). Measuring the performance of ERP system - from the balanced scorecard perspectives. Journal of American Academy of Business, 10(1), 256-263. 
Fiol, C. M., \& Lyles, M. A. (1985). Organizational Learning. The Academy of Management Review, 10(4), 803-813.

Fornell, C., \& Larcker, D. F. (1981). Evaluating structural equation models with unobservable variables and measurement error. Journal of Marketing Research, 18(1), 39-50.

Forslund, H. (2010). ERP systems' capabilities for supply chain performance management. Industrial Management \& Data Systems, 110(3), 351-367.

Fowler, F. J. (2002). Survey research methods (Applied social research methods) $\left(3^{\text {rd }}\right.$ ed.). Thousand Oaks, CA: SAGE Publications.

Gable, G. G., Sedera, D., \& Chan, T. (2003). Enterprise systems success: A measurement model. Paper presented at the 24th International Conference on Information Systems, 15-17 December 2003. Retrieved from Retrieved from http://eprints.qut.edu.au/archive/00004743

Gable, G. G., Sedera, D., \& Chan, T. (2008). Re-conceptualizing information system success: The IS-impact measurement model. Journal of the Association for Information Systems, 9(7), 377-408.

Gefen, D., Straub, D., \& Boudreau, M.-C. (2000). Structural equation modeling and regression: Guidelines for research practice. Communications of the Association for Information Systems, 4(1), 1-79.

Grant, R. M. (1996). Toward a knowledge-based theory of the firm. Strategic Management Journal, 17(S2), 109-122.

Guba, E. G., \& Lincoln, Y. S. (1994). Competing paradigms in qualitative research. In N. K. Denzin \& Y. S. Lincoln (Eds.), Handbook of qualitative research (pp. 105-117). Thousand Oaks, CA: Sage Publications.

Haenlein, M., \& Kaplan, A. M. (2004). A beginner's guide to partial least squares analysis. Understanding Statistics, 3(4), 283-297.

Hair, J. F., Black, W. C., Babin, B. J., \& Anderson, R. E. (2010). Multivariate data analysis $\left(7^{\text {th }}\right.$ ed.). Upper Saddle River, NJ: Prentice Hall. 
Hair, J. F., Hult, G. T. M., Ringle, C., \& Sarstedt, M. (2014). A primer on partial least squares structural equation modeling (PLS-SEM). Thousand Oaks, CA: Sage Publications.

Hair, J. F., Ringle, C. M., \& Sarstedt, M. (2011). PLS-SEM: Indeed a silver bullet. Journal of Marketing Theory and Practice, 19(2), 139-152.

Hair, J. F., Ringle, C. M., \& Sarstedt, M. (2012). Partial least squares: the better approach to structural equation modeling? Long Range Planning, 45(5-6), 312-319.

Hair, J. F., Ringle, C. M., \& Sarstedt, M. (2013). Partial least squares structural equation modeling: Rigorous applications, better results and higher acceptance. Long Range Planning, 46(1-2), 1-12.

Hatch, N. W., \& Dyer, J. H. (2004). Human capital and learning as a source of sustainable competitive advantage. Strategic Management Journal, 25(12), 1155-1178. doi:10.1002/smj.421

Hattie, J. (1985). Methodology review: Assessing unidimensionality of tests and items. Applied Psychological Measurement, 9(2), 139-164. doi:10.1177/014662168500900204

Hawking, P., Stein, A., \& Foster, S. (2004). Revisiting ERP systems: Benefit realization. Paper presented at the 37th Annual Hawaii International Conference on System Sciences, 5-8 January 2004. Retrieved from doi:10.1109/hicss.2004.1265554

Henseler, J., \& Chin, W. W. (2010). A comparison of approaches for the analysis of interaction effects between latent variables using partial least squares path modeling. Structural Equation Modeling, 17(1), 82-109.

Henseler, J., \& Fassott, G. (2010). Testing moderating effects in PLS path models: An illustration of available procedures. In V. E. Vinzi, W. W. Chin, J. Henseler, \& H. Wang (Eds.), Handbook of partial least squares: Concepts, methods and applications (pp. 713-735). NY: Springer.

Henseler, J., Ringle, C. M., \& Sinkovics, R. R. (2009). The use of partial least squares path modeling in international marketing. In P. N. G. Rudolf R. 
Sinkovics (Ed.), New challenges to international marketing (pp. 277-319). Bingley BD16 1WA, United Kingdom: Emerald Group Publishing.

Holland, C., Light, B., \& Kawalek, P. (1999). Beyond enterprise resource planning projects: innovative strategies for competitive advantage. Paper presented at the 7th European Conference on Information Systems, 23-25 June 1999. Retrieved from Retrieved from http://usir.salford.ac.uk/17302/2/BERP_ECIS99.pdf

Hossain, L., Patrick, J. D., \& Rashid, M. A. (2002). Enterprise resource planning: Global opportunities and challenges. Hershey, PA: Idea Group Publishing.

Hsu, I.-C., \& Sabherwal, R. (2012). Relationship between intellectual capital and knowledge management: An empirical investigation. Decision Sciences, 43(3), 489-524.

Hsu, P.-F. (2013). Commodity or competitive advantage? Analysis of the ERP value paradox. Electronic Commerce Research and Applications, 12(6), 412-424.

Hsu, Y.-H., \& Fang, W. (2009). Intellectual capital and new product development performance: The mediating role of organizational learning capability. Technological Forecasting and Social Change, 76(5), 664-677.

Huang, Y.-C., \& Wu, Y.-C. J. (2010). Intellectual capital and knowledge productivity: the Taiwan biotech industry. Management Decision, 48(4), 580599.

Huang, Z., \& Palvia, P. (2001). ERP implementation issues in advanced and developing countries. Business Process Management Journal, 7(3), 276 - 284.

Huber, G. P. (1991). Organizational learning: The contributing processes and the literatures. Organization Science, 2(1), 88-115.

Hwang, Y., Al-Arabiat, M., \& Shin, D.-H. (2015, July). Understanding technology acceptance in a mandatory environment: A literature review. Information Development. Retrieved from doi:10.1177/0266666915593621 
Ifinedo, P. (2006). Extending the Gable et al. enterprise systems success measurement model: a preliminary study. Journal of Information Technology Management, 17(1), 14-33.

Ifinedo, P. (2011). Examining the influences of external expertise and in-house computer/IT knowledge on ERP system success. Journal of Systems and Software, 84(12), 2065-2078.

Isaac, R. G., Herremans, I. M., \& Kline, T. J. (2010). Intellectual capital management enablers: a structural equation modeling analysis. Journal of Business Ethics, 93(3), 373-391.

Jarvis, C. B., MacKenzie, S. B., \& Podsakoff, P. M. (2003). A critical review of construct indicators and measurement model misspecification in marketing and consumer research. Journal of Consumer Research, 30(2), 199-218.

Jerez-Gómez, P., Céspedes-Lorente, J., \& Valle-Cabrera, R. (2005). Organizational learning capability: a proposal of measurement. Journal of Business Research, $58(6), 715-725$.

Jones, M. C., Zmud, R. W., \& Clark, T. D. J. (2008). ERP in practice: A snapshot of post-installation perception and behaviors. Communications of the Association for Information Systems, 23(1), 437-462.

Kaplan, R. S., \& Norton, D. P. (1992). The balanced scorecard: Measures that drive performance. Harvard Business Review, 70(1), 71-79.

Kaplan, R. S., \& Norton, D. P. (1996). Using the balanced scorecard as a strategic management system. Harvard Business Review, 74(1), 75-85.

Kaplan, R. S., \& Norton, D. P. (2004). Measuring the strategic readiness of intangible assets. Harvard Business Review, 82(2), 52-63.

Karimi, J., Somers, T. M., \& Bhattacherjee, A. (2007). The impact of ERP implementation on business process outcomes: A factor-based study. Journal of Management Information Systems, 24(1), 101-134.

Kaufmann, L., \& Schneider, Y. (2004). Intangibles: a synthesis of current research. Journal of Intellectual Capital, 5(3), 366-388. 
Ke, W., Wei, K.-K., Chau, P., \& Deng, Z. (2003). Organizational learning in ERP Implementation: an exploratory study of strategic renewal. Paper presented at the 9th Americas Conference on Information Systems, August 2003. Retrieved from Retrieved from http://aisel.aisnet.org/cgi/viewcontent.cgi?article=1605\&context=amcis2003

Ke, W., \& Wei, K. K. (2006). Organizational learning process: Its antecedents and consequences in enterprise system implementation. Journal of Global Information Management, 14(1), 1-22.

Ke, W., \& Wei, K. K. (2008). Organizational culture and leadership in ERP implementation. Decision Support Systems, 45(2), 208-218.

Klaus, H., Rosemann, M., \& Gable, G. G. (2000). What is ERP? Information Systems Frontiers, 2(2), 141-162.

Kline, R. B. (2010). Principles and practice of structural equation modeling ( $3^{\text {rd }}$ ed.). New York, NY: The Guilford Press.

Ko, D.-G., Kirsch, L. J., \& King, W. R. (2005). Antecedents of knowledge transfer from consultants to clients in enterprise system implementations. MIS Quarterly, 59-85.

Kogut, B., \& Zander, U. (1992). Knowledge of the Firm, Combinative Capabilities, and the Replication of Technology. Organization Science, 3(3), 383-397.

Koh, S. C. L., \& Simpson, M. (2007). Could enterprise resource planning create a competitive advantage for small businesses? Benchmarking: An International Journal, 14(1), 59-76.

Kumar, N., Stern, L. W., \& Anderson, J. C. (1993). Conducting interorganizational research using key informants. Academy of Management Journal, 36(6), 1633-1651.

Kwon, T. H., \& Zmud, R. W. (1987). Unifying the fragmented models of information systems implementation Critical issues in information systems research (pp. 227-251): John Wiley \& Sons, Inc. 
Laframboise, K., \& Reyes, F. (2005). Gaining Competitive Advantage From Integrating Enterprise Resource Planning and Total Quality Management. Journal of Supply Chain Management, 41(3), 49-64.

Law, K. S., Wong, C.-S., \& Mobley, W. H. (1998). Toward a taxonomy of multidimensional constructs. The Academy of Management Review, 23(4), 741-755.

Lee, C.-P., Lee, G.-G., \& Lin, H.-F. (2007). The role of organizational capabilities in successful e-business implementation. Business Process Management Journal, 13(5), 677-693.

Lenart, A. (2011). ERP in the cloud - Benefits and challenges. In S. Wrycza (Ed.), Research in systems analysis and design: Models and methods (Vol. 93, pp. 39-50). Heidelberg, Germany: Springer.

Lengnick-Hall, C. A., Lengnick-Hall, M. L., \& Abdinnour-Helm, S. (2004). The role of social and intellectual capital in achieving competitive advantage through enterprise resource planning (ERP) systems. Journal of Engineering and Technology Management, 21(4), 307-330.

Levitt, B., \& March, J. G. (1988). Organizational Learning. Annual Review of Sociology, 14(1), 319-338.

Liao, S.-H., \& Wu, C.-c. (2010). System perspective of knowledge management, organizational learning, and organizational innovation. Expert Systems with Applications, 37(2), 1096-1103.

Light, B., \& Papazafeiropoulou, A. (2008). Contradictions and the appropriation of ERP packages. In B. Grabot, A. Mayère, \& I. Bazet (Eds.), ERP systems and organisational Change: A social-technical insight (pp. 85-99). London, United Kingdom: Springer.

Lin, H. F. (2008). Empirically testing innovation characteristics and organizational learning capabilities in e-business implementation success. Internet Research, 18(1), 60-78.

Lohmöller, J. B. (1989). Latent variable path modeling with partial least squares. New York, NY: Springer. 
López-Cabrales, Á., Real, J. C., \& Valle, R. (2011). Relationships between human resource management practices and organizational learning capability: The mediating role of human capital. Personnel Review, 40(3), 344-363.

MacKenzie, S. B., Podsakoff, P. M., \& Podsakoff, N. P. (2011). Construct measurement and validation procedures in MIS and behavioral research: Integrating new and existing techniques. MIS Quarterly, 35(2), 293-334.

Maditinos, D., Chatzoudes, D., \& Tsairidis, C. (2011). Factors affecting ERP system implementation effectiveness. Journal of Enterprise Information Management, 25(1), 60-78.

March, J. G. (1991). Exploration and exploitation in organizational learning. Organization Science, 2(1), 71-87. doi:10.2307/2634940

Markus, M. L. (2004). Technochange management: Using IT to drive organizational change. Journal of Information Technology, 19(1), 4-20.

Markus, M. L., \& Tanis, C. (2000). The enterprise system experience - From adoption to success. In R. W. Zmud (Ed.), In framing the domains of IT management: glimpsing the future throught the past (pp. 173-207). Cincinnati, OH: Pinnaflex Educational Resources.

Markus, M. L., Tanis, C., \& Van Fenema, P. C. (2000). Enterprise resource planning: multisite ERP implementations. Communications of the ACM, 43(4), 42-46.

Marnewick, C., \& Labuschagne, L. (2005). A conceptual model for enterprise resource planning (ERP). Information Management \& Computer Security, 13(2), 144-155.

Marr, B., \& Adams, C. (2004). The balanced scorecard and intangible assets: similar ideas, unaligned concepts. Measuring Business Excellence, 8(3), 18-27.

Marr, B., \& Chatzkel, J. (2004). Intellectual capital at the crossroads: managing, measuring, and reporting of IC. Journal of Intellectual Capital, 5(2), 224-229. doi:10.1108/14691930410533650 
Martín-de-Castro, G., Delgado-Verde, M., López-Sáez, P., \& Navas-López, J. (2011). Towards 'an intellectual capital-based view of the firm': Origins and nature. Journal of Business Ethics, 98(4), 649-662. doi:10.1007/s10551-010-0644-5

Masli, A., Richardson, V. J., Sanchez, J. M., \& Smith, R. E. (2011). The business value of IT: A synthesis and framework of archival research. Journal of Information Systems, 25(2), 81-116.

McElyea, B. E. (2002). Knowledge management, intellectual capital, and learning organizations: A triad of future management integration. Futurics, 26(1/2), $59-65$.

Melville, N., Kraemer, K., \& Gurbaxani, V. (2004). Review: Information technology and organizational performance: An integrative model of IT business value. MIS Quarterly, 28(2), 283-322.

Michalisin, M. D., Smith, R. D., \& Kline, D. M. (1997). In search of strategic assets. International Journal of Organizational Analysis, 5(4), 360-387.

Møller, C. (2005). ERP II: A conceptual framework for next-generation enterprise systems? Journal of Enterprise Information Management, 18(4), 483-497. doi:10.1108/17410390510609626

Moohebat, M. R., Asemi, A., \& Jazi, M. D. (2010). A comparative study of critical success factors (CSFs) in implementation of ERP in developed and developing countries. International Journal of Advancements in Computing Technology, 2(5), 99-110.

Moon, Y. B. (2007). Enterprise resource planning (ERP): A review of the literature. International Journal of Management and Enterprise Development, 4(3), 235264.

Muscatello, J. R., \& Chen, I. J. (2008). Enterprise resource planning (ERP) implementations: theory and practice. International Journal of Enterprise Information Systems, 4(1), 63-83.

Nahapiet, J., \& Ghoshal, S. (1998). Social capital, intellectual capital, and the organizational advantage. The Academy of Management Review, 23(2), 242266. 
Neuman, W. L. (2011). Social research methods: Qualitative and quantitative approaches $\left(7^{\text {th }}\right.$ ed.). Boston, MA: Pearson Education.

Nevis, E. C., DiBella, A. J., \& Gould, J. M. (1995). Understanding organizations as learning systems. MIT Sloan Management Review, 36(2), 73-85.

Nicolaou, A. I. (2004). Firm performance effects in relation to the implementation and use of enterprise resource planning systems. Journal of Information Systems, 18(2), 79-105.

Nonaka, I., Toyama, R., \& Nagata, A. (2000). A firm as a knowledge-creating entity: A new perspective on the theory of the firm. Industrial and Corporate Change, 9(1), 1-20.

Nunnally, J. C., \& Bernstein, I. A. (1994). Psychometric theory ( $3^{\text {rd }}$ ed.). New York, NY: McGraw-Hill.

Nwankpa, J., \& Roumani, Y. (2014). Understanding the link between organizational learning capability and ERP system usage: An empirical examination. Computers in Human Behavior, 33, 224-234. doi:10.1016/j.chb.2014.01.030

Pan, S. L., Newell, S., Huang, J., \& Galliers, R. D. (2007). Overcoming knowledge management challenges during ERP implementation: The need to integrate and share different types of knowledge. Journal of the American Society for Information Science and Technology, 58(3), 404-419. doi:10.1002/asi.20523

Panayides, P. M. (2007). The impact of organizational learning on relationship orientation, logistics service effectiveness and performance. Industrial Marketing Management, 36(1), 68-80.

Panorama. (2015). Annual ERP report 2015. Retrieved from Retrieved from http://go.panoramaconsulting.com/rs/panoramaconsulting/images/2015\%20ERP\%20Report.pdf

Parr, A. N., \& Shanks, G. (2000). A taxonomy of ERP implementation approaches. Paper presented at the 33rd Annual Hawaii International Conference on System Sciences, 4-7 January 2000. Retrieved from doi:10.1109/hicss.2000.926908 
Parthasarathy, S., \& Anbazhagan, N. (2007). Evaluating ERP implementation choices using AHP. International Journal of Enterprise Information Systems (IJEIS), $3(3), 52-65$.

Penrose, E. T. (1959). The theory of the growth of the firm. New York, NY: John Wiley.

Pentland, B. T. (1995). Information systems and organizational learning: the social epistemology of organizational knowledge systems. Accounting, Management and Information Technologies, 5(1), 1-21.

Perez, G., \& Ramos, I. (2013). Understanding organizational memory from the integrated management systems (ERP). Journal of Information Systems and Technology Management, 10(3), 541-560.

Piccoli, G., \& Ives, B. (2005). Review: IT-dependent strategic initiatives and sustained competitive advantage: A review and synthesis of the literature. MIS Quarterly, 29(4), 747-776.

Pinsonneault, A., \& Kraemer, K. L. (1993). Survey research methodology in management information systems: An assessment. Journal of Management Information Systems, 10(2), 75-105. doi:10.1080/07421222.1993.11518001

Podsakoff, P. M., MacKenzie, S. B., Lee, J.-Y., \& Podsakoff, N. P. (2003). Common method biases in behavioral research: A critical review of the literature and recommended remedies. Journal of Applied Psychology, 88(5), 879-903. doi:10.1037/0021-9010.88.5.879

Priem, R. L., \& Butler, J. E. (2001). Is the resource-based" view" a useful perspective for strategic management research? The Academy of Management Review, 26(1), 22-40.

Probst, G., \& Buchel, B. T. (1997). Organizational learning. London, United kingdom: Prentice Hall.

Purvis, R. L., Sambamurthy, V., \& Zmud, R. W. (2001). The assimilation of knowledge platforms in organizations: An empirical investigation. Organization Science, 12(2), 117-135. 
Raihana, G. F. H. (2012). Cloud ERP - a solution model. International Journal of Computer Science and Information Technology \& Security (IJCSITS), 2(1), 76-79.

Ram, J., Corkindale, D., \& Wu, M.-L. (2013). Implementation critical success factors (CSFs) for ERP: Do they contribute to implementation success and postimplementation performance? International Journal of Production Economics, 144(1), 157-174.

Ramanujam, V., Venkatraman, N., \& Camillus, J. C. (1986). Multi-objective assessment of effectiveness of strategic planning: A discriminant analysis approach. The Academy of Management Journal, 29(2), 347-372.

Ramayah, T., Roy, M. H., Arokiasamy, S., Zbib, I., \& Ahmed, Z. U. (2007). Critical success factors for successful implementation of enterprise resource planning systems in manufacturing organizations. International Journal of Business Information Systems, 2(3), 276-297.

Ranganathan, C., \& Brown, C. V. (2006). ERP investments and the market value of firms: Toward an understanding of influential ERP project variables. Information Systems Research, 17(2), 145-161.

Reinecke, J. (1999). Interaktionseffekte in strukturgleichungsmodellen mit der theorie des geplanten verhaltens. Multiple gruppenvergleiche und produktterme mit latenten variablen. ZUMA-Nachrichten, 23(45), 88-114.

Ringle, C. M., Wende, S., \& Will, A. (2005). SmartPLS 2.0, Hamburg. www.smartpls.de.

Robey, D. (1979). User attitudes and management information system use. Academy of Management journal, 22(3), 527-538.

Robey, D., Boudreau, M.-C., \& Rose, G. M. (2000). Information technology and organizational learning: A review and assessment of research. Accounting, Management and Information Technologies, 10(2), 125-155.

Robey, D., Ross, J. W., \& Boudreau, M.-C. (2002). Learning to implement enterprise systems: An exploratory study of the dialectics of change. Journal of Management Information Systems, 19(1), 17-46. 
Robinson, C. D., Tomek, S., \& Schumacker, R. E. (2013). Tests of moderation effects: Difference in simple slopes versus the interaction term. Multiple Linear Regression Viewpoints, 39(1), 16-24.

Robinson, J. P., Shaver, P. R., \& Wrightsman, L. S. (1991). Criteria for scale selection and evaluation. In J. P. Robinson, P. R. Shaver, \& L. S. Wrightsman (Eds.), Measures of personality and social psychological attitudes (Vol. 1, pp. 1-16). San Diego, CA: Elsevier.

Ronald, E. M., \& Angappa, G. (2007). Enterprise resource planning (ERP): Past, present and future. International Journal of Enterprise Information Systems, $3(3), 23-35$.

Roos, J., Roos, G., Dragonetti, N. C., \& Edvinsson, L. (1997). Intellectual capital: Navigating in the new business landscape. London, United Kingdom: Palgrave Macmillan.

Sánchez-Rodríguez, C., \& Martínez-Lorente, A. R. (2011). Effect of IT and quality management on performance. Industrial Management \& Data Systems, 111(6), 830-848.

Schryen, G. (2013). Revisiting IS business value research: What we already know, what we still need to know, and how we can get there. European Journal of Information Systems, 22(2), 139-169.

Seddon, P. B. (2005). Are ERP systems a source of competitive advantage? Strategic Change, 14(5), 283-293.

Senge, P. M. (2006). The fifth discipline: The art and practice of the learning organization. London, United Kingdom: Random House.

Shang, S., \& Seddon, P. (2002). Assessing and managing the benefits of enterprise systems: The business manager's perspective. Information Systems Journal, 12(4), 271-299.

Shin, B., \& Kim, G. (2011). Investigating the reliability of second-order formative measurement in information systems research. European Journal of Information Systems, 20(5), 608-623. 
Sinkula, J. M., Baker, W., \& Noordewier, T. (1997). A framework for market-based organizational learning: Linking values, knowledge, and behavior. Journal of the Academy of Marketing Science, 25(4), 305-318.

Soh, C., Kien, S. S., \& Tay-Yap, J. (2000). Enterprise resource planning: Cultural fits and misfits: is ERP a universal solution? Communications of the ACM, 43(4), 47-51.

Stewart, T. A. (1997). Intellectual capital: The new wealth of organizations $\left(1^{\text {st }} \mathrm{ed}.\right)$. New York, NY: Doubleday.

Stratman, J. K. (2007). Realizing benefits from enterprise resource planning: Does strategic focus matter? Production \& Operations Management, 16(2), 203216.

Subramaniam, M., \& Youndt, M. A. (2005). The influence of intellectual capital on the types of innovative capabilities. The Academy of Management Journal, $48(3), 450-463$.

Teece, D. J. (1986). Profiting from technological innovation: Implications for integration, collaboration, licensing and public policy. Research Policy, 15(6), 285-305.

Teece, D. J. (1998). Capturing value from knowledge assets: The new economy, markets for know-how, and intangible assets. California Management Review, 40(3), 55-79.

Teece, D. J., Pisano, G., \& Shuen, A. (1997). Dynamic capabilities and strategic management. Strategic Management Journal, 18(7), 509-533.

Thong, J. Y. L., Yap, C.-S., \& Raman, K. S. (1994). Engagement of external expertise in information systems implementation. Journal of Management Information Systems, 11(2), 209-231.

Ting-Peng, L., Jun-Jer, Y., \& Chih-Chung, L. (2010). A resource-based perspective on information technology and firm performance: A meta analysis. Industrial Management \& Data Systems, 110(8), 1138-1158.

doi:10.1108/02635571011077807 
Tsai, W.-H., Chen, H.-C., Chang, J.-C., Leu, J.-D., Chen, D. C., \& Purbokusumo, Y. (2015). Performance of the internal audit department under ERP systems: Empirical evidence from Taiwanese firms. Enterprise Information Systems, 9(7), 725-742. doi:10.1080/17517575.2013.830341

Tsai, W.-H., Lee, P.-L., Shen, Y.-S., \& Lin, H.-L. (2012). A comprehensive study of the relationship between enterprise resource planning selection criteria and enterprise resource planning system success. Information \& Management, 49(1), 36-46.

Tsai, W., \& Ghoshal, S. (1998). Social capital and value creation: The role of intrafirm networks. The Academy of Management Journal, 41(4), 464-476.

Tsang, E. W. (1997). Organizational learning and the learning organization: A dichotomy between descriptive and prescriptive research. Human relations, 50(1), 73-89.

Urbach, N., \& Ahlemann, F. (2010). Structural equation modeling in information systems research using partial least squares. Journal of Information Technology Theory and Application, 11(2), 5-40.

VECOM. (2013). Vietnam e-business index 2013 report. Vietnam E-commerce Association. Retrieved from Retrieved from http://www.vecom.vn/wpcontent/uploads/2013/12/bao-cao-chi-so-thuong-mai-dien-tu-viet-nam2013.pdf

Venkatraman, N. (1989). The concept of fit in strategy research: Toward verbal and statistical correspondence. The Academy of Management Review, 14(3), 423444.

Vera, D., \& Crossan, M. (2003). Organizational learning and knowledge management: Toward an integrative framework. In M. Easterby-Smith \& M. A. Lyles (Eds.), The Blackwell handbook of organizational learning and knowledge management (pp. 122-142). Oxford, United Kingdom: WileyBlackwell. 
Wade, M., \& Hulland, J. (2004). Review: The resource-based view and information systems research: Review, extension, and suggestions for future research. MIS Quarterly, 28(1), 107-142.

Wagner, S. M., Rau, C., \& Lindemann, E. (2010). Multiple informant methodology: A critical review and recommendations. Sociological Methods \& Research, $38(4), 582-618$.

Wang, E. T., Lin, C. C.-L., Jiang, J. J., \& Klein, G. (2007). Improving enterprise resource planning (ERP) fit to organizational process through knowledge transfer. International Journal of Information Management, 27(3), 200-212.

West, S. G., Finch, J. F., \& Curran, P. J. (1995). Structural equation models with nonnormal variables: Problems and remedies. In R. H. Hoyle (Ed.), Structural equation modeling: Concepts, issues and applications (pp. 56-75). Thousand Oaks, CA: Sage Publications.

Winter, S. G. (1998). Knowledge and competence as strategic assets. In D. A. Klein (Ed.), The strategic management of intellectual capital (pp. 165-188). Woburn, MA: Butterworth-Heinemann.

Wylie, L. (1990). A vision of the next-generation MRP II. Scenario S-300-339. Retrieved from Stamford, CT:

Xu, Q., \& Ma, Q. (2008). Determinants of ERP implementation knowledge transfer. Information \& Management, 45(8), 528-539.

Yeh, J. Y., \& OuYang, Y.-C. (2010). How an organization changes in ERP implementation: a Taiwan semiconductor case study. Business Process Management Journal, 16(2), 209-225.

Yen, D. C., Chou, D. C., \& Chang, J. (2002). A synergic analysis for web-based enterprise resources planning systems. Computer Standards \& Interfaces, 24(4), 337-346.

Youndt, M. A., \& Snell, S. A. (2004). Human Resource Configurations, Intellectual Capital, and Organizational Performance. Journal of Managerial Issues, 16(3), 337-360. 
Youndt, M. A., Subramaniam, M., \& Snell, S. A. (2004). Intellectual capital profiles: An examination of investments and returns. Journal of Management Studies, 41(2), 335-361.

Young, C. S., \& Tsai, L. C. (2012). Information technology, organisational capital and firm performance. International Journal of Learning and Intellectual Capital, 9(1), 151-169.

Zack, M. H. (2002). Developing a knowledge strategy. In C. W. Choo \& N. Bontis (Eds.), The strategic management of intellectual capital and organizational knowledge (pp. 255-277). New York, NY: Oxford University Press.

Zhang, M. J., \& Lado, A. A. (2001). Information systems and competitive advantage: a competency-based view. Technovation, 21(3), 147-156.

Zhuang, Y., \& Lederer, A. L. (2003). An instrument for measuring the business benefits of e-commerce retailing. International Journal of Electronic Commerce, 7(3), 65-99. 